\title{
Uso de Árvores de Decisão na Geração de Hipóteses Indutivas em Aprendizado de Máquina ${ }^{1}$
}

\author{
Claudia Aparecida Martins
}

Orientação:

Profa. Dra. Maria Carolina Monard

Dissertação apresentada ao Instituto de Ciências Matemáticas de São Carlos, USP, como parte dos requisitos para obtenção do título de mestre em Ciências - Área: Ciências de Computação e Matemática Computacional.

\author{
USP - São Carlos \\ Novembro de 1994
}

\footnotetext{
${ }^{1}$ Trabalho realizado com auxílio da FAPESP de acordo com o Processo 92/1586-0 e Processo 92/2151-8.
} 


\section{Agradecimentos}

À Profa. Maria Carolina Monard, pela dedicação, paciência e incentivo na orientação desta dissertação

Às Profas. Carmo, Solange, Graça e Roseli, pela ajuda e amizade durante este trabalho

Aos Profs. Joãozinho, Pacheco e Mauro pela força, incentivo e apoio no começo do mestrado

À todos amigos de São Carlos, especialmente, Rô, Zero, Carlos, Tchelo, Marquinho, Gawa, Sadao, Stein, Lenz, Delamaro, Cozin, Marta, Gaby, Jandira, Neyva, Miau, Heli e Gracinha de quem sentirei saudades e dos amigos que sinto saudades, João, Omar e Fábio (Costa)

À todos funcionários e professores do ICMSC-USP que de um jeito ou de outro contribuíram para este trabalho

À minha família que soube compreender meus objetivos

À FAPESP pelo auxílio financeiro. 


\section{Resumo}

Aprendizado Indutivo é uma técnica utilizada em Aprendizado de Máquina cujo objetivo é induzir uma descrição geral de conceitos - hipóteses - através de instâncias destes conceitos - exemplos de treinamento. Entre os vários paradigmas de aprendizado indutivo, um bastante difundido é o uso de árvores de decisão. Árvores de decisão são utilizadas como linguagem de descrição de conceitos quando os exemplos são descritos como vetores de pares atributo-valor. A indução de uma árvore de decisão é realizada através do conjunto de treinamento que tenta classificar os exemplos na árvore de forma a acomodá-los. Os algoritmos de construção da árvore de decisão podem operar de dois modos: no modo não incremental, no qual o algoritmo infere o conceito de uma vez, baseado no conjunto total de instâncias disponiveis, e no modo incremental, no qual o algoritmo revê a definição do conceito corrente, se necessário, em resposta a cada nova instância de treinamento observada.

Uma questão importante a ser observada na indução de árvores de decisão, através de exemplos, é que muitas vezes os atributos iniciais - features primitivas - não são relevantes para descrever os conceitos, mas quando convenientemente combinados, gerando novas features, podem tornar-se altamente representativos para expressar um conceito. Este processo de construção de features é denominado de Indução Construtiva e seu objetivo é ampliar os limites de uma linguagem baseada em atributos.

Este trabalho apresenta dois algoritmos de indução de árvores de decisão, um no modo incremental e outro não incremental, para um conjunto de instâncias de treinamento com atributos booleanos. É apresentado, também, um algoritmo de pós-poda para árvore de decisão binária com o objetivo de melhorar a confiabilidade estatística da árvore. Referente à indução construtiva, três algoritmos para a construção automática de features de funções booleanas são apresentados. As implementações realizadas foram integradas a dois ambientes de aprendizado experimental denominados Ambiente Experimental TDIDT para Atributos Booleanos e Ambiente Experimental Construtivo para Atributos Booleanos, respectivamente. 


\begin{abstract}
Inductive learning systems aim to induce a general description - hyphotesis - of concepts from instances - examples - of these concepts. Among the wide variety of techniques used in inductive learning systems, the decision tree-structured paradigm has been established as the determinant form for rule-based data analysis. Although decision trees are a simple formalism, they are capable of capturing knowledge which is useful to solve new problems. A tree induction program takes a set of examples - training set - and generates a decision tree classifying them. The examples in the training set are described as vectors of attribute-value. This description is called attribute base.

The induction algorithms can operate in a non incremental or incremental mode. In the former case, the algorithm infers a concept once, based on the entire set of available training instances. In the incremental case, the algorithm revises the current concept definition, if necessary, in response to each newly observed training instance.

Sometimes the initial attributes - referenced as primitive features - used to describe the examples are not directly relevant to the concept but, when conveniently combined generating new features, can become highly representative for the expression of the concept. When new features are constructed and then used to form generalized concept descriptions, the feature construction process becomes a form of constructive induction.

This works presents two algorithms for induction of decision trees. One incremental, the other non incremental, for set of training instances having boolean-value attributes. An algorithm for prunning the binary decision tree to give statistical reliability is also presented. It also presents tree constructive induction algorithms for automatic feature construction for boolean-value attributes which improve the decision tree induced by the two previous algorithms. The implementations gave rise to two experimental learning environments.
\end{abstract}




\section{Conteúdo}

Introdução 1

1 Aprendizado de Máquina 4

1.1 Introdução . . . . . . . . . . . . . . . . . . . 4

1.2 Modelo de Sistemas de Aprendizado . . . . . . . . . . 5

1.3 Breve Histórico de Aprendizado de Máquina . . . . . . . . . . . 7

1.4 Linhas de Pesquisa de AM . . . . . . . . . . . . 8

1.4.1 Análise Teórica . . . . . . . . . . . . . . 8

1.4.2 Algoritmos de Aprendizado Simbólico . . . . . . . . . . . . 9

1.4.3 Clustering e Descoberta . . . . . . . . . . . 10

1.4.4 Aprendizado Baseado em Explicação . . . . . . . . . . . . 11

$\rightarrow 1.4 .5$ Conexionismo ou Redes Neurais . . . . . . . . . . . 15

1.4.6 Aprendizado Indutivo Direcionado pelo Conhecimento . . . . . . 16

1.4.7 Aprendizado Analógico e Baseado em Casos . . . . . . . . . . 18

$\rightarrow 1.4 .8$ Algoritmos Genéticos $\ldots \ldots \ldots 22$

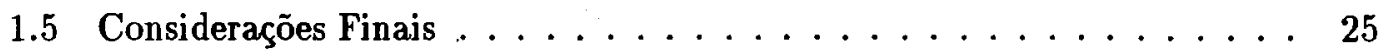

2 Aprendizado Simbólico $\quad 27$

2.1 Aprendizado Indutivo e Dedutivo . . . . . . . . . . . . . 28

2.2 Aprendizado Indutivo por Exemplos . . . . . . . . . . . 30

2.2 .1 Linguagem de Descrição . . . . . . . . . . . . . . . 31

2.2.2 O Problema do Aprendizado por Exemplos . . . . . . . . 32 
2.2.3 Critérios de Sucesso . . . . . . . . . . . . 33

2.3 Aprendizado Incremental e Não Incremental . . . . . . . . . . . . . 34

2.4 Indução Construtiva . . . . . . . . . . . . . . 35

2.5 Considerações Finais $\ldots \ldots \ldots \ldots \ldots \ldots$

3 Aprendizado de Árvores de Decisão 37

3.1 Árvores de Decisão . . . . . . . . . . . . . . . . . 38

3.2 Família TDIDT . . . . . . . . . . . . . . . . 40

3.3 Algoritmo Geral da Família TDIDT . . . . . . . . . . . . 41

3.4 Alguns Sistemas da Familia TDIDT . . . . . . . . . . . . . 43

3.5 Poda em Árvores de Decisão . . . . . . . . . . . . . . . . 45

3.6 Mecanismo de Janela . . . . . . . . . . . . . . . . . 47

3.7 Ambiente Experimental TDIDT . . . . . . . . . . . . . . . 48

3.8 Considerações Finais . . . . . . . . . . . . . . 52

4 Ambiente Experimental TDIDT para Atributos Booleanos 53

4.1 Descrição do Ambiente . . . . . . . . . . . . . . 53

4.2 Estrütura de Dados . . . . . . . . . . . . . . 56

4.3 Algoritmo Não Incremental para a Construção da Árvore de Decisão Binária ..................... 57

4.3 .1 o Algoritmo ID3 . . . . . . . . . . . . . 57

4.3.2 Descrição da Implementação do ID3 para Atributos Booleanos . 60

4.3.3 Exemplos de Execução . . . . . . . . . . . . . 62

4.4 Algoritmo Incremental para a Construção da Árvore de Decisão Binária 64

4.4 .1 Os Algoritmos ID5 e ID5R . . . . . . . . . . . . 64

4.4.2 Descrição da Implementação do ID5 para Atributos Booleanos . 68

4.4.3 Exemplos de Execução . . . . . . . . . . . . 73

4.5 Algoritmo de Poda da Árvore de Decisão Binária . . . . . . . . . . . 76

4.5.1 Método de Poda de Redução do Erro . . . . . . . . . . . 77

4.5.2 Descrição da Implementação do MPRE para Árvores de Decisão Binárias ........................ 79 
4.5.3 Exemplos de Execução . . . . . . . . . . . . . . . . . . 81

4.6 Considerações Finais . . . . . . . . . . . . . . . . 82

5 Ambiente Experimental Construtivo para Atributos Booleanos 83

5.1 Indução Construtiva de Features . . . . . . . . . . . . 83

5.2 Construção Automática de Features para Atributos Booleanos . . . . . 85

5.3 Descrição do Ambiente . . . . . . . . . . . . . . . . . 87

5.4 Descrição dos Algoritmos . . . . . . . . . . . . . . . . . 89

5.4.1 Algoritmo Iterativo de Construção de Árvore de Decisão com Construção Automátịca de Features . . . . . . . . . 89

5.4 .2 Algoritmo Root . . . . . . . . . . . . . . . . . 91

5.4 .3 Algoritmo Fringe . . . . . . . . . . . . . . . . 93

5.4 .4 Algoritmo Root-Fringe . . . . . . . . . . . . . 95

5.4 .5 Exemplos de Execução . . . . . . . . . . . . . . . . . 97

5.5 Módulo Gerador de Exemplos de Funções Booleanas . . . . . . . . . 101

5.5 .1 Descrição da Implementação . . . . . . . . . . . . . . 103

5.5.2 Exemplos de Execução . . . . . . . . . . . . . . . . . 105

5.6 Avaliação Empírica dos Algoritmos para Construção de Features . . . . 106

5.7 Considerações Finais . . . . . . . . . . . . . . . . . . 106

6 Conclusões e Trabalhos Futuros 108

$\begin{array}{ll}\text { Bibliografia } & 111\end{array}$ 


\section{Lista de Figuras}

1.1 Componentes de Aprendizado do Modelo de Simon . . . . . . . . . . 6

1.2 O Processo de Generalização Baseada em Explicação . . . . . . . . . . 13

1.3 Estrutura da Explicação . . . . . . . . . . . . . . 15

1.4 Uma Rede Neural de Três Camadas . . . . . . . . . . . . . . . 17

1.5 Problemas de Geometria com Segmentos . . . . . . . . . . . . . . 19

1.6 Problema de Geometria com Ângulos . . . . . . . . . . . . 20

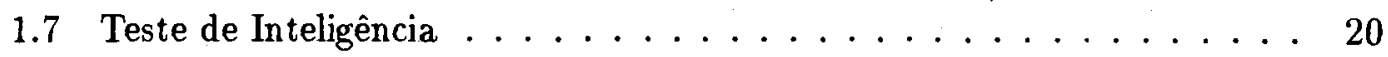

1.8 Sistema Baseado em Casos . . . . . . . . . . . . 21

2.1 Relação entre Dedução e Indução . . . . . . . . . . . . . . . 29

3.1 Árvore de Decisão para Diagnóstico do Estado do Motor (a.) . . . . . . . 39

3.2 Árvore de Decisão para Diagnóstico do Estado do Motor (b) . . . . . . . 40

3.3 A Familia TDIDT $\ldots \ldots \ldots \ldots \ldots$

3.4 Mecanismo de Janela . . . . . . . . . . . . . . . . . . . . 48

3.5 Ambiente Experimental TDIDT . . . . . . . . . . . . . 50

3.6 Visão Geral do Ambiente Experimental TDIDT . . . . . . . . . . . . 51

4.1 Ambiente Experimental TDIDT para Atributos Booleanos . . . . . . 55

4.2 Visão Geral do Ambiente Experimental TDIDT para Atributos Booleanos 56

4.3 Procedimento Responsável pela Construção da Árvore de Decisão . . . . 60

4.4 Estrutura da Árvore de Decisão Durante o Processo de Construção . . . 61

4.5 Procedimento Responsável pela Construção da Árvore de Decisão Incremental . . . . . . . . . . . . . . . . . 69 
4.6 Subárvore de uma Árvore Estatística de Classificação . . . . . . . . . 78

4.7. Procedimento Responsável pela Poda da Árvore de Decisão . . . . . . 79

5.1 Árvore de Decisão que Classifica um Robô em amigo ou inimigo . . . 84

5.2 Árvore de Decisão que Classifica um Robô em amigo ou inimigo Usando a Feature mesma_forma . . . . . . . . . . . . . 85

5.3 Árvore de Decisão da Função $f\left(x_{1}, x_{2}, x_{3}, x_{4}\right)=\sum \min (1,3,5,7) \ldots 86$

5.4 Árvore de Decisão da Função $f\left(x_{1}, x_{2}, x_{3}, x_{4}\right)=\sum \min (1,3,5,7)$ com a Feature $f_{1}=\operatorname{and}\left(x_{1}=0, x_{4}=1\right) \ldots \ldots \ldots$

5.5 Visão Geral do Ambiente Experimental Construtivo . . . . . . . . . 87

5.6 Biases para a Construção de Features para Atributos Booleanos . . . . . 88

5.7 Construção de Árvore de Decisão com Construção Automática de Features 89

5.8 Root-Primeira Iteração . . . . . . . . . . . . . . . . . . 91

5.9 Root -Segunda Iteração . . . . . . . . . . . . . . . 92

5.10 Root - Terceira e Última Iteração . . . . . . . . . . . . . . . . . . 92

5.11 Fringe - Primeira Iteração . . . . . . . . . . . . . . . 93

5.12 Fringe-Segunda Iteração . . . . . . . . . . . . . . . . . . 94

5.13 Fringe - Terceira Iteração . . . . . . . . . . . . . . . 94

5.14 Fringe - Quarta e Última Iteração . . . . . . . . . . . . . . . . 95

5.15 Root-Fringe-Primeira Iteração . . . . . . . . . . . . . 96

5.16 Root-Fringe -Segunda Iteração . . . . . . . . . . . . . 96

5.17 Root-Fringe - Terceira e Última Iteração . . . . . . . . . . . . . . 96

5.18 Árvore de Decisão Inicial . . . . . . . . . . . . . . . . . . 98

5.19 Árvore de Decisão após o Processamento do Algoritmo Root . . . . . . . 99

5.20 Árvore de Decisão após o Processamento do Algoritmo Fringe . . . . . 100

5.21 Árvore de Decisão após o Processamento do Algoritmo Root_Fringe . . . 101

5.22 Módulo Gerador de Exemplos . . . . . . . . . . . . . . . . . . 101

5.23 Procedimento Principal do Módulo Gerador de Exemplos . . . . . . . 103 


\section{Lista de Tabelas}

2.1 Argumentos Dedutivos versus Indutivos . . . . . . . . . . 30

3.1 Atributos e Valores para Diagnóstico do Estado de um Motor . . . . . . 38

3.2 Conjun to de Observações ou Exemplos . . . . . . . . . . . . 38

5.1 Exemplos de Robôs Amigos e Robôs Inimigos . . . . . . . . . . . . . . . 84

5.2 Exemplos de Robôs Amigos e Robôs Inimigos Estendidos com o Novo Atributo mesma_forma . . . . . . . . . . . . . . . . . . 85

5.3 Formas Normais Disjuntivas . . . . . . . . . . . . . . . . . . 102

5.4 Características Medidas . . . . . . . . . . . . . . . . 107 


\section{Introdução}

Aprendizado é a essência da Inteligência [McDonald 89]

Considerando essa afirmação, nota-se que uma das características da inteligência é sua habilidade para aprender. Aprendizado pode ser definido em termos gerais como um processo no qual sistemas inteligentes adquirem conhecimento e melhoram suas habilidades [Kocabas 91].

Aprendizado de Máquina - AM - é uma área de pesquisa em Inteligência Artificial - IA - que estuda métodos computacionais para adquirir novos conhecimentos, novas habilidades e novos meios de organizar o conhecimento existente, incorporando características dos seres humanos no processo de aprendizado. Aprendizado de Máquina é uma área importante em Inteligência Artificial já que a capacidade de aprender é essencial para um comportamento inteligente.

Um dos objetivos de Aprendizado de Máquina é auxiliar a automação do processo de aquisição de conhecimento na construção de Sistemas Baseados em Conhecimento. Um outro objetivo mais teórico é entender o próprio processo de aprendizado - que foge do escopo deste trabalho.

São várias as estratégias de Aprendizado de Máquina. Uma das estratégias utilizadas para acelerar o processo da aquisição, amplamente defendida por Donald Michie [Michie 90] e outros, é o Aprendizado Indutivo por Exemplos que têm sido usada frequentemente com relativo sucesso comercial. Nesta estratégia de aprendizado o sistema deve induzir a descrição do conceito através de processos de generalização e especialização, realizados sobre os exemplos e, opcionalmente, contra-exemplos do conceito.

Entre os sistemas que adotam a estratégia de Aprendizado por Exemplos estão os sistemas da família TDIDT - Top Down Induction of Decision Trees. Os elementos desta família se caracterizam por construir árvores de decisão para tarefas de classificação.

0 algoritmo geral dos sistemas da família TDIDT começa com um conjunto de exemplos de aprendizado $E$ - conjunto de treinamento - e uma árvore de decisão vazia, que é construída gradualmente até que classifique corretamente os exemplos do conjunto $E$.

Os algoritmos desta família podem ser classificados em incrementais e não incrementais. No primeiro caso, a árvore vai sendo construída exemplo a exemplo; um novo exemplo, 
eventualmente, causa uma acomodação da árvore, de maneira a classificá-lo. A árvore vai se alterando e crescendo, à medida que os exemplos vão se tornando disponíveis. Já no caso não incremental, o conjunto de treinamento deve estar disponível desde o início do processo, uma vez que a árvore é construída considerando todos os exemplos de uma vez.

Um problema tratado pelos algoritmos desta família é o de como evitar a construção de subárvores não confiáveis. Entre as soluções propostas, encontra-se a do uso do mecanismo de pós-poda. A pós-poda é utilizada após a construção da árvore, quando o erro de classificação de novos exemplos - que não pertencem ao conjunto de treinamento $E$ - é calculado e, em função desse erro, decide-se pela poda de algumas subárvores.

Neste trabalho são apresentados algoritmos não incrementais e incrementais de AM pertencentes à família TDIDT de sistemas de aprendizado, que induz descrições de conceitos através de processos de generalização e especialização de um conjunto de treinamento. Foram implementados algoritmos que constrõem árvores de decisão no modo incremental e não incremental, utilizando uma estrutura de dados de árvores binárias, onde os atributos assumem dois valores possíveis - o atributo está presente ou ausente no conjunto de treinamento. Estes algoritmos, assim como um mecanismo de pós-poda da árvore de decisão, foram integrados no Ambiente Experimental TDIDT para Atributos Booleanos.

Quando o conjunto de treinamento é representado como vetores de atributos, algumas vezes os atributos iniciais não são diretamente relevantes para descrever um conceito, mas quando convenientemente combinados gerando novos atributos, podem tornarse altamente representativos para expressar um conceito. Este processo que muda o espaço de representação de conceitos é conhecido como Indução Construtiva. Um outro ambiente - Ambiente Experimental Construtivo para Atributos Booleanos -, também descrito neste trabalho, tenta ampliar os limites da linguagem de descrição de hipóteses através da construção automática de features usando indução construtiva. Este ambiente utiliza os algoritmos implementados de construção da árvore de decisão pertencentes ao Ambiente Experimental TDIDT para Atributos Booleanos.

As diversas implementações desses algoritmos, assim como os ambientes experimentais de aprendizado, estão integradas como módulos participantes a um sistema mais geral de Aprendizado de Máquina para geração de regras de conhecimento, que está sendo desenvolvido no ICMSC-USP.

O trabalho está organizado da seguinte forma:

O Capítulo 1 apresenta uma introdução geral sobre Aprendizado de Máquina no contexto de Inteligência Artificial. É feito um breve histórico sobre Aprendizado de Máquina mostrando seu desenvolvimento e as diversas linhas de pesquisa que compõem esta área.

O Capítulo 2 descreve uma dessas linhas de pesquisa - Aprendizado Simbólico de Máquina -, e mostra a relação existente entre indução e dedução. Alguns dos critérios 
de sucesso de um sistema de aprendizado são considerados. É também abordado Aprendizado de Máquina incremental e não incremental e o uso de Indução Construtiva para gerar novos atributos que não estão, a principio, no conjunto de treinamento inicial.

o Capítulo 3 apresenta aprendizado de árvores de decisão. Árvore de decisão é um dos formalismos utilizados em Aprendizado de Máquina para representar conceitos. É apresentado a família TDIDT, o algoritmo básico e alguns dos mais importantes sistemas desta família. É também, discutida a importância da poda em árvores de decisão, que procura evitar a construção de subárvores não confiáveis.

O Capítulo 4 descreve os algoritmos ID3, ID5 e o Método de Poda de Redução do Erro e as respectivas implementações, realizadas para atributos com valores booleanos. O Ambiente Experimental TDIDT para Atributos Booleanos, que integra essas implementações, é descrito em detalhes.

O Capítulo 5 mostra o Ambiente Experimental Construtivo para Atributos Booleanos. São apresentadas diversas biases implementadas - root, fringe e root_fringe - para construção automática de features, assim como o Módulo Gerador de Exemplos de funções booleanas representadas na FND.

Finalmente, o Capítulo 6 apresenta as conclusões e trabalhos futuros. 


\section{Capítulo 1}

\section{Aprendizado de Máquina}

\subsection{Introdução}

Inteligência Artificial é uma área de pesquisa da Ciência da Computação. Entre seus objetivos está a construção de máquinas "inteligentes". Isto sugere, implicitamente, o conceito de Aprendizado de Máquina, uma vez que, para ser "inteligente" é necessário conhecimento e aprendizado.

Pode-se considerar que o ser humano está pré-programado para o aprendizado. Ainda recém-nascido ele possui reflexos e é curioso por natureza, sendo uma das essências da inteligência humana a capacidade de aprender. $O$ ser humano aprende utilizando seus sentidos através da experiência, ouvindo e interpretando o que lhe é dito, etc. Isto é, aprende ampliando o alcance do conhecimento que já possui, através de reordenações sucessivas.

Segundo Charniak \& McDermott [Charniak 86]:

Para um organismo aprender, ele já deve saber muita coisa. O aprendizado começa com a organizaçâo do conhecimento, que vai crescendo e ficando melhor organizado. Sem uma forte indicação do que aprender, nada será aprendido.

Em contraste, o computador não possui o programa inicial para procurar por informações e realizar aprendizado em geral. Portanto, é bom ressaltar que os paradigmas e técnicas de Aprendizado de Máquina que serão discutidos neste trabalho, possuem um alvo bem mais limitado do que o aprendizado humano.

Aprendizado de Máquina é uma subárea de Inteligência Artificial, que tenta incorporar aspectos da capacidade humana de aprender. Neste sentido, lida com métodos computacionais que fazem com que as máquinas "aprendam". Este "aprender" significa 
chegar a novas conclusões através do conhecimento existente ou disponível, fazendo com que existam mudanças na forma como são realizadas as tarefas.

Segundo Carbonell \& Langley [Carbonell 87]

Aprendizado de Máquina é a área que estuda métodos computacionais apropriados para a aquisição de novos conhecimentos, novas habilidades e novas formas de organização do conhecimento já existente.

Michie [Michie 90] diferencia Aprendizado de Máquina em geral do Aprendizado de Máquina tipo IA e segundo ele:

Um sistema de Aprendizado de Máquina (do tipo IA) usa dados de amostra - denominado conjunto de treinamento - para gerar e atualizar sua base, para modificar a sua representação a fim de melhorar seu desempenho na classificação de outros dados da meșma fonte, assim como - este é o aspecto caracteristico de IA - o sistema deve ser capaz de comunicar aos usuários sua base atualizada ou o aumento de sua representação de uma forma que o usuário possa entender e verificar mentalmente. Caso contrário, a máquina simplesmente gera uma descrição mas não um conceito. Em IA estamos interessados no desenvolvimento de estruturas de informação que podem ser interpretadas pelo cérebro humano.

Segundo Michie, a necessidade de que as novas teorias e descrições geradas sejam entendidas pelos seres humanos não é uma necessidade meramente acadêmica, mas uma exigência das empresas comerciais e industriais.

A próxima seção apresenta um modelo simples de um sistema de aprendizado de máquina. O restante do Capítulo abordará a evolução da pesquisa em AM através de um breve histórico e a diversas linhas de pesquisa que a compõem.

\subsection{Modelo de Sistemas de Aprendizado}

Simon [Simon 83] propôs um modelo de sistemas de aprendizado que engloba os seguintes componentes:

1. Ambiente

2. Unidade de Aprendizado

3. Base de Conhecimento 


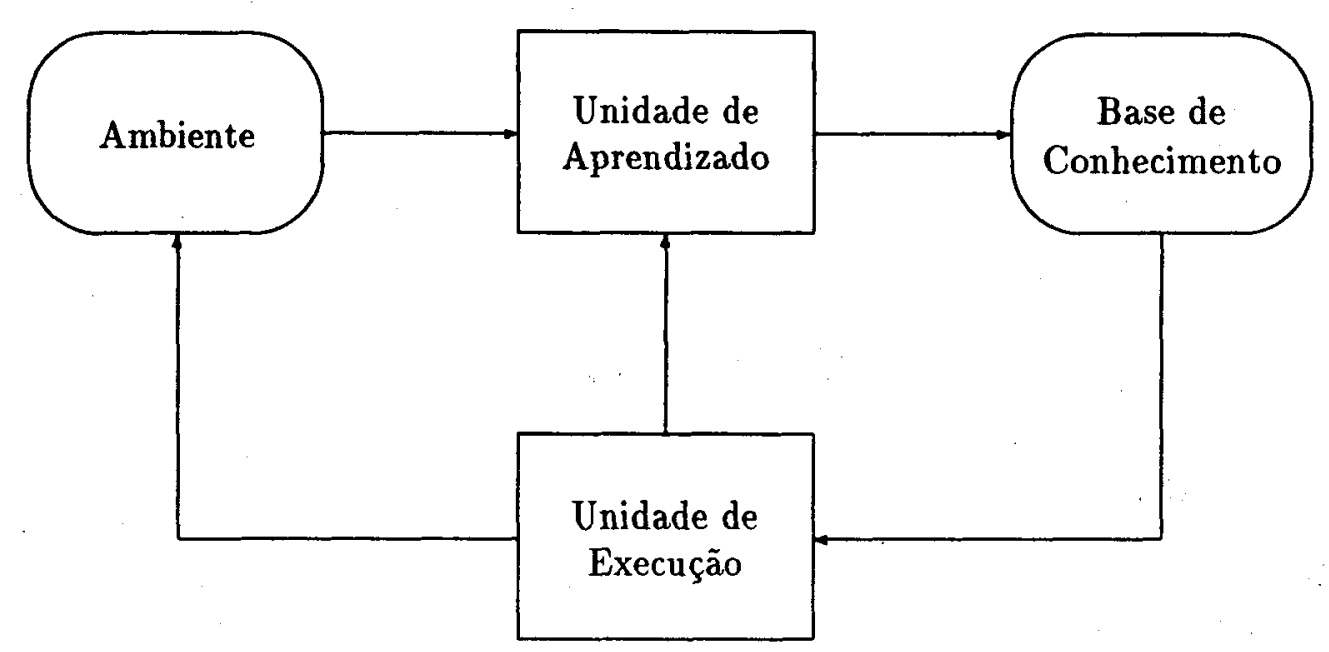

Figura 1.1: Componentes de Aprendizado do Modelo de Simon

\section{Unidade de Execução}

Neste modelo - Figura 1.1 - o Ambiente fornece alguma informação à Unidade de Aprendizado que a utiliza para aperfeiçoar a Base de Conhecimento. Esta informação é utilizada pela Unidade de Execução na realização de uma tarefa. A informação obtida durante esta atividade, pode servir tanto como feedback para a Unidade de Aprendizado, quanto para mudar o Ambiente.

Com base neste modelo simples é possível classificar sistemas de aprendizado conforme o relacionamento desses quatro componentes.

O grau de generalidade da abstração e a qualidade da informação fornecida pelo Ambiente é um fator importante no projeto de sistemas de aprendizado. Informação geral ou abstrata é relevante para uma ampla classe de problemas enquanto que informação especializada é relevante para um simples problema. A tarefa da Unidade de Aprendizado é fazer a ligação entre os níveis de generalidade da informação fornecida pelo Ambiente e o nível de informação que a Unidade de Execução necessita para realizar sua função. A Unidade de Aprendizado deve ser capaz de formar hipóteses para ligar as diferenças entre os níveis de generalidade, e deverá receber algum feedback que lhe permite avaliar suas hipóteses e revisá-las, se necessário. Se é dado ao sistema de aprendizado uma informação geral ou abstrata sobre sua tarefa de execução, o sistema deverá detalhar a informação para que a Unidade de Execução possa usá-la em situações particulares. Do mesmo modo, se é dado ao sistema uma informação muito específica, a Unidade de Aprendizado deverá generalizar esta informação, dentro de uma hipótese ou regra, que pode ser usada pela Unidade de Execução em uma classe mais ampla de situações. 


\subsection{Breve Histórico de Aprendizado de Máquina}

De acordo com Shavlik [Shavlik 90], a evolução da pesquisa envolvendo AM pode ser classificada nos seguintes 3 períodos de atividades:

1. exploração - 1950-1960

2. desenvolvimento de algoritmos práticos -1970

3. explosão de diversas linhas de pesquisa -1980

Os primeiros trabalhos em AM foram inspirados por pesquisas nas áreas de biologia, neuropsicologia e psicologia. Foram desenvolvidas e testadas analogias computacionais de neurônios, destacando-se entre esses trabalhos o Perceptron de Rosenblatt [Rosenblatt 58]. Outros grupos de pesquisadores tentaram linhas diferentes, por exemplo, construir sistemas simples de processamento simbólico para modelar o aprendizado humano.

Nesse primeiro período, iniciou-se também a exploração de técnicas para aprendizado através de exemplos fornecidos por um "professor", este tipo de aprendizado é chamado de Aprendizado Supervisionado. Samuel [Samuel 59,Samuel 63] em seu trabalho sobre aprendizado de funções de avaliação para busca alfa-beta no domínio do jogo de damas, estudou extensivamente aprendizado speedup. $\mathrm{O}$ aprendizado speedup é um tipo de aprendizado onde o sistema pode modificar seu próprio conhecimento, tornando-o mais eficiente.

Em geral, neste período, os pesquisadores preocuparam-se em construir sistemas gerais que aprendiam com pouco conhecimento inicial.

A Análise Teórica de AM começou em 1960. Gold [Gold 67] desenvolveu uma definição de aprendizado - chamado Identificação no Limite - que enfatiza o que pode ser aprendido quando não existe limites colocados no número de exemplos de treinamento, ou na quantidade de tempo computacional disponível.

Outra importante contribuição teórica foi o trabalho de Minsky e Papert [Minsky 69] que analisou as vantagens e limitações do perceptron. A forte crítica sobre a pesquisa com o perceptron desestimulou trabalhos futuros em modelagem neuropsicológica orientado ao aprendizado por quase 20 anos. Nesta fase, a representação simbólica e métodos heurísticos foram os principais tópicos estudados pelos pesquisadores.

O desenvolvimento de algoritmos práticos na década de 70, começou com a publicação da dissertação de Winston [Winston 70] sobre Aprendizado no Mundo dos Blocos, o qual começou o processo de fazer com que o aprendizado fosse o ponto central na pesquisa em IA. $O$ trabalho relacionado com aprendizado de conceitos e aquisição de conhecimento continuou, e foi agrupado ao trabalho de aprendizado no contexto de 
solução de problemas, assim como formação de taxonomias, raciocínio analógico e descoberta de máquina.

A seguir surgiram outros sistemas como o META-DENDRAL [Buchanan 78], AQ11 [Michalski 80] e ID3 [Quinlan 83], MACROPS [Fikes 72], AM"1 [Lenat 77], seguidos por sistemas de aprendizado indutivo direcionados pelo conhecimento e aprendizado analógico.

A partir de 1980 houve uma grande explosão de direções nas linhas de pesquisa em AM. Estas são discutidas na próxima seção.

\subsection{Linhas de Pesquisa de AM}

Não há uma classificação única para as linhas de pesquisa atuais em Aprendizado de Máquina. Autores diferentes utilizam classificações diferentes. Neste trabalho será seguida a classificação utilizada por [Shavlik 90]. A classificação segue oito linhas paralelas, elas são:

- Análise Teórica

- Algoritmos de Aprendizado Simbólico .

- Clustering e Descoberta

- Aprendizado Baseado em Explicação

- Conexionismo (Redes Neurais)

- Aprendizado Indu tivo Direcionado pelo Conhecimento

- Aprendizado Analógico e Baseado em Casos

- Algoritmos Genéticos

A seguir são descritos sucintamente cada uma destas linhas de pesquisa.

\subsubsection{Análise Teórica}

Análise Teórica de técnicas práticas de AM começou com trabalhos desenvolvidos por Mitchell, Utgoff e Quinlan. Mitchell desenvolveu um algoritmo de eliminação de candidatas e a noção de um "espaço de versões" de hipóteses. Este "espaço de versões"

\footnotetext{
${ }^{1} \mathrm{O}$ sinal * é utilizado apenas para diferenciar da sigla de Aprendizado de Máquina (AM).
} 
de hipóteses possui a habilidade de reconhecer quando os exemplos de treinamento observados são suficientes e quando exemplos de treinamento adicionais são necessários. Juntamente com Utgoff, também definiu o conceito de linhas indutivas para algoritmos de aprendizado indutivo [Mitchell 80,Mitchell 82].

Quinlan [Quinlan 83] obteve alguns limites na relação entre o tamanho de uma amostra de treinamento e a complexidade da função que pode ser confiavelmente aprendida usando essa amostra de treinamento//porém, o maior impacto nesta linha de pesquisa de AM surgiu com a publicação do artigo de Valiant [Valiant 84] que definiu a noção de aprendizado Provavelmente Aproximadamente Correto ${ }^{2}$ - PAC.

Esta definição requer que o algoritmo de aprendizado apresente uma hipótese que, com uma alta probabilidade, seja uma boa aproximação do conceito fonte [Haussler 88]. As questões pertencentes a esta definição levaram a pesquisar, qual é a probabilidade de serem classificados corretamente novas observações, e qual a probabilidade da certeza que a hipótese produzida pelo algoritmo é aproximadamente correta.

A estrutura proposta por Valiant prevê os limites no número de exemplos de treinamento exigido - por uma dada linha indutiva - para dar uma alta confiabilidade ao resultado dado pelo algoritmo de aprendizado. Este número de exemplos é chamado complexidade da amostra da linha indutiva. Se o número de exemplos de treinamento usado no aprendizado for maior que a complexidade da amostra, então a confiabilidade de que os resultados do algoritmo de aprendizado estão corretos, é grande.

A idéia básica é analisar a expressividade do espaço de hipóteses. Se o espaço de hipóteses $H$ é muito pequeno, então é pouco provável que o algoritmo de aprendizado terá sucesso em descobrir uma hipótese $f$ pertencente a $H$, que seja consistente com os exemplos de treinamento. Consequentemente, se $f$ for encontrado, então $f$ é uma boa aproximação para a hipótese correta [Shavlik 90].

Este artigo entusiasmou vários pesquisadores da área de Teoria da Computação a fim de explorar as consequências desta definição. Foram provadas condições necessárias e suficientes para o aprendizado de várias classes de funções [Haussler 88].

\subsubsection{Algoritmos de Aprendizado Simbólico}

Aprendizado simbólico é uma técnica que explora representaçōes de estrutura gráfica ou lógica, no lugar de métodos estatísticos ou numéricos. Os sistemas aprendem descrições simbólicas representando conhecimento de mais alto nível, e fazem fortes suposições estruturais sobre os conceitos a serem adquiridos [Castineira 90].

Um sistema que utiliza este tipo de representação é o ID3 de Quinlan [Quinlan 86b, Quinlan 87a,Quinlan 87b] para aprendizado de árvores de decisão, outro sistema é o

\footnotetext{
${ }^{2}$ Probably Approximately Correct.
} 
programa de Winston [Winston 75], que aprende conceitos no mundo dos blocos.

Esta técnica de aprendizado será vista no próximo capítulo por ser a linha de pesquisa seguida pelo trabalho de dissertação.

\subsubsection{Clustering e Descoberta}

Clustering é usualmente visto como um processo para agrupar objetos físicos ou abstratos dentro de classes de objetos similares. Para isto, é necessário definir uma medida de similaridade entre os objetos e então aplicar esta medida para determinar as classes em que serão agrupados os objetos. Diversos trabalhos desenvolvidos nesta linha de aprendizado enfatizam que os objetos devem ser agrupados, não apenas porque eles são similares em relação a uma dada medida, mas porque agrupados, eles representam uma certa classe conceitual, chamada Clustering Conceitual [Michalski 83b].

No clustering conceitual a configuração de objetos forma uma classe apenas se é descrita por um conceito através de um conjunto pré-definido de conceitos [Kocabas 91]. A classifição de objetos é realizada dentro de hierarquias formando uma rede conceitual. Os vários métodos de clustering existentes se diferenciam na forma em que agrupam os objetos em classes.

Kocabas define o problema de classificação em clustering conceitual da seguinte forma: Dados:

1. um conjunto de objetos

2. um conjunto de atributos para ser usado para caracterizar objetos

3. o número de clusters desejado

4. conhecimento sobre limitações do problema, propriedades dos atributos e um critério de avaliação da qualidade das classificações construídas

Encontrar:

uma hierarquia de classes de objetos, na qual cada classe é descrita por um conceito complexo (usualmente disjuntivo), baseado em um conjunto de atributos. Subclasses da classe pai e suas próprias subclasses devem ter uma descrição similar e devem otimizar um critério assumido.

Estruturar objetos dentro dessas hierarquias é chamado clustering conceitual conjuntivo se os conceitos complexos que descrevem os clusters são conjuntivos. 
Em análise de dados convencionais, a similaridade entre dois objetos quaisquer é caracterizado pelo valor de uma função de similaridade aplicada a descrições simbólicas de objetos. No clustering conceitual, a similaridade entre os objetos $a$ e $b$ é chamada de coesão conceitual, definida como:

$$
\text { coesão-conceitual }(a, b)=f(a, b, E, C)
$$

onde $E$ são os objetos mais próximos e $C$ é um conjunto de conceitos que estão disponíveis para descrever $a$ e $b$ juntos [Kocabas 91].

Os algoritmos mais conhecidos que utilizam este método são o COBWEB [Fisher 87] e o CLUSTER/2 [Michalski 83a].

Aprendizado por Descoberta é uma forma de aprendizado onde a aquisição de conhecimento é feita sem auxílio de um "professor". Nesta estratégia, o aprendiz analisa e observa entidades e determina alguns subconjuntos destas entidades que serão agrupados em certas classes, isto é, conceitos. Um exemplo clássico de sistemas que utilizam estes métodos é o programa $\mathrm{AM}^{*}$ de Lenat [Lenat 77].

O programa $\mathrm{AM}^{*}$ descobre novos conceitos matemáticos e relações entre eles. Estes conceitos são descobertos através de busca em algumas centenas de regras heurísticas, em um espaço de conceitos parcialmente desenvolvidos. Em uma aplicação de $\mathrm{AM}^{*}$ foi descobertó o conceito de "Multiplicação". Uma das regras heurísticas de AM* é

Se fé uma operação interessante,

Então faça seu inverso

Neste caso, onde $f=$ Multiplicação, $\mathrm{AM}^{*}$ definiu e estudou a relação "divisores de".

Clustering e Descoberta são algoritmos não supervisionados. $\mathrm{O}$ objetivo destes algoritmos é, através de alguns atributos, buscar as "regularidades" dos mesmos até chegar a um conceito. Uma das dificuldades é encontrar técnicas que descobrem estas "regularidades" que variam entre as diversas aplicações. Aprendizado por Descoberta busca relações mais complexas entre os atributos do que o método de Clustering, que simplesmente busca as regularidades e coloca-as na forma de clusters.

\subsubsection{Aprendizado Baseado em Explicação}

A maneira mais simples de falar sobre Aprendizado Baseado em Explicação - ABE é no contexto do aprendizado de macro operadores [Shavlik 90,Nicolet ti 93a].

Considere um resolvedor de problemas que trabalha aplicando operadores que transformam um estado inicial $-P$ (descrição do problema) em um estado final $-S$ (solução do problema). 
Como existem muitos operadores que podem ser aplicados a cada estado, o resolvedor de problemas deve conduzir uma busca de maneira a evidenciar qual a sequência de operadores que conduz à solução. Uma maneira de acelerar a solução do problema é reter um conjunto de problemas previamente resolvidos e suas correspondentes soluções (i.e., pares da forma $<P, S>$ ). Assim sendo, para cada novo problema a ser resolvido, verifica-se se o referido problema já foi resolvido anteriormente. Esta estratégia apenas produz resultados se o mesmo problema precisar novamente ser resolvido.

Uma possível alternativa é generalizar $\langle P, S\rangle$, eliminando detalhes irrelevantes e substituindo constantes por variáveis $(x)$, de maneira a obter $\left\langle P^{*}(x), S^{*}(x)>\right.$ a partir de $\langle P, S\rangle$. Novos problemas podem, então, ser comparados com $P^{*}(x)$. Se uma correspondência for encontrada, os valores de $x$ estabelecidos pela correspondência são substituídos em $S^{*}(x)$ para obter a solução.

Este par generalizado de problema/solução $\left\langle P^{*}(x), S^{*}(x)>\right.$ pode ser visto como um novo macro operador. A chave do aprendizado baseado em explicação está no registro dos passos na resolução do problema $P$ de maneira a obter $S$. Este registro fornece a informação necessária para a generalização de $\langle P, S\rangle$; tal registro é frequentemente chamado de explicação, uma vez que explica como a solução foi alcançada. O sistema de ABE analisa esta explicação para poder extrair $\left\langle P^{*}(x), S^{*}(x)\right\rangle$ e, consequentemente, aprender um novo macro operador.

Via de regra a explicação é o próprio trace das ações do solucionador de problemas. Geralmente a generalização de uma explicação de um problema específico é obtida através do uso de unificação [Nilsson 80].

Sistemas ABE lembram versões generalizadas de soluções pressupondo que isto irá acelerar a solução de problemas futuros. Pode acontecer, entretanto, que o fato de lembrar soluções generalizadas traga inconvenientes. Se o novo problema a ser resolvido é similar a um anterior cuja solução generalizada está armazenada, este novo problema pode facilmente ser solucionado, usando para tanto a solução generalizada disponível. Entretanto, existe o tempo de busca a ser considerado - se um problema similar já solucionado não for encontrado, este tempo é perdido. Além do mais, dependendo da quantidade de pares problema/solução armazenados, as vezes o tempo de busca do problema e recuperação da solução pode ser maior do que uma nova resolução do problema. Esse problema é conhecido como utility problem [Minton 87].

\section{Generalização Baseada em Explicação}

Mitchell [Mitchell 86] apresentou um formalismo chamado de Generalização Baseada em Explicação - GBE. Este formalismo utiliza métodos dedutivos para fazer generalizações sobre o exemplo de treinamento, e é capaz de justificar estas generalizações através de uma explicação de como o exemplo satisfaz a definição do conceito, utilizando uma árvore de prova e regras de inferência expressas na teoria do domínio. 
O processo de generalização baseada em explicação - Figura 1.2 [Kocabas 91] - consiste em:

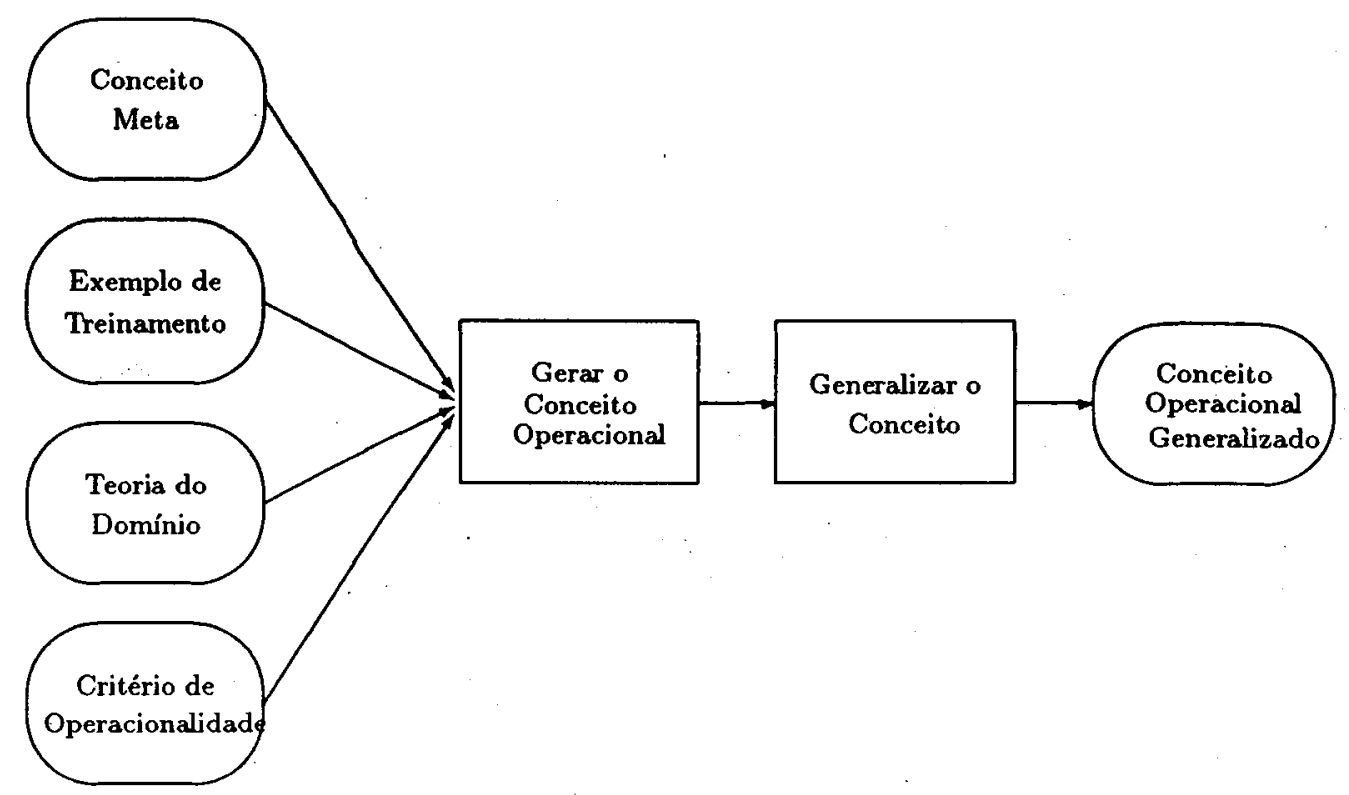

Figura 1.2: O Processo de Generalização Baseada em Explicação

1. Dados:

- Conceito Meta: definição do conceito a ser aprendido (assume-se que essa definição não satisfaz o critério de operacionalidade)

- Exemplo de Treinamento: exemplo do conceito

- Teoria do Domínio: conjunto de regras e fatos a serem usados para explicar como o exemplo de treinamento é um exemplo do conceito

- Critério de Operacionalidade: um predicado definido sobre o conceito, especificando a forma através da qual o conceito aprendido deve ser expresso

2. Determinar:

- uma generalização do exemplo de treinamento que seja uma definição suficiente do conceito e que satisfaça o critério de operacionalidade

Dadas as quatro entradas, a tarefa é determinar a generalização do exemplo de treinamento que seja uma definição suficiente do conceito e que satisfaça o critério de operacionalidade. A noção de operacionalidade é crucial para a generalização: sem ela a definição inicial do conceito poderia sempre ser a definição correta do conceito e não haveria nada a ser aprendido. 0 critério de operacionalidade impõe que as definições aprendidas do conceito não apenas estejam corretas, mas que também estejam em uma forma utilizável. Dado, então, um exemplo de treinamento, a abordagem de aprendizado baseado em explicação envolve: 
1. criação de uma explicação que prova que o exemplo de treinamento é uma instância positiva do conceito, e que separa as características relevantes do exemplo, das irrelevantes. Os nós terminais da árvore de explicação resultante devem ser operacionais. Como a explicação constitui-se em uma prova, em geral sua construção envolve as complexidades relacionadas à prova de teoremas,

2. análise da explicação para determinar as restrições nos valores dessas características que sejam suficientes para que a estrutura de explicação possa ser aplicada de uma maneira geral, isto é, encontrar a versão mais geral da prova, consistente com a teoria do domínio.

Como ilustração é mostrado a seguir um exemplo de Mitchell. A meta é aprender a reconhecer pares de objetos $(X, Y)$ de modo que se possa empilhar $X$ em $Y$. O exemplo foi alterado por Van Harmelen e Bundy [Van Harmelen 88] para a notação Prolog.

\section{Conceito Meta:}

local_a_empilhar $(X, Y)$ :- mais_leve $(X, Y)$.

\section{Exemplo de Treinamento:}

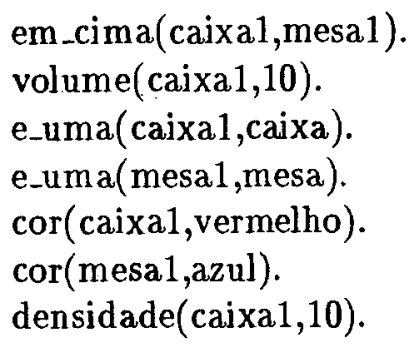

\section{Teoria do Domínio:}

mais leve(X,Y) :- peso(X,W1), peso(Y,W2), menor(W1,W2). peso $(X, 500)$ :- e_uma(X,mesa). peso(X,Y) :- volume $(X, V), \operatorname{densidade}(X, D), \operatorname{mult}(\mathrm{V}, \mathrm{D}, \mathrm{Y})$. mult $(\mathrm{V}, \mathrm{D}, \mathrm{Y})$ :- $\mathrm{Y}$ is $\mathrm{D} * \mathrm{~V}$.

\section{Critério de Operacionalidade:}

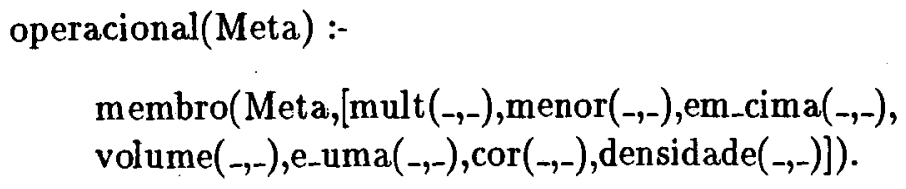


O sistema, primeiramente, constrói uma estrutura de explicação, ou árvore de prova, que explica como o exemplo de treinamento é um exemplo do conceito meta - Figura 1.3. Depois generaliza esta explicação usando um algoritmo que envolve backtracking através da estrutura de explicação, começando na meta - que é a cabeça da árvore de prova -, e troca todas as constantes por variáveis que não se originam na teoria do domínio.

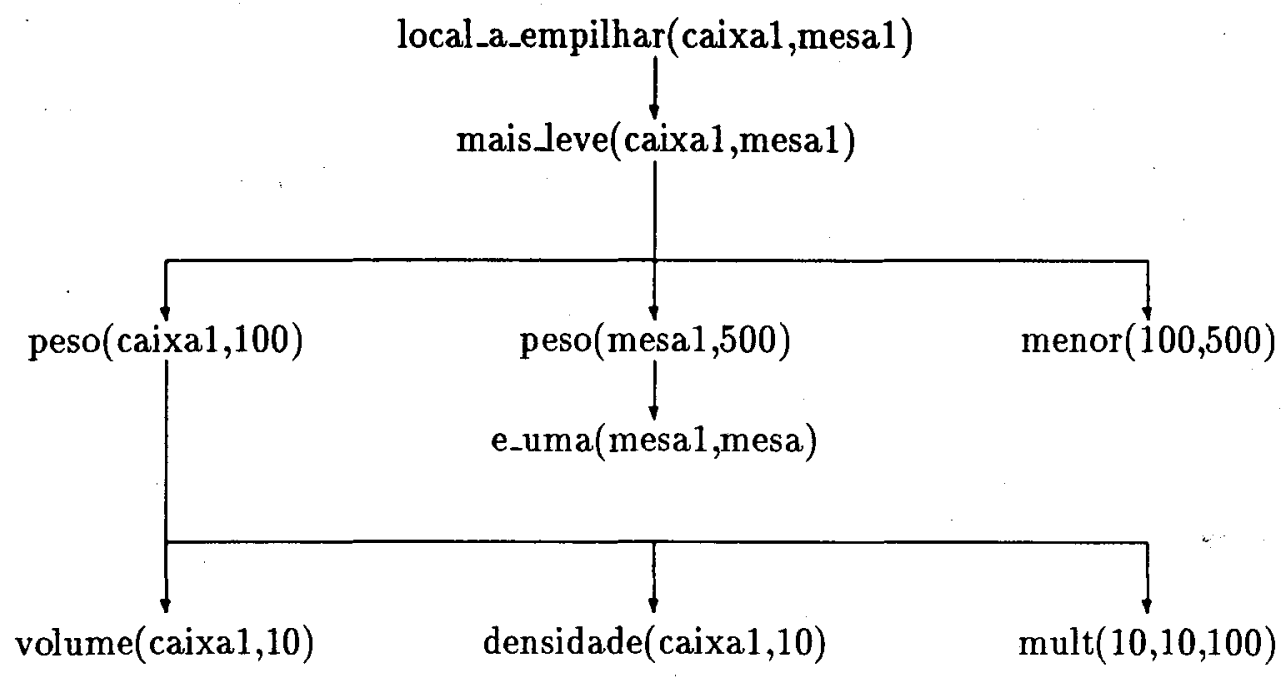

Figura 1.3: Estrutura da Explicação

O resultado final do aprendizado, a definição operacional do conceito meta, é simplesmente a conjunção dos nós folhas da árvore de prova generalizada, que tem como resultado a seguinte regra:

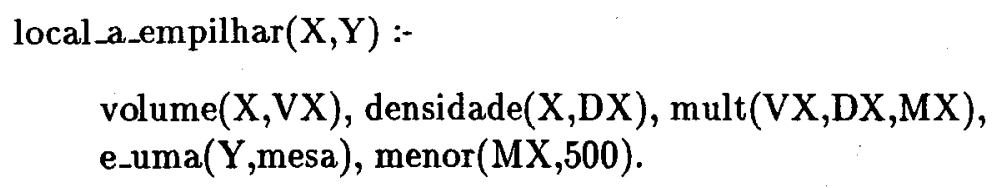

Então, uma regra geral foi aprendida sobre as circunstâncias na qual um objeto pode se utilizar de outro, usando uma situação de um simples exemplo e a teoria do domínio.

\subsubsection{Conexionismo ou Redes Neurais}

Conexionismo ou Redes Neurais é uma técnica computacional que utiliza o mecanismo de paralelismo, onde são conectados um grande número de pequenas unidades de processamento ligadas em rede. Seus elementos são modelados como os neurônios do sistema nervoso humano [Raggett 92]. 
Um sistema que utiliza redes neurais não executa instruções sequenciais como em uma arquitetura de Von Neumann. Sua resposta às entradas, que são apresentadas em paralelo, é o resultado dado pelo estado geral da rede, depois que esta atinge uma condição de equilíbrio. 0 conhecimento é representado na forma como as unidades estão interconectadas e na importância - ou peso atribuído - de cada entrada a uma determinada unidade [Francelin 92].

As unidades interconectadas da rede são formadas por camadas. Uma rede neural pode ter várias camadas, por exemplo, a Figura 1.4 mostra uma rede neural constituída de 3 camadas, onde a primeira camada contém nós de entrada, a segunda nós ocultos e a terceira nós de saídas. Uma unidade de processamento soma os pesos de suas linhas de saída, transforma esta soma de acordo com uma simples fórmula matemática, e passa a função resultante para sua linha de saída; que pode ser, por sua vez, entradas para outras unidades. Aprendizado nestes sistemas é definido em termos de ajustamento total dos pesos para que a saída dada pela rede seja a saída desejada, sem que ocorra mudanças na estrutura da rede [Kocabas 91].

Camadas ocultas são utilizadas no método Back Propagation. Este método de aprendizado é usado em redes neurais que tenham mais de 2 camadas de neurônios, isto é, não apenas a unidade de entrada e saída, mas nós intermediários - ocultos - onde são realizados processamento de problemas mais complexos. Para uma dada entrada, a saída atual é comparaḑa à saída desejada. Sé a diferença (erro) for relativamente pequena, diz-se que o aprendizado está completo (ou em um nível adequado). Caso contrário, o erro é propagado de volta pelas mesmas conexões e estas unidades têm suas forças reduzidas.

Redes Neurais são treinadas através da especificação de limitações e de exemplos de treinamento. Quando o aprendizado está completo, o conhecimento é representado pela totalidade dos pesos das conexões entre as unidades de processamento da rede.

Um dos primeiros estudos sobre AM foi o perceptron [Rosenblatt 58]. Perceptron é o nome de uma rede neural simples de 2 camadas, isto é, não utiliza o método back propagation.

A estrutura de uma rede neural é complexa. Existe a vantagem da flexibilidade, onde pode-se alterar o número de nós e a conectividade entre eles. Entretanto, o que se pode interpretar em uma rede são suas ligações, seus nós e pesos. Saber como a rede chegou a um resultado no processo de aprendizado, o caminho percorrido, o porquê deste caminho, são informações difíceis de saber [Barletta 91].

\subsubsection{Aprendizado Indutivo Direcionado pelo Conhecimento}

Um dos primeiros trabalhos nesta área foi o sistema SIERRA de VanLehn [VanLehn 87]. Este sistema é um modelo de como crianças aprendem, incrementalmente, o procedi- 


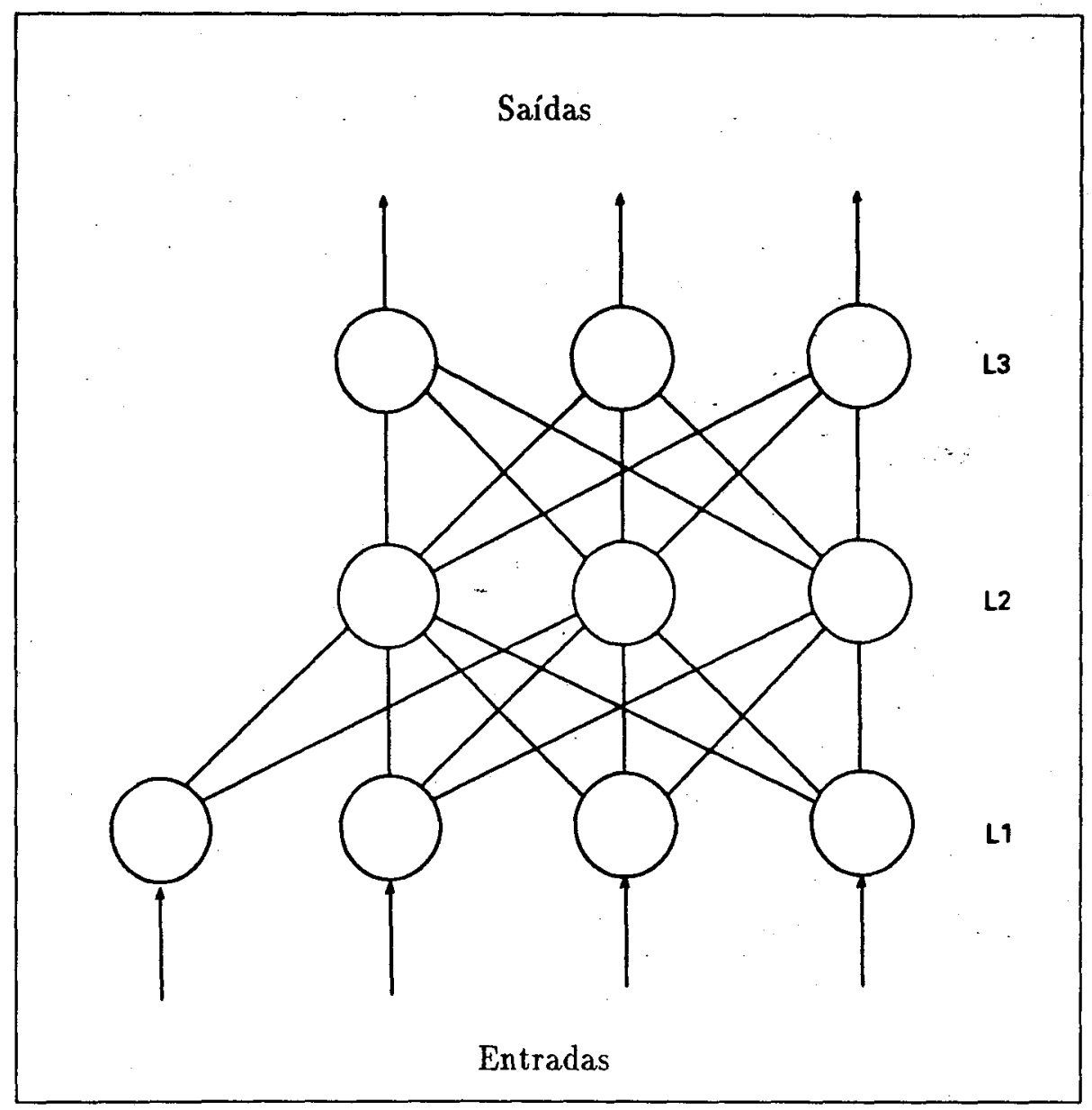

Figura 1.4: Uma Rede Neural de Três Camadas

mento da subtração de números com múltiplas colunas.

A técnica de Aprendizado Indutivo Direcionado pelo Conhecimento - AIDC - é semelhante ao Aprendizado Baseado em Explicação no que se refere à construção de explicações geradas pelo sistema. A diferença está no tipo de conhecimento que é utilizado. Enquanto que o Aprendizado Baseado em Explicação se caracteriza, principalmente, por sumarizar as regras dentro de regras macro, o AIDC dá ênfase aos defeitos $^{3}$ existentes no conhecimento do sistema de aprendizado, isto é, os dados estão imperfeitos, incompletos ou são intratáveis computacionalmente. Uma tentativa de solucionar estes problemas é através de métodos indutivos de aprendizado, pois um dos maiores desafios para AM é descobrir meios de "usar o conhecimento para adquirir mais conhecimento" [Shavlik 90].

Este método, geralmente, é utilizado em conjunto com outros métodos como Redes

\footnotetext{
${ }^{3}$ Mitchell et all chamou de Problema da Teoria Imperfeita [Mitchell 86].
} 
Neurais, ABE, etc.; para tentar diminuir o problema de "ruídos" ou "buracos" existentes no conhecimento, tornando-os assim sistemas híbridos. Por exemplo, um sistema de Aprendizado Baseado em Explicação consiste basicamente de uma teoria do domínio correta mas, algumas vezes, ineficientes para definir um conceito. Em geral, quando AICD é usado em conjunto com ABE, a idéia é, para cada exemplo de treinamento, de acordo com a teoria do domínio, provar que o exemplo é uma instância do conceito, e assim extrair as condições "mais fracas" para avaliação do conceito. Este mecanismo, de extração de condições "mais fracas", poderá ser aplicado para adquirir novos conhecimentos, através da indução de um programa de aprendizado. Isto é, ele realiza aprendizado a nível de conhecimento e não apenas a nível de melhores informações.

\subsubsection{Aprendizado Analógico e Baseado em Casos}

Aprendizado Analógico consiste, basicamente, na transferência de conhecimento de como realizar uma tarefa bem compreendida à outra menos compreendida. Frequentemente, os seres humanos percebem que um determinado problema é semelhante à outro problema que já foi solucionado. Assim, se o primeiro problema foi resolvido de uma certa forma, parece razoável resolver o novo problema através de um mapeamento entre ambos os problemas.

Uma dificuldade encontrada na resolução de problemas análogos é que este tipo de mapeamento não é unicamente invertível - consequência do não determinismo da generalização. Dois exemplos para resolver problemas de geometria, encontrados em [Anderson 83] e [Anderson 79] respectivamente, ilustram bem esta dificuldade. No primeiro exemplo - Figura 1.5 - o aprendiz resolve o Problema I.1, isto é, prova que $\overline{R N}=\overline{O Y}$, usando o seguinte argumento:

$$
\begin{aligned}
\overline{R O} & =\overline{N Y} \\
\overline{O N} & =\overline{O N} \\
\overline{R O}+\overline{O N} & =\overline{O N}+\overline{N Y} \rightarrow \overline{R N}=\overline{O Y}
\end{aligned}
$$

Quando ao mesmo aprendiz é apresentado o Problema I.2, com base na resolução do Problema I.1, o aprendiz faz o seguinte mapeamento:

$$
\begin{aligned}
& R \longrightarrow A \\
& O \longrightarrow B \\
& N \longrightarrow C \\
& Y \longrightarrow D \\
& =\longrightarrow>
\end{aligned}
$$

e tenta, por analogia, resolver o problema da seguinte forma: 
Problema I.1

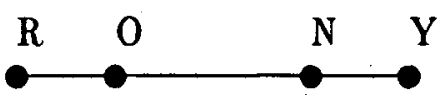

Dado $\overline{R O}=\overline{N Y}$

Prove $\overline{R N}=\overline{O Y}$

\section{Problema I.2}

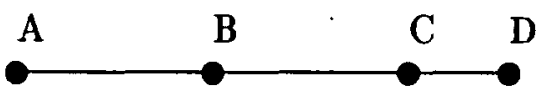

Dado $\overline{A B}>\overline{C D}$

Prove $\overline{A C}>\overline{B D}$

Figura 1.5: Problemas de Geometria com Segmentos

$$
\overline{\overline{A B}}>\overline{\overline{C D}}
$$

Então...

Este raciocínio é logo descartado por absurdo - proveniente da correspondência entre o sinal "=" e o ">". Para chegar na solução é necessário inapear somente "uma" ocorrência do sinal "=" no ">".

Assim como é difícil estabelecer as correspondências válidas em um mapeamento por analogia, é mais difícil ainda estabelecer a sua inversão válida.

No segundo exemplo é apresentado ao estudante o mesmo Problema I.1 - Figura 1.5 - e, logo a seguir, o Problema II ilustrado na Figura 1.6. Neste caso, a resolução do problema por analogia faz, diretamente, a correspondência de retas com ângulos, bem como de igualdade com congruência:

$$
\begin{aligned}
\widehat{B A C} & =\widehat{D A E} \\
\widehat{C A D} & =\widehat{C A D} \\
\widehat{B A C}+\widehat{C A D} & =\widehat{C A D}+\widehat{D A E} \rightarrow \widehat{B A D}=\widehat{C A E}
\end{aligned}
$$

Um outro exemplo clássico de analogia é o utilizado em testes de inteligência. A Figura 1.7 mostra um problema simples deste tipo onde várias figuras $-A, B$ e $C-$ são apresentadas ao sujeito e a seguinte pergunta é a ele colocada:

\section{A está para B como C está para?}

As possíveis respostas são 1,2 ou 3 .

Uma forma simples de resolver este problema é dada pelo seguinte algoritmo [Sterling 86]

Encontrar uma regra que relaciona $A$ com $B$

Aplicar a regra a $C$ para obter a figura $X$

Encontrar $X$ (ou semelhante) entre as possiveis respostas. 
Problema II

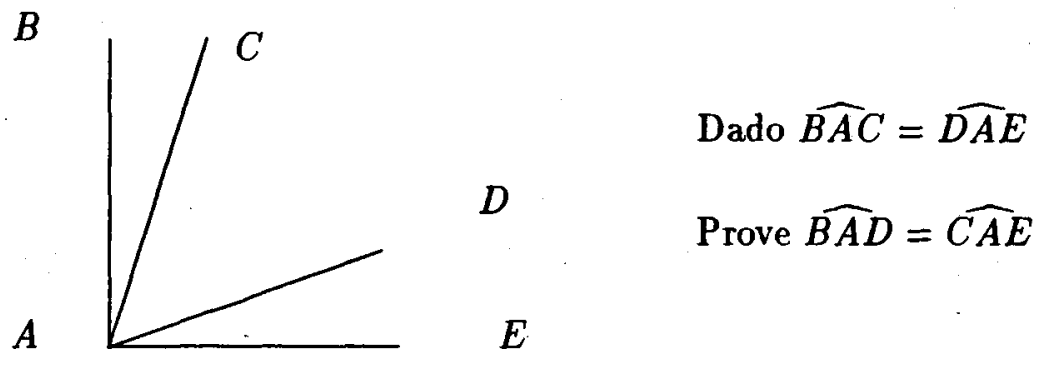

Figura 1.6: Problema de Geometria com Ângulos
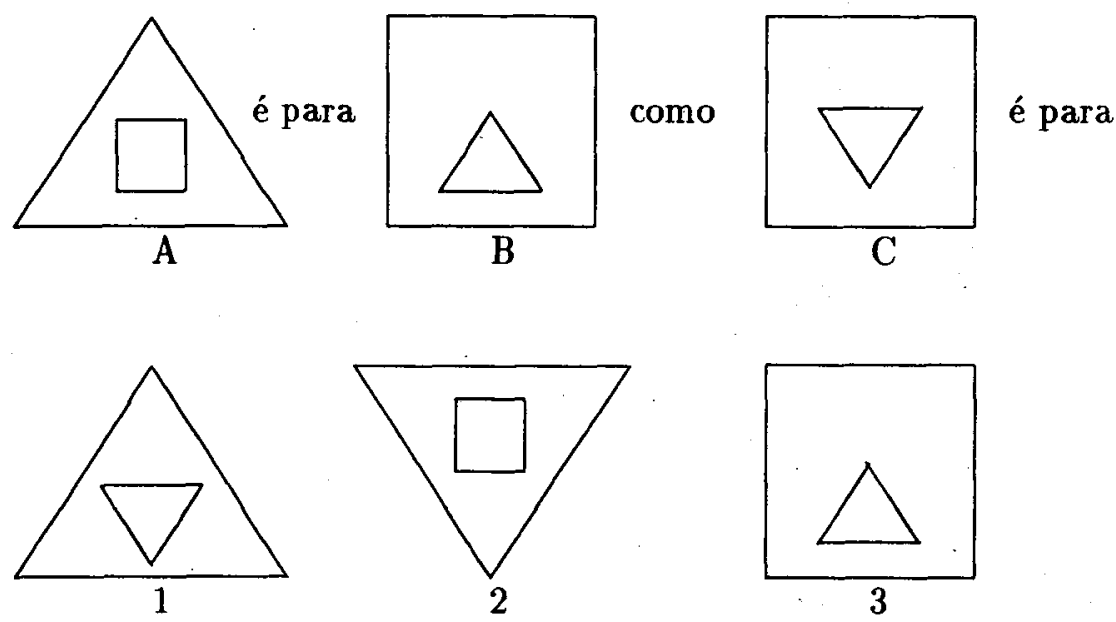

Figura 1.7: Teste de Inteligência

No problema ilustrado na Figura 1.7, a posição dos quadrados e triângulos do tipo $\triangle$ das figuras $A$ e $B$ - dimensionados apropriadamente - está trocada. A resposta óbvia é trocar o quadrado e o triângulo do tipo $\nabla$ na figura $C$. A figura resultante é a correspondente à resposta 2.

Aprendizado por Analogia é uma ferramenta útil na resolução de problemas. Entretanto, os problemas devem ser suficientemente semelhantes para que a analogia possa ser estabelecida diretamente. Caso contrário, o método por analogia serve apenas para "sugerir" soluções para o problema sendo tratado, para fornecer idéias iniciais sobre um conceito ou solução, que devem ser elaborados e depurados para serem convertidos numa solução final.

Winston [Winston 80] foi um dos primeiros pesquisadores a desenvolver algoritmos com 
essa abordagem.

Aprendizado Baseado em Casos - ABC - é uma técnica que utiliza experiências passadas para chegar a uma nova solução. Através de acertos e erros anteriores, o sistema "aprende" a reutilizar ou a evitar a utilização de certas informações em novas situações. O sistema "lembra" das ações envolvidas em outros casos e busca semelhanças que possam ajudar no novo caso.

Esta técnica é semelhante ao raciocínio utilizado por um médico com anos de experiência. Estes profissionais buscam o tratamento apropriado para seus pacientes de acordo com sua experiência em casos similares. Essa experiência é mais em termos dos vários casos tratados do que os procedimentos técnicos que conhecem [Barletta 91].

Barletta propõe uma arquitetura básica - Figura 1.8 - de um sistema de ABC. Dada a especificação do problema, o sistema buscará em sua memória casos semelhantes a este. Se encontrar, o sistema vai diretamente à sua solução. Caso contrário, restabelecerá um caso que é o mais similar ao problema, mas não totalmente apropriado para ser uma solução completa. O sistema então fará uma adaptação do caso, isto é, descobrir e modificar algumas partes do caso recuperado que não se encontram nas especificações do problema. O resultado desta adaptação é uma solução "completa" além da geração de um novo caso que pode, eventualmente, ser adicionado à memória de casos do sistema. O conhecimento é armazenado definindo termos e colecionando casos pré-classificados de um especialista.

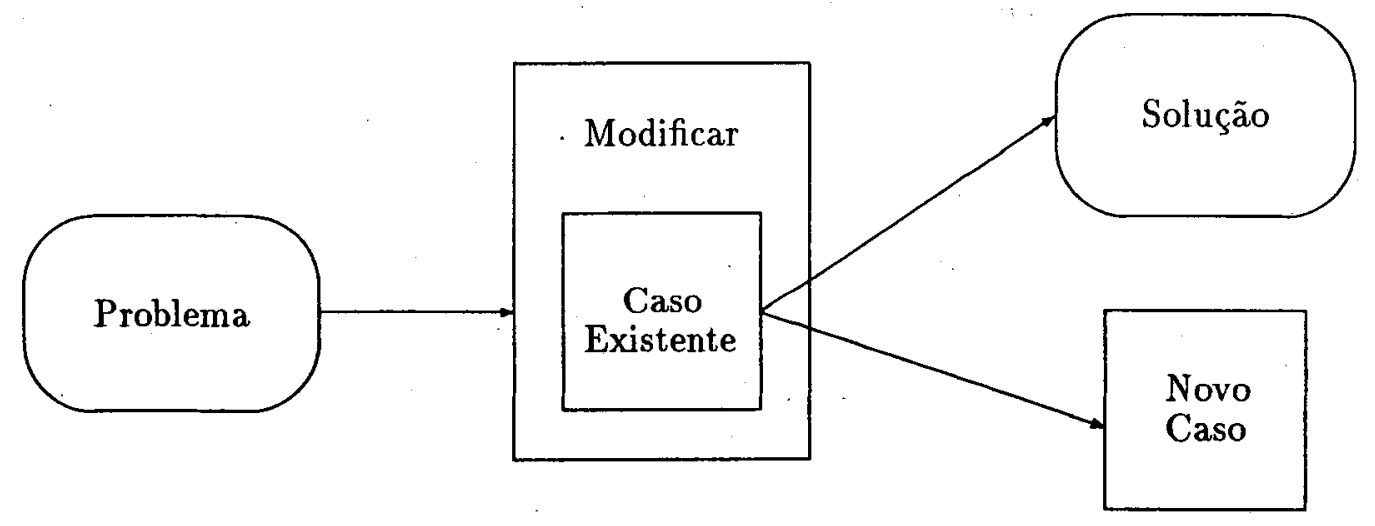

Figura 1.8: Sistema Baseado em Casos

A principal utilização de um sistema de ABC é em aplicações onde é possível derivar valores de planos ou projetos passados. Como ilustração de uma aplicação, segue um exemplo que compara o desempenho de dois sistemas de aprendizado, um baseado em regras e outro baseado em casos, na realização da mesma tarefa [Barletta 91].

O Sistema Prism. Grandes bancos recebem em média 2.000 chamadas de telex por dia, descrevendo mais de 100 tipos de transações que necessitam ocorrer. As chamadas necessitam ser lidas, classificadas e rotuladas, 
em tempo real, e devem ser enviadas para o departamento apropriado do banço. Este processo de classificação e rotulamento é normalmente feito pelo staff do banco. Uma empresa, denominada Sistemas Cognitivo, foi contratada para automatizar a classificação e rotulamento dessas chamadas. A experiência de Sistemas Cognitivo consiste no desenvolvimento de sistemas baseados em regras, assim um classificador de chamadas de telex baseado em regras, chamado Prism, foi desenvolvido. 0 sistema original levou 1 ano para ser construído. Sistemas Cognitivo foi contratado por um segundo banco para construir uma versão baseada em regras para classificar chamadas de telex para o tráfico de mensagens. Foram necesssários 4 meses para construir o segundo classificador baseado em regras. 0 sistema baseado em regras processa as chamadas de telex em 2 a 7 segundos e a classificação geral das chamadas tem um padrão de precisão de $72 \%$.

Como uma experiência, Sistemas Cognitivo decidiu reimplantar a segunda versão do classificador de chamadas de telex usando um shell baseado em casos. Esta versão foi desenvolvida basicamente em 2 semanas. $O$ processamento das chamadas de telex é feito em 0.19 a 0.25 segundos e a classificação tem um padrão de precisão de $77 \%$. Com estes resultados, o cliente decidiu trocar a versão baseada em regras do sistema com o sistema baseado em casos, porque este foi mais rápido, mais exato e mais fácil de modificar e atualizar que o sistema baseado em regras.

Um sistema de $\mathrm{ABC}$ deve reconhecer novos casos reconhecendo as características dos problemas e aprender o que foi feito quando os problemas chegam em circunstâncias diferentes. Uma dificuldade dos sistemas de $A B C$ é decidir como descrever, armazenar e indexar experiências que serão utilizadas novamente, tal que elas possam ser rapidamente recuperadas e manipuladas pelo sistema.

\subsubsection{Algoritmos Genéticos}

Algoritmos genéticos são técnicas de busca de propósito geral e adaptativas baseadas nos princípios genéticos de uma população. Estes princípios estão fundamentados no processo de evolução dos seres vivos de Darwin, "Seleção Natural", onde apenas indivíduos mais aptos sobrevivem, transmitindo suas características a seus descendentes.

Segundo Freitas \& Kirner [Freitas 92]:

Um algoritmo genético é um procedimento iterativo que mantém uma população de indivíduos, cada um dos quais é um candidato à solução de algum problema especifico. Em cada iteração - denominada geração -, os indivíduos da população atual são avaliados quanto à sua aptidão ${ }^{4}$ para a

\footnotetext{
${ }^{4}$ Fitness.
} 
solução do problema. Com base nessas avaliações aplicam-se alguns operadores genéticos aos individuos, formando-se uma nova população, que substituirá a população atual. Isso é feito de modo que, quanto maior a aptidão de um indivíduo da população atual, maior a sua influência na formação dos individuos da nova população. Assim, com o passar do tempo, a seleção natural tende a fazer com que a população seja formada por individuos cada vez melhores (soluções cada vez mais próximas da solução ótima para o problema). Como critério de parada do algoritmo genético, geralmente define-se um limite no número de gerações. Dentre os individuos da última geração, aqueles mais aptos representam a melhor solução encontrada pelo algoritmo. Pode-se também especificar que o algoritmo se encerrará quando for gerado algum individuo que satisfaça alguma condiçâo mínima de aptidão.

Os operadores genéticos são aplicados a uma cadeia de símbolos de comprimento fixo, para gerar a próxima geração de indivíduos. Os quatro operadores genéticos básicos são:

1. Reprodução

2. Cruzamento

3. Mutação

4. Inversão

onde:

1. Reprodução: é a quantidade de cópias que um indivíduo produz, proporcional à sua aptidão. Estas cópias serão submetidas à ação de outros operadores genéticos na geração de novos indivíduos.

2. Cruzamento: é a troca de material genético entre indivíduos.

Por exemplo, considerando os dois seguintes indivíduos representados por uma cadeia de símbolo de comprimento 6 :

Indivíduo 1: $x_{1} x_{2} x_{3} x_{4} x_{5} x_{6}$

Indivíduo 2: $\begin{array}{lllllll}y_{1} & y_{2} & y_{3} & y_{4} & y_{5} & y_{6}\end{array}$

aplicando o operador de cruzamento na sexta posição, são gerados os seguintes novos indivíduos:

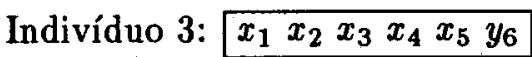

Indivíduo 4: $\begin{array}{lllllll}y_{1} & y_{2} & y_{3} & y_{4} & y_{5} & x_{6}\end{array}$ 
3. Mutação: como em biologia, a mutação, geralmente, é importante para uma espécie sobreviver. Aplicado aos algoritmos genéticos, a mutação modifica o valor de uma posição aleatória da cadeia de símbolos que representa o indivíduo.

Por exemplo, dado um indivíduo representado por uma cadeia de símbolos binários.

Individuo 1: 0100010010

aplicando o operador de mutação na quarta posição da cadeia é gerado o seguinte indivíduo:

Indivíduo 2: 0101011010

A vantagem deste operador é que a probabilidade de pesquisar um problema em qualquer região do espaço nunca será zero, problema que os outros operadores não garantem.

4. Inversão: é a troca de símbolos na cadeia que representa o indivíduo. Símbolos em posições mais próximas têm maior probabilidade de serem rearranjados dentro da cadeia.

Por exemplo, dado o Indivíduo 1, o operador de inversão (posições 3 e 5) gera o Indivíduo 2:

Indivíduo 1: $x_{1} x_{2} x_{3} x_{4} x_{5} x_{6}$

Indivíduo 2: $\begin{array}{llllll}x_{1} & x_{2} & x_{5} & x_{4} & x_{3} & x_{6}\end{array}$

Um exemplo simples do uso de algoritmos genéticos em aprendizado é o seguinte [Kocabas 91].

Considere um conjunto ordenado de propriedades e um conjunto aberto de objetos, onde cada objeto possui um subconjunto destas propriedades, tal que cada objeto pode ser caracterizado por este subconjunto. Operadores genéticos, tais como mutação e cruzamento, podem ser aplicados para gerar conceitos novos e úteis, começando com um objeto já existente. Para ilustrar, considere que existem objetos $B, C$ e $D$ e um conjunto ordenado de propriedades $p, q, r, s, t$ e $u$ tal que os objetos $B, C$ e $D$ têm as seguintes propriedades:
$B:(q s)$
$C:(q r t)$
$D:(q s t)$

Os mesmos objetos podem agora ser redefinidos de um modo equivalente como 

$B: 010100$
$C: 011010$
$D: 010110$

onde os valores 1's nas cadeias de comprimento fixo que representam cada objeto, indicam que o objeto tem a propriedade correspondente ao conjunto ordenado das propriedades $(p, q, r, s, t, u)$.

$O$ operador de mutação pode ser aplicado a $B$ para obter $\begin{array}{llllllll}0 & 1 & 1 & 1 & 0 & 0 & \text { fa- }\end{array}$ zendo a mutação na terceira posição da descrição do conceito. Novas observações podem ser realizadas para ver se existem objetos que "casam" com a nova descrição do conceito. Se existem tais objetos, então este será um conceito útil. Deve ser observado que $\begin{array}{llllll}0 & 1 & 1 & 1 & 0 & 0\end{array}$ é também uma especialização de $\begin{array}{lllllll}0 & 1 & 0 & 1 & 0 & 0 & 0\end{array}$. Mutações podem também produzir generalizações de conceitos pela simples troca de 1 por 0 na descrição do conceito.

Similarmente, o operador de cruzamento gera novos conceitos através da combinação de algumas propriedades de dois objetos. Por exemplo, o cruzamento entre $B$ e $C$, poderá produzir $D$, o qual herda as propriedades $q$ de ambos os objetos, $r$ e $s$ do objeto $B$ e $t$ do objeto $C$. Os novos conceitos podem ser usados na classificação de objetos dentro de uma hierarquia baseada na generalização das descrições do conceitos e do tipo de propriedades que os objetos possuem.

De Jong [De Jong 88] explica o uso de algoritmos genéticos em sistemas de aprendizado.

Algoritmo genético é uma técnica utilizada para solucionar problemas de otimização e de aprendizado de máquina, utilizando simulações e regras probabilísticas (e não determinísticas). 0 sistema trabalha na forma de tentativa e erro com alguma forma de retroalimentação do erro, onde consequentemente "aprende" soluções melhores para os problemas. $O$ algoritmo nem sempre encontra uma solução correta, mas procura adquirir novos conhecimentos e chegar o mais próximo possível da solução.

\subsection{Considerações Finais}

Este Capítulo apresentou uma introdução geral sobre a área de pesquisa em Aprendizado de Máquina no contexto de IA, mostrando que esta área de pesquisa teve início com a exploração de trabalhos relacionados ao aprendizado biológico dos seres humanos. Em geral, a pesquisa em AM utiliza métodos computacionais para adquirir conhecimento que possa ser utilizado em Sistemas Baseados em Conhecimento, Sistemas de 
Planejamento, Sistemas Tutores Inteligentes, Sistemas Sensoriais (visão, locomoção), Descoberta de Conhecimento em grandes Bases de Dados, etc.

AM foi dividida em diversas linhas de pesquisas, entre elas Aprendizado Simbólico que é o tema do próximo Capítulo. 


\section{Capítulo 2}

\section{Aprendizado Simbólico}

A abordagem simbólica está baseada na hipótese do sistema de símbolos físicos, definida por Newell e Simon [Newell 76] da seguinte forma:

O sistema de simbolos físicos consiste em um conjunto de entidades, denominadas símbolos, que são padrões físicos que podem ocorrer como componentes de outro tipo de entidade denominada expressão (ou estrutura simbólica). Assim, uma estrutura simbólica é composta de diversas instâncias (tokens) de simbolos relacionados de alguma forma física. Em qualquer instante, o sistema conterá uma coleção dessas estruturas simbólicas. Além dessas estruturas, o sistema também contém uma coleção de processos que operam sobre expressões para produzir outras expressóes: processos de criação, modificação, reprodução e destruição. O sistema de símbolos físicos é uma máquina que produz através do tempo uma coleção evolutiva de estruturas simbólicas. Tal sistema existe em um mundo de objetos mais amplos do que as próprias expressões simbólicas.

Eles então declaram a hipótese como:

Hipótese do Sistema de Símbolos Físicos: um sistema de símbolos físicos possui os meios necessários e suficientes para ação inteligente.

Deve ser ressaltado que esta hipótese é apenas uma hipótese. Até os dias de hoje não parece haver meios de provar (ou contestar) essa hipótese através de uma prova lógica formal. Portanto, ela está sujeita apenas a uma validação empírica.

0 acúmulo de representações simbólicas é o modelo para o aprendizado dentro do paradigma simbólico de IA. Quando um sistema aprende alguma coisa, é porque este acrescentou algum tipo de informação ao seu conhecimento. Esta é uma característica do aprendizado dentro do paradigma simbólico. A nova informação é representada 
simbolicamente. Assim, o aprendizado é basicamente um processo de construção de estruturas simbólicas que o sistema suporta [Partridge 91].

Em outras palavras, aprendizado simbólico é uma técnica que explora representações de estruturas gráficas ou lógicas, no lugar de métodos estatísticos ou numéricos. Estes sistemas aprendem descrições simbólicas que representam um conhecimento de alto nível, fazendo fortes suposições estruturais sobre os conceitos a serem adquiridos.

Neste paradigma de AM, a ênfase está em descobrir princípios gerais de aprendizado, independente do domínio de aplicação.

O restante deste Capítulo abordará alguns conceitos relacionados ao aprendizado simbólico.

\subsection{Aprendizado Indutivo e Dedutivo}

Dedução é definida como inferência logicamente correta, isto é, a conclusão obtida de várias premissas iniciais verdadeiras sempre preserva a verdade. A inferência atua somente nas informações contidas no conhecimento, nada além disso [Raggett 92]. Um exemplo de sistema que utiliza dedução são Sistemas de Aprendizado Baseado em Explicação - seção 1.4.4, página 11.

Indução é a forma de inferência lógica que permite que conclusões gerais sejam obtidas de exemplos particulares. É caracterizado como o raciocínio que parte do específico para o geral, do particular para o universal, da parte para o todo. Hipóteses geradas pela inferência indutiva podem ou não preservar a verdade.

As inferências feitas pelos métodos de indução e dedução relacionadas com aprendizado necessitam, em sua base, de um conhecimento de fundo. $\mathrm{O}$ conhecimento de fundo contém conceitos gerais e específicos do domínio para interpretar as premissas na realização da tarefa de inferência. Isto inclui conceitos aprendidos anteriormente, restrições do domínio, hipóteses candidatas, metas a serem inferidas, métodos para avaliar as hipóteses candidatas, etc.

A relação entre os métodos de indução e dedução é mostrada na Figura 2.1 [Michalski 87].

O conhecimento utilizado por estes métodos é representado como argumentos. Um argumento é uma coleção de enunciados que estão relacionados uns com os outros. Um destes enunciados é a conclusão e os demais são chamados de premissas ou axiomas [Salmon 81].

Considere o seguinte exemplo de argumento lógico dedutivo:

Todo cachorro é amigo do homem

Rex é um cachorro 


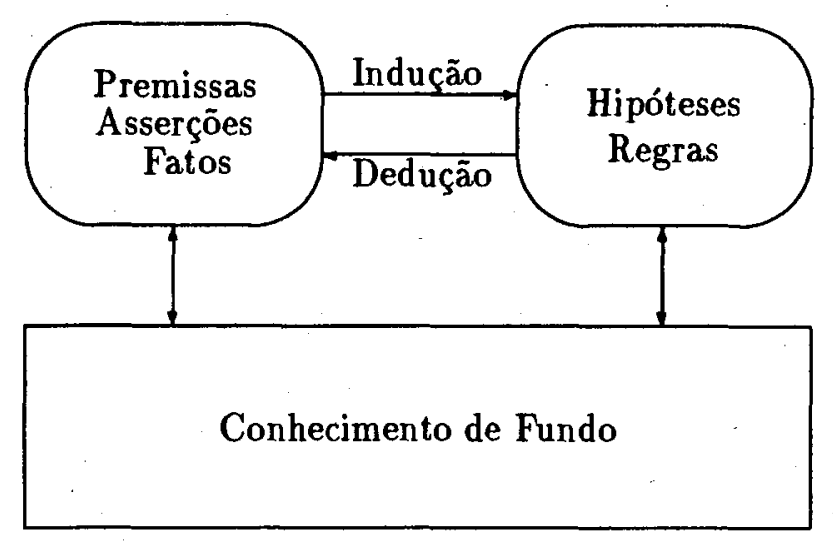

Figura 2.1: Relação entre Dedução e Indução

Rex é amigo do homem

Neste caso, o argumento é formado por três enunciados. Os dois primeiros enunciados são as premissas e o terceiro é a conclusão.

A seguir, são mostrados exemplos de argumento dedutivo e indutivo, onde as premissas aparecem primeiro e a conclusão é identificada com o símbolo $\rightarrow$.

Argumento dedutivo:

Todos os quadrúpedes têm cabeças

Todos os cavalos são quadrúpedes

$\rightarrow$ Todos os cavalos têm cabeça

Argumento indutivo:

Todos os cavalos que foram observados tinham cabeça

$\rightarrow$ Todos os cavalos têm cabeça

Argumentos dedutivos e argumentos indutivos atendem à finalidades diversas. $\mathrm{O}$ argumento dedutivo destina-se a deixar explícito o conteúdo das premissas, enquanto que o argumen to indutivo destina-se a ampliar o alcance de nossos conhecimentos. A relação que há entre a generalização científica e a observação de evidências é do tipo indutivo.

A validade de um argumento dedutivo depende, exclusivamente, da relação que se estabelece entre as premissas e a conclusão. Dizer que um argumento dedutivo é válido, significa dizer que as premissas estão de tal modo relacionadas com a conclusão que quando as premissas são verdadeiras a conclusão também o será. Validade é uma propriedade dos argumentos - que são uma coleção de enunciados - e não uma 
propriedade dos enunciados isoladamente considerados. Verdade, por outro lado, é uma propriedade de enunciados isolados, não de argumentos.

A Tabela 2.1 mostra um resumo das características básicas que distinguem os argumentos dedutivos dos indutivos [Castineira 90]:

\begin{tabular}{|l|l|}
\hline \hline \multicolumn{1}{|c|}{ Argumentos. Dedutivos } & \multicolumn{1}{c|}{ Argumentos Indutivos } \\
\hline \hline $\begin{array}{l}\text { Se todas as premissas são verdadeiras } \\
\text { a conclusão é verdadeira }\end{array}$ & $\begin{array}{l}\text { Se todas as premissas são verdadeiras, } \\
\text { a conclusão é provavelmente verdadei- } \\
\text { ra - mas não necessariamente verda- } \\
\text { deira - com exceção dos argumentos } \\
\text { matemáticos indutivos. }\end{array}$ \\
$\begin{array}{l}\text { Toda a informação do conteúdo factual } \\
\text { da conclusão já está, pelo menos impli- } \\
\text { citamente, nas premissas. }\end{array}$ & $\begin{array}{l}\text { A conclusão contém informação que ex- } \\
\text { cede a das premissas. }\end{array}$ \\
\hline
\end{tabular}

Tabela 2.1: Argumentos Dedutivos versus Indutivos

\subsection{Aprendizado Indutivo por Exemplos}

A inferência indutiva e a estrutura básica para guiar a busca em aprendizado indutivo é descrito em [Shaw 90] da seguinte forma:

... inferência indutiva é um processo de solução de problemas que obtém soluções - descrições do conceito indutivo - através de busca e de uma sequência de transformações. Generalização e especialização são passos essenciais quando se faz inferência indutiva. Se a descrição do conceito $Q$ é mais geral que a descrição do conceito $P$, a transformação de $P$ para $Q \dot{e}$ chamada generalização, e a transformação de $Q$ para $P$ é chamada especialização. $P$ é dito ser mais geral que $Q$ se (e apenas se) $P$ cobre mais instâncias que $Q$. Inferência indutiva pode ser vista como um processo que faz iterações sucessivas de generalização e especialização nas descrições do conceito, e é consistente com todos os exemplos. Então, relações generalização/especialização entre descrições de conceito fornecem a estrutura básica para guiar a busca em aprendizado indutivo.

Aprendizado Indutivo é o processo de inferência indutiva através de fatos fornecidos por 
um professor ou ambiente. Um tipo especial de aprendizado indutivo é o aprendizado de conceitos através de exemplos, cuja tarefa é induzir descrições gerais de conceitos através de instâncias específicas destes conceitos [Michalski 83a].

O problema de aprendizado de conceitos através de exemplos pode ser formalizado do seguinte modo [Bratko 89]:

Seja $U$ o conjunto universal dos objetos, isto é, todos os objetos que o aprendiz pode encontrar. Não existe limite, a princípio, no tamanho de $U$. Um conceito $C$ pode ser formalizado como um subconjunto de objetos em $U$ :

$$
C \subset U
$$

Aprender um conceito $C$ significa aprender a reconhecer objetos em $C$. Ou seja, uma vez que o conceito $C$ é aprendido, para qualquer objeto $X$ em $U$, o sistema é capaz de reconhecer se $X$ está em $C$.

\subsubsection{Linguagem de Descrição}

Qualquer que seja o tipo de aprendizado, é necessário uma linguagem para descrever objetos (ou possíveis eventos) e uma linguagem para descrever conceitos...Em geral, é possível distinguir dois tipos de descrições:

1. descrições estruturais

2. descrições de atributos

Em uma descrição estrutural, um objeto é descrito em termos de seus componentes e a relação entre eles. Por exemplo, a descrição estrutural de um arco pode ser: um arco consiste de três componentes - dois postes e um lintel ${ }^{1}$ - tal que, cada um deles é um bloco; os dois postes suportam o lintel; os postes estão na vertical, são paralelos, não se tocam e o lintel está na horizontal.

Em uma descrição de atributos, um objeto é descrito em termos de suas características globais como um vetor de valores de atributos. Uma descrição de atributos de um arco pode ser: seu tamanho é $8 \mathrm{~cm}$, sua altura é $5 \mathrm{~cm}$ e sua cor é amarelo.

Alguns formalismos frequentemente usados em AM para descrever objetos e conceitos são:

- vetores de atributos para representar objetos

\footnotetext{
${ }^{1}$ Palavra usada em Arquitetura que denomina a parte superior de um arco; vergo.
} 
- regras if-then para representar conceitos

- árvores de decisão para representar conceitos

- redes semânticas

- lógica de predicados

Linguagens específicas para descrever objetos e conceitos que podem ser usadas em programas de aprendizado são semelhantes àquelas que podem ser usadas para representação de conhecimento em geral.

\subsubsection{O Problema do Aprendizado por Exemplos}

Aprender um conceito pode ser visto como um processo de busca. Para cada classe de objetos, o aprendiz "navega" através de um espaço de descrições de conceitos até encontrar um conceito apropriado [Mitchell 82]. No caso de aprendizado por exemplos, a meta é encontrar a descrição de um conceito e a fonte de informação para o aprendizado consiste de exemplos.

Um exemplo para aprender um conceito $C$ é um par

$$
\text { (objeto, classe) }
$$

onde objeto é uma descrição do objeto e classe é "+" ou "-". Tal que:

$$
\begin{aligned}
& \text { Se o objeto pertence a } C \\
& \text { então classe = "十" } \\
& \text { caso contrário, classe = "-" }
\end{aligned}
$$

É dito que o exemplo é positivo ou negativo. O problema de aprendizado de um conceito $C$ através de exemplos pode ser formulado do seguinte modo [Bratko 89]:

Dado um conjunto $S$ de exemplos, encontrar uma fórmula $F$ expressa na linguagem de descrição do conceito, tal que:

Para todo objeto $X$ :

1. se $X$ é um exemplo positivo no conjunto de treinamento $S$, então $X$ "casa" com $F$

2. se $X$ é um exemplo negativo em $S$, então $X$ não "casa" com F 
Como resultado do aprendizado, $F$ é a "compreensão do sistema" do conceito $C$ obtido através de exemplos. De acordo com esta definição, $F$ e $C$ concordam em todos os exemplos dos objetos em $S$. Em outras palavras, $F$ é completa (cobre todos os exemplos positivos) e consistente (não cobre nenhum exemplo negativo). Não existe, entretanto, nenhuma garantia que $F$ corresponderá a $C$ em outros objetos também. A principal meta do aprendizado é aprender a classificar objetos não vistos ${ }^{2}$ (aqueles contidos em $U$ mas não contidos em $S$ ) em relação a $C$. Entretanto, um critério importante para o sucesso do aprendizado é a precisão da classificação de $F$ em objetos não vistos.

A construção da fórmula $F$ pode não classificar corretamente alguns objetos em $S$. Isto ocorre quando os dados de aprendizado contêm erros ou outros tipos de incertezas. Estas propriedades dos dados são usualmente denominadas ruído ${ }^{3}$. Ruído é típico de alguns domínios de aplicações como medicina. Desde que os dados de aprendizado não são confiáveis, o "casamento" exato entre a fórmula $F$ e o conceito $C$ no conjunto de aprendizado $S$ não garante a correção e pode, entretanto, ser abandonada em favor de alguma outra vantagem, tal como simplicidade conceitual de $F$.

\subsubsection{Critérios de Sucesso}

Há vários critérios para medir o sucesso de um sistema de aprendizado. Os critérios mais usuais são:

1. precisão da classificação

2. transparência da descrição induzida

3. complexidade computacional.

Precisão da Classificação. É geralmente definida como a percentagem de objetos corretamente classificados pela fórmula aprendida $F$. É possível distinguir dois tipos de precisão da classificação:

- Precisão em objetos não vistos - aqueles que não estão contidos no conjunto de treinamento $S$

- Precisão nos objetos em $S$ - este tipo de precisão é interessante somente se o algoritmo de aprendizado relaxar as condições para $F$ ser completa e consistente.

Transparência da Descrição do Conceito Induzido F. É importante que a descrição gerada seja compreensível por um ser humano para que possa mostrar ao usuário alguma

\footnotetext{
${ }^{2}$ Objetos não utilizados para o aprendizado do conceito.

${ }^{3}$ Noise.
} 
coisa interessante sobre o domínio da' aplicação. Tal descrição pode então ser usada diretamente pelo usuário sem ajuda da máquina, como uma intensificação ao seu próprio conhecimento. Este critério é também muito importante quando descrições induzidas são usadas em um Sistema Especialista cujo comportamento tem que ser transparente, tal como explicar como se chega a uma conclusão.

Complexidade Computacional. Está relacionada com os recursos computacionais necessários (tempo e espaço) para realizar o aprendizado. É possivel distinguir dois tipos de complexidade:

- Complexidade de Geração: recursos necessários para induzir uma descrição do conceito através de exemplos.

- Complexidade de Execução: complexidade em classificar um objeto usando a fórmula induzida.

\subsection{Aprendizado Incremental e Não Incremental}

0 modo como os exemplos de treinamento para o aprendizado de conceitos através de exemplos estão disponíveis para um algoritmo induzir um conceito, poderá ser incremental ou não incremental.

Um algoritmo não incremental necessita que todos os exemplos de treinamento, simultaneamente, estejam disponíveis para que seja induzido um conceito. É vantajoso usar estes algoritmos para problemas de aprendizado onde todos os exemplos estão disponíveis e, provavelmente, não irão ocorrer mudanças. Os sistemạ da família TDIDT, também utilizam esta abordagem, mas já existem alguns sistemas incrementais, como $I D 5$ e $I D 5 R$ - veja seção 3.4, página 43.

Um algoritmo incremental revê a definição do conceito corrente se necessário, em resposta a cada nova instância de treinamento observada. Os exemplos observados são considerados um a um pelo sistema. Isto é, o sistema considera o primeiro exemplo e, de acordo com este exemplo constrói uma determinada hipótese, a seguir considera um segundo exemplo que pode ou não modificar a primeira hipótese, baseando-se em como esta classifica o segundo exemplo. À medida que majs exemplos são apresentados, o sistema continua modificando o conceito.

Por exemplo, o programa ARCH [Winston 75] utiliza processamento incremental para aprender um conceito. Ele aprende descrições estruturais de conceitos no mundo dos blocos (o conceito de um arco) através de exemplos positivos e negativos fornecidos por um "professor". O programa representa exemplos e conceitos na forma de uma rede semântica. A cada passo do aprendizado é mantido uma hipótese corrente do conceito. A hipótese inicial assume as descrições do primeiro exemplo que é, necessariamente, 
positivo. Se o próximo exemplo é positivo e não satisfaz a descrição do conceito corrente, o programa então generaliza a descrição para que inclua este exemplo. Se o próximo exemplo é negativo e satisfaz a descrição corrente, então a descrição é especializada para que exclua o exemplo do conceito. O programa processa todos os exemplos restantes, individualmente, até que o conceito englobe todos os exemplos positivos e nenhum negativo.

Uma das vantagens de usar algoritmo incremental é que o conhecimento pode ser rapidamente atualizado a cada nova observação. É mais eficiente revisar uma hipótese existente do que gerar uma hipótese cada vez que uma nova instância é observada [Utgoff 89].

\subsection{Indução Construtiva}

Uma tentativa de superar a limitação de uma linguagem baseada em atributos é através do uso de Indução Construtiva, um processo que muda o espaço de descrições - algumas vezes os atributos iniciais usados para descrever os exemplos, não são diretamente relevantes para o conceito mas, quando combinados convenientemente geram novos atributos, podendo tornar-se altamente representativos para expressar um conceito.

Indução construtiva pode ser definida como uma forma de indução que gera novos atributos não presentes no conjunto de treinamento inicial. Através da indução construtiva o "vocabulário" das linguagens de descrição aumenta - o que provoca uma mudança das instâncias bem como do espaço de representação de conceitos [Nicoletti 93b].

O processo de construção de novos atributos pode ser automaticamente realizado pelo sistema ou interativamente guiado pelo usuário. Dependendo do domínio do conhecimento, tal construção pode ser uma tarefa difícil pois envolve uma busca através do espaço de todos os possíveis operadores construtivos (usados para combinar atributos antigos para gerar novos atributos).

Indução Construtiva tem sido utilizada em problemas de aprendizado de funções booleanas com uma representação de $\mathrm{FND}^{4}$ usando árvores de decisão como uma linguagem de descrição de conceito [Nicoletti 92,Nicoletti 93b]. Entretanto, devido ao fato de ser altamente dependente do domínio do conhecimento, indução construtiva continua sendo um problema em aberto com poucos resultados práticos.

Ainda que bem sucedidos, métodos de aprendizado baseados em atributo-valor (com ou sem indução construtiva) são limitados pela linguagem usada para descrever exemplos e conceitos bem como pela forma inexpressiva e limitada em que o conhecimento de fundo pode ser usado no processo de aprendizado. Uma linguagem baseada em atributo-valor tem a mesma força expressiva que uma linguagem baseada em lógica

\footnotetext{
"Forma Normal Disjuntiva.
} 
proposicional. Consequentemente, apenas aqueles conceitos expressos na lógica proposicional são candidatos a serem aprendidos por um sistema que usa uma linguagem baseada em atributo-valor. Esta forte restrição não permite representar objetos estruturados nem relações entre objetos ou entre seus componentes - aspectos relevantes das instâncias de treinamento, os quais de algum modo poderiam caracterizar o conceito sendo aprendido, não podem ser representados. Além disso, algumas descrições relacionais, descritas em uma linguagem baseada em atributo-valor podem ser extensas, inexatas e algumas vezes completamente incompreensíveis pelos seres humanos.

Assim, domínios onde descrições relacionais são importantes para o aprendizado de um conceito, não são apropriados para os métodos de aprendizado baseados em atributovalor.

\subsection{Consideraçōes Finais}

Neste Capítulo foram apresentados alguns conceitos utilizados em AM, como indução e dedução. Um outro conceito enfocado foi a incrementalidade de um algoritmo de $\mathrm{AM}$, isto é a forma como este opera na manipulação dos exemplos para construção da árvore de decisão na indução de um conceito; e o aprendizado construtivo como forma de ampliar o espaço de representação da linguagem de representação do conceito aprendido.

Os conceitos apresentados foram abordados dentro do paradigma de aprendizado simbólico, onde as informações são manipuladas através de estruturas gráficas ou lógicas. Dentro do paradigma simbólico, o aprendizado indutivo de conceitos através de exemplos é um dos mais utilizados. Neste tipo de aprendizado os conceitos aprendidos podem ser representados utilizando árvores de decisão como linguagem de descrição quando os exemplos do conceito - conjunto de treinamento - são representados como vetores de atributo-valor.

O próximo Capítulo mostra em majores detalhes o aprendizado de conceitos através da construção de uma árvore de decisão utilizando um conjunto de exemplos. 


\section{Capítulo 3}

\section{Aprendizado de Árvores de Decisão}

Este Capítulo apresenta a estrutura de árvore de decisão como um formalismo utilizado em Aprendizado de Máquina para descrever conceitos quando objetos são descritos pelos seus atributos.

Os valores dos atributos, na abordagem do aprendizado de conceitos através de exemplos, podem ser simbólicos ou numéricos. Um atributo simbólico consiste de um conjunto desordenado de valores, geralmente um conjunto pequeno de valores, como por exemplo o sexo de um paciente. Um atributo numérico consiste de um conjunto ordenado de valores, como a idade de um paciente que pode ser pré-definido entre $0 \mathrm{e}$ 100 .

A declaração do problema em AM pode ser mais geral do que classificar objetos em duas classes - positivo e negativo. Os objetos podem ser classificados de acordo com múltiplas classes, mas cada objeto pertence a uma classe apenas. Por exemplo, para determinar o meio de transporte a ser utilizado para ir ao trabalho, é possível utilizar os atributos simbólicos tempo e temperatura, onde:

$$
\begin{gathered}
\text { tempo }=\{\text { sol, chuva, nublado }\} \\
\text { temperatura }=\{\text { fria, quente, média }\}
\end{gathered}
$$

Os valores assumidos pelas múltiplas classes poderiam ser:

$$
\text { classe }=\{\text { caminhando, bicicleta }, \text { carro, ônibus }\}
$$

A seguir é mostrado um exemplo detalhado de construção de árvore de decisão onde os exemplos são descritos como pares (objeto, classe). 


\section{1 Árvores de Decisão}

Para ilustrar a construção de uma árvore de decisão será considerado o seguinte exemplo [Durkin 91]: Diagnosticar um problema na linha de produção automobilística de uma empresa, onde a maior causa do problema é o motor defeituoso.

Um motor defeituoso é determinado pelos atributos e valores mostrados na Tabela 3.1:

\begin{tabular}{|c|c|}
\hline \hline ATRIBUTO & VALOR \\
\hline Rotação do Motor & $\{$ baixa,normal, alta $\}$ \\
Tempo de Uso & $\{$ pouco,, medio, muito $\}$ \\
Temperatura & $\{$ baixa,normal, alta $\}$ \\
\hline
\end{tabular}

Tabela 3.1: Atributos e Valores para Diagnóstico do Estado de um Motor

A classe identifica o estado do motor, que neste exemplo é classe $=\{$ bom, ruim $\}$. É bom ressaltar que a classe poderia eventualmente ter mais valores, isto é, \{muito bom, bom, defeito menor, ruim\}, etc.

A Tabela 3.2 mostra o conjunto de observações (exemplos de treinamento), ou seja, eventos passados observados que relacionam os valores dos atributos ao estado do motor.

\begin{tabular}{|c|c|c|c|}
\hline \hline Rotação do Motor & Tempo de Uso & Temperat ura & Classe \\
\hline baixo & muito & alta & ruim \\
baixo & muito & normal & ruim \\
normal & pouco & normal & bom \\
normal & muito & alta & ruim \\
alto & muito & alta & ruim \\
alto & pouco & normal & bom \\
normal & pouco & normal & bom \\
baixo & pouco & alta. & ruim \\
baixo & pouco & alta & ruim \\
\hline \hline
\end{tabular}

Tabela 3.2: Conjunto de Observações ou Exemplos

Uma maneira de representar este conjunto de exemplos usando árvore de decisão é mostrada na Figura 3.1.

Para construir a árvore, um atributo é selecionado para ser a sua raiz - neste caso o primeiro atributo selecionado foi Temperatura - e o conjunto de exemplos é dividido de acordo com os valores deste atributo. Este procedimento é recursivamente utilizado nas subárvores. $\mathrm{O}$ critério de parada na construção da árvore é obtido quando cada sub-ramo tem observações que pertencem à mesma classe.

As regras geradas pela árvore de decisão são obtidas percorrendo os ramos em profundi- 


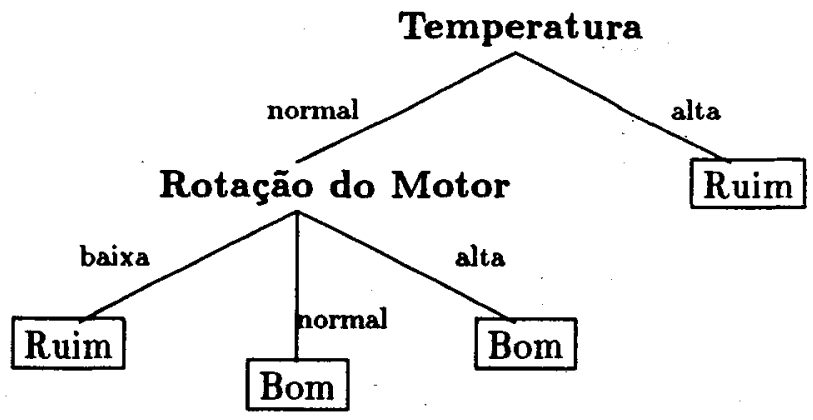

Figura 3.1: Árvore de Decisão para Diagnóstico do Estado do Motor (a)

dade até chegar aos nós folhas. Percorrendo a árvore da Figura 3.1, tem-se as seguintes regras:

$\begin{array}{ll}\text { Se } & \text { temperatura do motor está alta } \\ \text { Então } & \text { motor está ruim } \\ \text { Se } & \text { temperatura do motor está normal } \\ \mathbf{E} & \text { a rotação do motor está baixa } \\ \text { Então } & \text { motor está ruim } \\ \text { Se } & \text { temperatura do motor está normal } \\ \mathbf{E} & \text { a rotação do motor está normal } \\ \text { Ou } & \text { a rotação do motor está alta } \\ \text { Então } & \text { motor está bom }\end{array}$

Pode ser observado que nem todos os atributos são necessários para que a árvore de decisão classifique os exemplos. Estes atributos são chamados irrelevantes. Por exemplo o atributo tempo de uso não foi considerado na construção da árvore da Figura 3.1. Estes atributos irrelevantes demonstram a importância em utilizar uma medida de avaliação para determinar qual a hierarquia da relevância dos atributos. Se a árvore de decisão fosse construída utilizando outro atributo como raiz, o resultado poderá ser uma árvore mais complexa e ramificada do que a da Figura 3.1, gerando regras menos eficientes pois estas terão mais condições e serão mais numerosas. Por exemplo se fosse escolhido o atributo rotação do motor para ser a raiz da árvore. A árvore gerada seria a mostrada na Figura 3.2.

A seguir é apresentado uma família de algoritmos de AM que utiliza árvores de decisão para representar conceitos. 


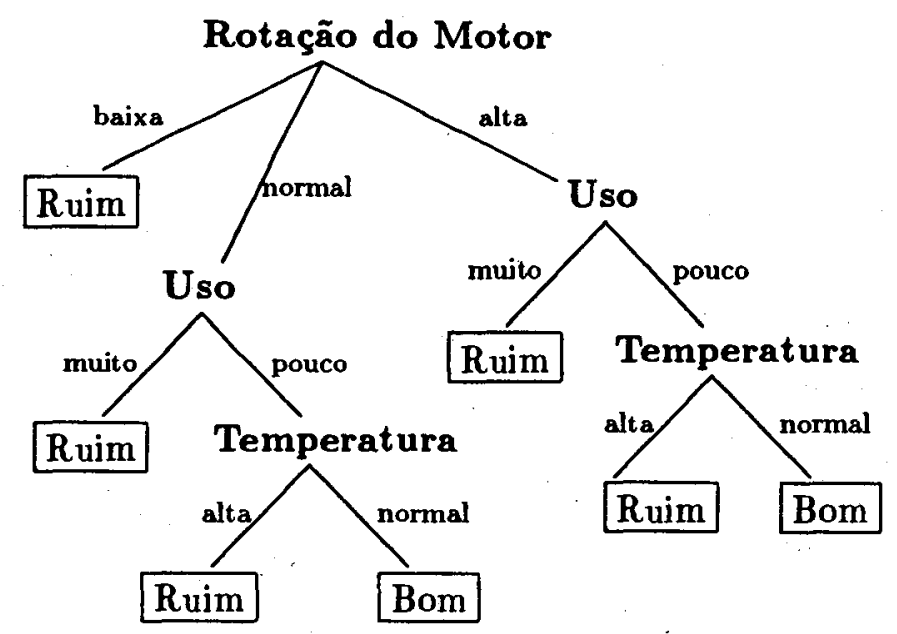

Figura 3.2: Árvore de Decisão para Diagnóstico do Estada do Motor (b)

\subsection{Família TDIDT}

Top Down Induction of Decision Tree - TDIDT - é uma familia de sistemas de aprendizado que são caracterizados por representar o conhecimento adquirido através de árvores de decisão.

Esta forma de representação, relativamente simples, não tem o poder expressivo de redes semânticas ou outras representações de primeira ordem. Como consequência da simplicidade de representação do conhecimento utilizada, estes algoritmos são significativamente menos complexos que aqueles utilizados em outros sistemas que fazem uso de uma linguagem mais poderosa para expressar seus conhecimentos. Entretanto, é possível gerar conhecimento na forma de árvores de decisão, capaz de resolver problemas difíceis [Castineira 90].

Os sistemas desta família não são limitados a uma área de aplicação específica, tal como química, xadrez ou medicina. Isto é, são sistemas de propósito geral. O objetivo de todos eles é classificar objetos. Eles produzem regras ou descrições de um determinado número de classes de objetos. Quando novos objetos são observados, estas regras devem predizer a que classe estes objetos pertencem. Por exemplo, algumas tarefas de classificação são:

- diagnosticar um problema de saúde a partir dos sintomas do paciente. Neste caso, as classes são as diversas doenças ou as possiveis terapias;

- decidir, a partir de observações climáticas e condições dos solos, se uma determinada região geográfica é apta para um dado plantio ou não. Aqui as classes poderiam ser: apta, näo apta; 
- decidir, segundo diversas condições particulares e do mercado financeiro, qual o melhor investimento a realizar. Neste caso as classes poderiam ser: ouro, dólar, over, poupança.

Resumindo, estes sistemas desenvolvem árvores de decisão para tarefas de classificação. Estas árvores são construídas começando da raiz e descendo até as folhas (top-down). 0 próprio nome desta família de sistemas enfatiza estas características: Top Down Induction of Decision Trees (TDIDT).

Os objetos-exemplo, a partir dos quais são geradas as regras de classificação, são conhecidos somente através dos valores de um conjunto de atributos. Por sua vez, as árvores de decisão são construídas usando os mesmos atributos.

Os exemplos podem ter duas origens diferentes:

- podem vir de uma base de dados existente, por exemplo, de uma que contenha um histórico de observações clínicas de pacientes. Objetos identificados em exemplos deste tipo dão um quadro estatístico confiável; entretanto, podem ser redundantes ou omissos com relação a casos raros que não tenham sido encontrados durante o período de registro das observações.

- podem ser um conjunto tutorial cuidadosamente escolhido e preparado por um especialista, onde cada exemplo diz respeito a uma regra de classificação completa e correta. Neste caso, o especialista deve tomar o cuidado de evitar casos redundantes e se lembrar de incluir exemplos de casos raros.

Os sistemas aqui descritos trabalham satisfatoriamente com exemplos provenientes de qualquer uma destas duas origens.

\subsection{Algoritmo Geral da Família TDIDT}

O algoritmo geral destes sistemas começa com uma árvore de decisão vazia que é refinada gradualmente até que classifique corretamente todos os exemplos da amostra. 0 procedimento geral é o seguinte:

Dado um conjunto de exemplos de aprendizado $E$;

uma condição de parada $t(E)$; e

uma função de avaliação aval $(E$, atributo $)$

Se todas as instâncias em $E$ satisfazem a condição de término $t(E)$

então retorne o valor da classe 


\section{caso contrário}

1. para cada atributo $a_{i}$ determine o valor da função aval $\left(E, a_{i}\right)$. Seja $a_{j}$ o atributo que possui o melhor valor ${ }^{1}$ de $\operatorname{aval}\left(E, a_{i}\right)$.

2. se $a_{j}$ possui valores $a_{j_{1}}, a_{j_{2}}, \ldots a_{j_{k}}$ crie o seguinte nó da árvore:

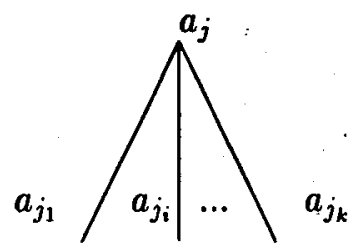

3. Particione os exemplos do conjunto $E$ nos subconjuntos $E_{1}, E_{2}, \ldots E_{k}$ segundo os valores de $a_{j}$ na árvore de decisão.

4. Aplique o algoritmo recursivamente para cada um dos subconjuntos $E_{i}$.

$O$ critério de parada $t$ pode ser definido tanto para construir a árvore de decisão, que classifica exatamente todos os elementos do conjunto de aprendizado em domínios completos, quanto para decidir pela não expansão da árvore quando a evidência for insuficiente nos exemplos fornecidos, este mecanismo é denominado pré-poda da árvore de decisão. A função de avaliação aval pode ser definida de várias formas diferentes.

As diversas condições de parada e funções de avaliação dão origem a vários algoritmos desta família. Por exemplo, o sistema ID3 [Quinlan 79] utiliza a "entropia" como função de avaliação dos atributos e seu critério de parada é que todos os exemplos no nó pertençam à mesma classe. Embora esta abordagem dê bons resultados neste sistema, nada garante que esses sejam os melhores resultados. Outro critério ou função de avaliação poderia ser utilizado.

Entre as diversas funções de avaliação podem ser citadas [Mingers 89]:

- Entropia ou Quinlan Information Measure (IM) [Quinlan 79,Quinlan 83],

- Medida da Razão do Ganho ou Gain-Ratio Measure (GR): medida proposta por Quinlan [Quinlan 86a] como uma correção do $I M$,

- Estatística Qui-Quadrado $\left(\chi^{2}\right)$ : função baseada na estatística do Qui-Quadrado, proposta por Hart [Hart 85] e Mingers [Mingers 87],

- A estatística $G(G)$ : medida proposta por Mingers [Mingers 87]

- Índice de Diversificação GINI (GINI): medida proposta por Breiman et al., similar a $I M$ [Breiman 84].

\footnotetext{
${ }^{1}$ Atributo mais relevante para realizar a ramificação, segundo a função de avaliação.
} 


\subsection{Alguns Sistemas da Família TDIDT}

A Figura 3.3 mostra alguns dos sistemas mais importantes que fazem parte da família TDIDT, junto com o ano de sua divulgação. Na figura são mostrados somente os sucessores diretos do $C L S$, que foi um dos primeiros sistemas desta família. Outros sistemas - como por exemplo o $C N 2$ [Clark 87] - que foram influenciados pela familia TDIDT [Gams 87], não são mostrados no desenho.

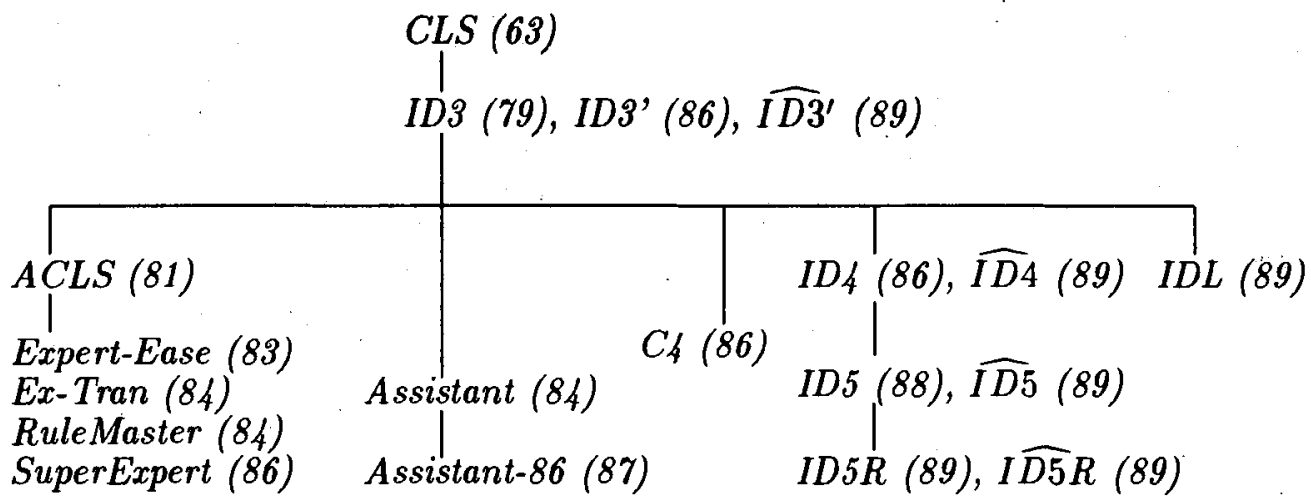

Figura 3.3: A Família TDIDT

$C L S$ (Concept Learning System) [Hunt 66], constrói uma árvore de decisão que tenta minimizar o custo de classificar um objeto. Este custo tem componentes de dois tipos: o custo de determinar o valor de um dado atributo do objeto e o custo de classificar erroneamente o objeto. Em cada estágio, $C L S$ explora o espaço de possíveis árvores de decisão de uma determinada altura, escolhe uma estratégia para minimizar o custo neste espaço limitado e, a seguir, desce um nível na árvore. Dependendo da altura escolhida para explorar, $C L S$ requer uma grande quantidade de cálculo.

$I D 3, I D 3^{\prime}$ [Quinlan 79,Quinlan 83] foi desenvolvido a partir do sistema CLS, tentando melhorar algumas de suas características. Este é um dos sistemas mais conhecidos da família TDIDT. ID3 constrói a árvore de decisão numa forma não incremental e iterativa que discrimina exemplos de um determinado conceito. Cada objeto é descrito por um conjunto de atributos e seus respectivos valores. Uma medida ${ }^{2}$ é aplicada a cada um dos atributos de maneira a determinar como cada um deles discrimina entre exemplos positivos e negativos do conceito. 0 atributo mais informativo é então usado como raiz para formar a árvore de decisão, e os exemplos são divididos de acordo com os valores deste atributo. 0 processo é aplicado recursivamente a cada um dos grupos, construindo as subárvores. $\mathbf{O}$ processo continua até que os exemplos em uma subárvore pertençam todos a mesma classe.

\footnotetext{
${ }^{2}$ ID3 utiliza a Entropia.
} 
Existe a possibilidade de tornar o ID3 incremental usando força bruta. Essa abordagem foi sugerida por Schlimmer e Fisher [Schlimmer 86] e é conhecida como $I D 3^{\prime}$. A sugestão é a de executar o ID3 cada vez que uma nova instância for observada. Esse procedimento, entretanto, é tremendamente ineficiente.

$A C L S$ (Analog Concept Learning System) [Patterson 83] é uma generalização de $I D 3$. Tanto em ID3 como em $C L S$, todos os atributos utilizados para descrever objetos podem assumir um número finito de valores pertencentes a um conjunto predeterminado. Por exemplo, o atributo cor pode assumir os valores $\{$ preto, branco,...verde $\}$ e nenhum outro que não tenha sido estabelecido previamente. Já o sistema $A C L S$ permite que os atributos utilizados também possam assumir qualquer valor numérico inteiro. Esta característica tem permitido que $A C L S$ seja aplicado em tarefas difíceis, tais como reconhecimento de imagens.

Os quatro sistemas na Figura 3.3 que estão abaixo do $A C L S$ são produtos comerciais, produzidos por Intelligent Terminals, descendentes diretos deste último sistema. Embora esses sistemas não apresentem inovações nas estratégias utilizadas, eles incorporaram interfaces amigáveis e alguns outros utilitários para facilitar a tarefa de construir regras a partir de exemplos. Expert-Ease, por exemplo, depois de gerar as regras relativas às observações correspondentes, cria automaticamente um sistema de consulta um Sistema Especialista que pode diagnosticar, baseando-se nas regras que aprendeu [Ford 87]. Todos estes sistemas foram bem sucedidos comercialmente [Mowforth 86].

Assistant [Kononenko 84] também é um descendente de ID3. Este sistema permite atributos com valores discretos e contínuos - atributos contínuos são representados por intervalos de reais -, bem como permite que as classes formem uma hierarquia; as classes não precisam ser necessariamente disjuntas, uma classe pode ser uma subdivisão de outra. Assistant não forma a árvore de decisão iterativamente como ID3; ele possui um algoritmo para escolher um "bom" conjunto amostra entre os exemplos disponíveis.

Assistant - 86 [Cestnik 87] é uma implementação de Assistant para microcomputador tipo IBM-PC, rodando com o sistema operacional DOS. Todas as características do sistema Assistant estão também presentes em Assistant - 86, porém, com algumas ligeiras modificações. Desta forma, Assistant - 86 manuseia atributos com valores contínuos, dados incompletos e com ruído e domínios incompletos, isto é, domínios onde os atributos não são suficientes para a tarefa de classificação.

C4 [Quinlan 86c] utiliza basicamente o mesmo procedimento de ID3, mas tem incorporadas melhorias que tratam com atributos com valores discretos ou contínuos, valores desconhecidos de atributos e dados com ruído. Para tratar dados com ruído, C4 utiliza um critério de parada, e realiza também uma poda na árvore [Breiman 84, Kononenko 84,Quinlan 86b]. O sistema gera várias árvores podadas, escolhendo no final a árvore mais promissora. $C 4$ está implementado na linguagem $\mathrm{C}$ para ambiente Unix.

ID4 [Schlimmer 86] foi uma primeira tentativa de tornar o algoritmo ID3 incremental. Neste sistema a árvore de decisão vai se adequando às instâncias de treinamento, à me- 
dida que estas vão se tornando disponíveis. ID4 elimina toda ou parte da árvore sempre que, durante sua construção, um atributo de teste for substituído por um atributo considerado mais informativo. Isto é, se a ordem relativa dos possíveis atributos de teste num nó for alterada durante a construção da árvore, ID4 elimina todas as subárvores penduradas naquele nó. Esta eliminação faz com que muito do esforço investido na construção da árvores seja perdido.

$I D 5$ [Utgoff 88] e ID5R [Utgoff 89] são algoritmos incrementais que constrõem a mesma árvore de decisão que o ID3. O ID5 difere do ID4 na maneira como substitui o atributo no nó. Ao invés de eliminar as subárvores penduradas no nó a ser substituído, o ID5 reestrutura a árvore empurrando o novo atributo de teste para cima. 0 processo de reestruturação - pull-up - é um rearranjo da árvore que preserva a consistência com as instâncias de treinamento até então observadas, e que coloca o atributo evidenciado como nó raiz da árvore ou subárvore. Entretanto, ID5 atualiza sua árvore apenas quando novos exemplos são classificados.

$I D 5 R$ é uma simples modificação do $I D 5$, que diferencia na forma de atualização da árvore. $I D 5 R$ recursivamente atualiza a subárvore resultante depois de cada operação de pull-up. Consequentemente, a árvore de decisão gerada pelo ID $R$ é, em cada passo, exatamente a mesma como se fosse a árvore de decisão final.

$\widehat{I D 3^{\prime}}, \widehat{I D 4}, \widehat{I D 5}$ e $I \widehat{D 5} R$ [Utgoff 89] são versões dos algoritmos $I D 3, I D 4, I D 5$ e $I D 5 R$. A modificação está na estratégia de treinamento. Esta estratégia de treinamento atualiza a árvore apenas se a árvore existente não classificar a instância de treinamento apresentada.

$I D L$ [Van de Velde 89] é um algoritmo incremental que rapidamente converge para uma árvore ótima se ela existe. Uma árvore ótima é definida em relação à topologia da árvore. IDL utiliza o critério estatístico de divisão como em algoritmos TDIDT clássicos, e um critério topológico para fazer transformações que criará oportunidades de poda na árvore.

\subsection{Poda em Árvores de Decisão}

Como já mencionado, em várias aplicações os dados para o aprendizado estão imperfeitos. Os dados no conjunto de treinamento podem estar apenas parcialmente especificados, isto é, existe a possibilidade de erros nos valores de atributos e nos valores da classe - denominados ruídos. Quando os dados estão com ruídos, o procedimento de aprendizado poderá gerar uma árvore de decisão que apenas parcialmente explica os dados aprendidos, não necessariamente classificando os dados do aprendizado dentro de classes como especificado nos exemplos.

Ruídos nos dados influenciam a tarefa de aprendizado tornando-a mais difícil, necessi- 
tando assim, de mecanismos especiais. No caso de ruídos, usualmente, não existe a necessidade de que as descrições de conceitos aprendidos, "casem" com todos os exemplos positivos e nenhum negativo. A descrição aprendida pode não classificar corretamente alguns dos objetos do aprendizado, devido a possibilidade de erros nos dados. Estes objetos são aqueles que contém erros e isto apenas indica que dados errados são, de fato, ignorados.

Alguns problemas que são encontrados quando é induzida uma árvore de decisão que contém dados com ruídos são:

- a árvore induzida não é confiável em classificar novos objetos

- árvores induzidas serão, provavelmente, maiores e, consequentemente, mais difíceis de serem induzidas.

Por exemplo [Bratko 89]:

Considere a construção de uma subárvore de uma árvore de decisão, onde $S$ é um subconjunto corrente de objetos utilizados no aprendizado. Existe 100 objetos em $S, 99$ pertencentes à classe $C 1$ e um deles à classe $C 2$. Sabendo que existe ruído nos dados de aprendizado e que todos os objetos concordam nos valores dos atributos já selecionados neste ponto da árvore de decisão, é possível que o objeto da classe $C 2$ esteja em $S$ apenas como resultado de um erro nos dados. Desse modo, é melhor ignorar este objeto e, simplesmente, retornar uma folha da árvore de decisão rotulada com a classe $C 1$.

Neste ponto a subárvore está sendo podada. A poda em árvores de decisão é um método importante para o aprendizado de dados com ruídos. Basicamente, existe duas maneiras de se podar uma árvore:

1. Pré-poda

2. Pós-poda

A pré-poda é usada durante a construção da árvore para parar a ramificação de um nó da árvore, quando a classificação correspondente deixa de ser confiável. Isto é, o programa poda a árvore utilizando algum critério que indica quando parar de expandir a árvore.

A pós-poda é utilizada após a construção completa da árvore, quando o erro de classificação de novos exemplos é calculado e, em função desse erro, é decidido podar algumas subárvores que, provavelmente, não são confiáveis.

Em geral, a pós-poda na árvore de decisão produz resultados mais satisfatórios que a pré-poda, uma vez que, com a pós-poda, tanto a precisão quanto a complexidade 
das árvores de decisão tendem a melhorar [Hart 85]. É importante analisar a variação da precisão e complexidade de árvores de decisão após a aplicação do mecanismo de pós-poda.

A poda em árvores de decisão afeta duas medidas de critérios de sucesso.

- a transparência de uma descrição do conceito é importante desde que as regras geradas possam ser usadas pela máquina e compreendidas pelo ser humano. A compreensão de uma descrição depende de sua estrutura e de seu tamanho. Uma árvore estruturada é de mais fácil compreensão do que outra completamente desestruturada. Por sua vez, árvores menores são, também, compreendidas mais facilmente independente de sua estrutura. Desde que o mecanismo de poda reduz o tamanho da árvore, ela contribui com a transparência do conceito apresentado por essa árvore. Resultados experimentais mostram que o número de nós de uma árvore de decisão pode ser reduzido, consideravelmente, pelo mecanismo de poda mantendo sua precisão de classificação.

- poda pode, também, melhorar a precisão de classificação de uma árvore. Apesar de estar "perdendo" informação, é através da poda que erros estão sendo eliminados nos dados de aprendizado devido à ruídos.

\subsection{Mecanismo de Janela}

Uma solução intermediária entre algoritmos não incrementais e incrementais é fornecida pelo mecanismo de janelas. Esta estratégia, ilustrada na Figura 3.4, consiste em:

Um subconjunto do conjunto original de exemplos é escolhido aleatoriamente para compor a janela - constrói-se então uma árvore de decisão utilizando os exemplos da janela. A árvore assim construida é então usada para classificar os exemplos do conjunto de exemplos original que não participaram da janela. Aqueles não classificados são inseridos na janela, e com essa janela ampliada constrói-se uma nova árvore de decisấo. O processo se repete até que a árvore construída utilizando a janela classifique todos os outros exemplos.

Se a janela não ficar muito grande, com certeza a construção da árvore irá requerer significativamente menos memória. A justificativa para o uso de janelas baseia-se na idéia que conjuntos de treinamento muito grandes, via de regra, contém muitos elementos redundantes e que, na realidade, apenas um conjunto bem menor de exemplos seria necessário para o aprendizado do conceito em questão. Se entretanto não for esse o caso, a janela pode se expandir tanto que eventualmente coincide com o próprio conjunto 


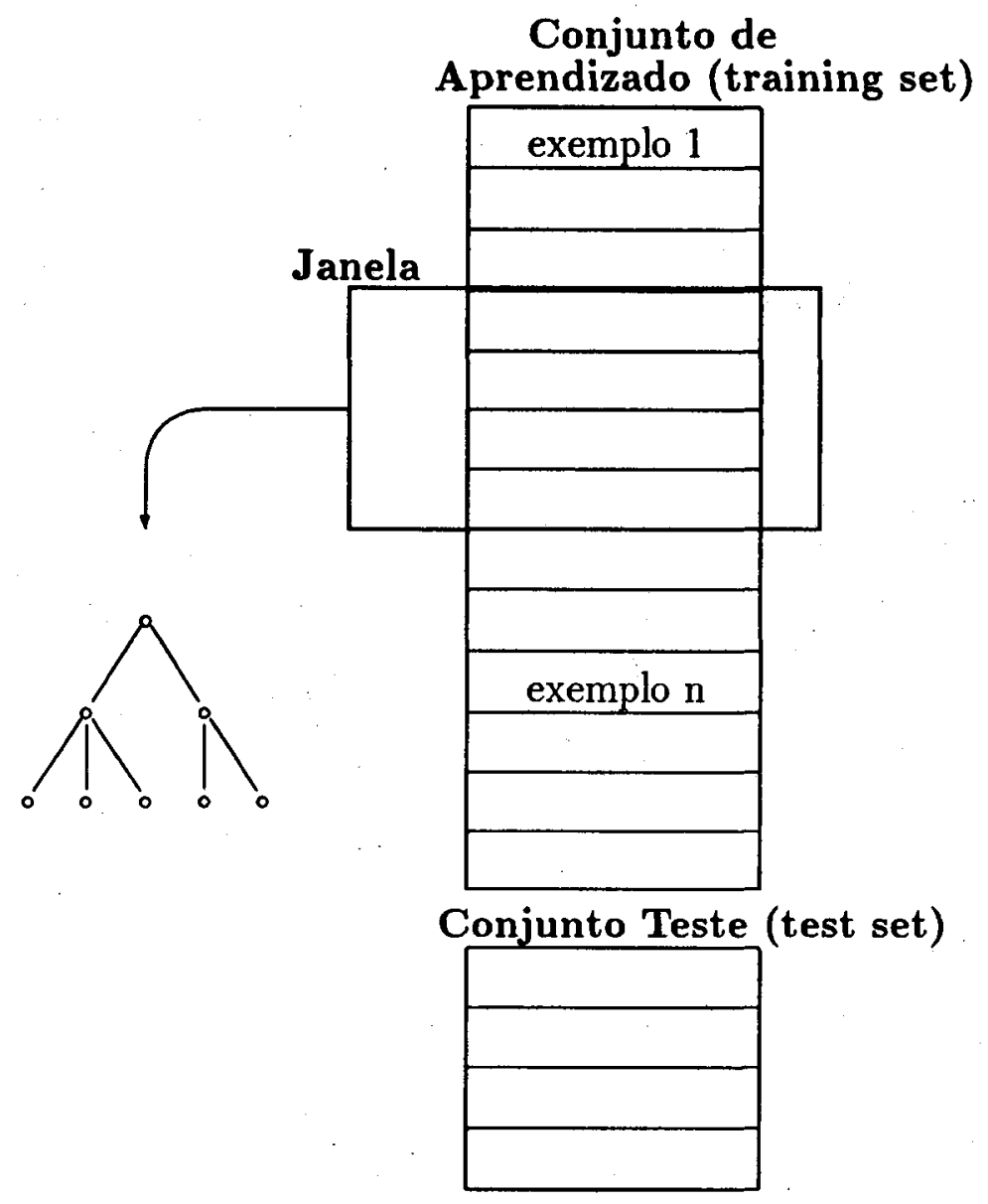

Figura 3.4: Mecanismo de Janela

original de exemplos. Nessa situação, o processo realizará tantas iterações que, com certeza, levará muito mais tempo do que se já tivesse, desde o início, usado o conjunto original.

\subsection{Ambiente Experimental TDIDT}

No ICMSC-USP está sendo desenvolvido um ambiente experimental denominado $A m b i$ ente Experimental TDIDT, ilustrado nas Figuras 3.5 e $3.6^{3}$ [Nicoletti 94], onde um dos objetivos é a geração de regras de conhecimento através de árvores de decisão utilizando

\footnotetext{
${ }^{3} \mathrm{Nas}$ Figuras citadas, os retângulos formados por linhas pontilhadas referem-se aos módulos que contêm entrada e saída de dados, já os retângulos de linhas contínuas são os módulos dos algoritmos e funções implementadas.
} 
a estratégia do aprendizado indutivo por exemplos dos sistemas da família TDIDT. A meta principal do projeto é ter um ambiente onde o software desenvolvido é flexível o suficiente para se adequar facilmente a mudanças de maneira a poder testar idéias e novas abordagens de algoritmos de AM. Dentro deste projeto já foram realizadas diversas implementações na linguagem de programação lógica Prolog.

Primeiramente, foi desenvolvido um procedimento geral não incremental da família TDIDT que constrói a árvore de decisão correspondente a um dado conjunto de exemplos, com qualquer número de atributos, bem como qualquer número de valores de atributos [Castineira 91].

A idéia geral da atuação desse procedimento é a seguinte:

Dada uma lista de exemplos e uma lista de atributos

1. obter o melhor atributo segundo uma função de avaliação - correspondente à aval

2. particionar os exemplos de acordo com os valores desse atributo

3. retirar esse atributo da lista de possíveis atributos

4. recursivamente continuar ramificando cada uma dessas partições.

O critério de parada é ativado quando todos os exemplos na partição pertencem à mesma classe ${ }^{4}$

O procedimento está estruturado de forma a permitir que diversas funções de avaliação aval, sejam implementadas a fim de estudar a eficácia das mesmas.

Para contornar, parcialmente, a não incrementabilidade desse procedimento, foi projetado e implementado o mecanismo de janelas - descrito anteriormente - , que procura evitar o aprendizado a partir de todos os exemplos [Nicoletti 92a].

Com base na estrutura da árvore de decisão gerada por esses procedimentos, foram projetados, implementados e comparados dois métodos de pós-poda: o método de redução do erro e uma variação do mesmo [Castineira 90a,Nicoletti 92b]. Como visto anteriormente, o método de poda de redução do erro tem como princípio buscar um erro de classificação dos nós folhas de uma subárvore qualquer, decidindo podar ou não a subárvore, dependendo do erro de classificação do conjunto de teste. O método de poda de redução do erro e sua variação diferem na ordem de visita às subárvores. 0 primeiro começa a análise das subárvores a partir dos nós terminais, e o segundo a partir dos filhos da raiz.

Também, dentro deste projeto, foram pesquisados e implementados algoritmos de aprendizado indutivo construtivo de máquina. Como já mencionado, os exemplos no

\footnotetext{
${ }^{4}$ No caso de não ser possível classificar exatamente todos os exemplos — isto é exemplos com igual valor de atributo que pertencem a classes diferentes -, a estratégia adotada nessa implementação é a de rotular essa folha com o valor da classe mais provável.
} 


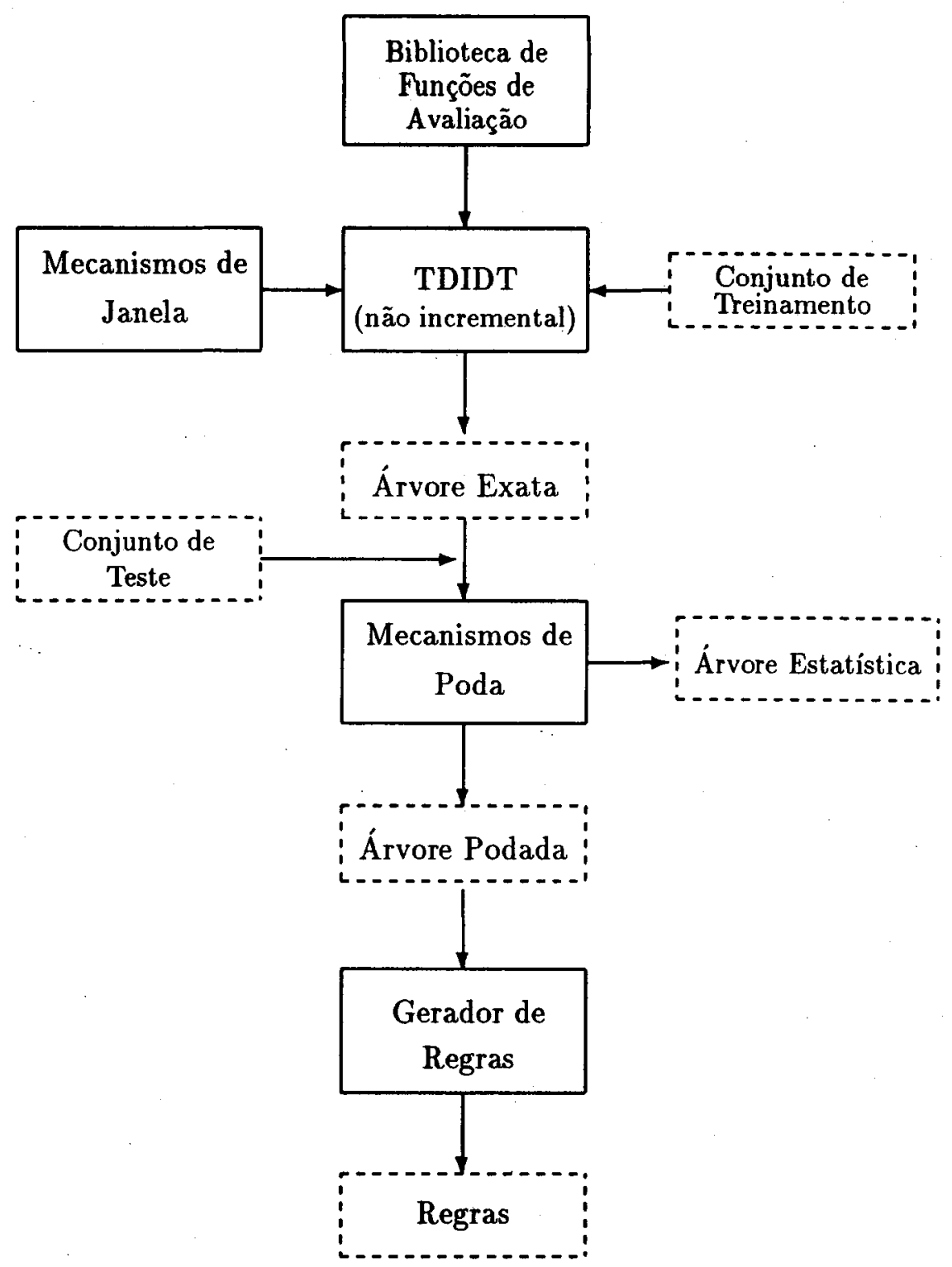

Figura 3.5: Ambiente Experimental TDIDT 


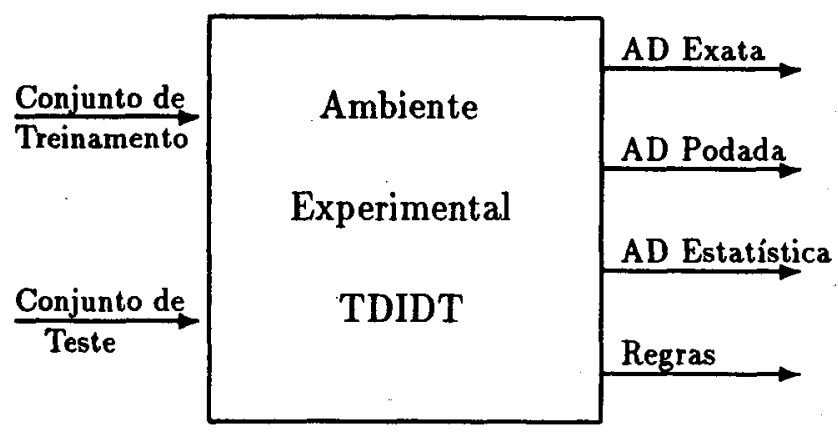

Figura 3.6: Visão Geral do Ambiente Experimental TDIDT

conjunto de treinamento são muitas vezes descritos em termos de atributos iniciais não diretamente relevantes ao conceito, mas que quando convenientemente compostos formando novos atributos - chamados features - passam a ser diretamente relevantes. $\mathrm{O}$ processo de construção de features pode ser direcionado e controlado pelo usuário ou automaticamente conduzido pelo sistema.

Trabalhos referentes ao processo de construção automáticà de features utilizando o domínio de funções booleanas, que investiga o desempenho de diversos biases ${ }^{5}$, podem ser encontrados em [Nicoletti 92,Nicoletti 92b,Nicoletti 93b,Nicoletti 93b].

Neste ambiente, os procedimentos - algoritmos de construção da árvore, mecanismo de janela e poda - responsáveis pelo critério de avaliação dos atributos e do critério de parada podem ser redefinidos facilmente para algoritmos particulares. Os algoritmos implementados utilizam uma mesma estrutura de dados. A estrutura de dados é formada por listas e árvores, e é uma estrutura bem geral, mas muito complexa, que permite representar qualquer árvore de decisão.

Entretanto, no caso de construção automática de features, onde as informações que se tem sobre os atributos é que eles estão presente ou ausente, por exemplo, já se sabe que essa árvore é uma árvore binária. Neste caso, utilizando uma estrutura de dados específica para este problema, as implementações correspondentes à construção da árvore, construção de features utilizando diferentes algoritmos e posteriormente a poda da árvore, podem ser bastante simplificadas, permitindo assim uma maior facilidade para pesquisar e implementar, no futuro, outros algoritmos e operadores construtivos. Isto motivou o desenvolvimento de um ambiente semelhante ao mostrado na Figura 3.5, que trata apenas com atributos booleanos. Este ambiente, denominado Ambiente Experimental TDIDT para Atributos Booleanos, contém algoritmos de construção e poda de árvores de decisão binárias. 0 Ambiente Experimental TDIDT para Atributos Booleanos é descrito no Capítulo 4. Com base nos algoritmos deste ambiente, desenvolveu-se o Ambiente Experimental Construtivo para Atributos Booleanos descrito em detalhes no Capítulo 5. As implementações realizadas em ambos os ambientes foram desenvolvidas na linguagem de programação lógica Prolog [Arity 92].

\footnotetext{
${ }^{5}$ Heurísticas.
} 


\subsection{Considerações Finais}

Os sistemas da família TDIDT utilizam árvores de decisão como linguagem de descrição de hipóteses. As árvores de decisão são estruturas relativamente simples que podem expressar problemas complexos. $\mathrm{O}$ algoritmo mais conhecido desta família de sistemas é o ID3. Os outros algoritmos pertencentes à esta família são adaptações e/ou melhoramentos deste algoritmo. Uma das vantagens de utilização de árvores de decisão é a simplicidade de transformar estas em regras de produção.

Este Capítulo mostrou uma visão geral sobre árvores de decisão como formalismo utilizado para representar conceitos quando os exemplos são descritos como pares atributovalor. Os dois próximos Capíitulos apresentam os ambientes experimentais desenvolvidos neste trabalho, que utilizam árvores de decisão para geração de regras de conhecimento. Estes ambientes estão inseridos como módulos participantes a um projeto maior desenvolvido no ICMSC-USP. 


\section{Capítulo 4}

\section{Ambiente Experimental TDIDT para Atributos Booleanos}

Este capítulo apresenta o Ambiente Experimental TDIDT para Atributos Booleanos e discute os três principais algoritmos implementados neste ambiente: o algoritmo que constrói a árvore de decisão no modo não incremental, o algoritmo que constrói a árvore de decisão no modo incremental e o algoritmo que poda a árvore de decisão gerada. Os três algoritmos têm como base os algoritmos ID3, ID5 (da família TDIDT) e o Método de Poda de Redução do Erro, respectivamente. Eles utilizam basicamente uma mesma estrutura de dados e têm como linguagem de descrição de instâncias uma linguagem baseada em um par atributo-valor com uma classe associada, representando um exemplo positivo ou negativo. A linguagem de descrição de conceitos é a árvore de decisão binária gerada a partir dos exemplos.

\subsection{Descrição do Ambiente}

Os exemplos disponiveis e os conceitos devem ser descritos através de uma linguagem denominada linguagem de descrição de instâncias - para representar o conjunto de exemplos - e linguagem de descrição de conceitos - para representar as hipóteses do conceito sendo aprendido.

O Ambiente Experimental TDIDT para Atributos Booleanos utiliza como linguagem de descrição de instâncias, uma linguagem baseada em atributos. Um atributo é uma possível característica relevante do conceito a ser aprendido. Exemplos de treinamento são descritos como vetores de pares atributo-valor e uma classe associada. Em um formalismo baseado em atributos, o conjunto de atributos usado para a descrição dos exemplos é fixo. Cada exemplo pertence a uma, entre várias classes mutuamente ex- 
clusivas. Os atributos são frequentemente discretos (nominal, ordinal ou intervalar) e alguns sistemas exigem, também, informações a respeito dos nomes de atributos e do escopo de seus valores. Num sistema de aprendizado que faz uso de uma linguagem baseada em atributos, a tarefa de aprendizado pode ser descrita como

dado um conjunto de exemplos de treinamento expressos como vetores de pares atributo-valor, cujas classes são conhecidas, encontrar uma regra que prediga a classe de um novo exemplo em função de seus atributos e valores.

Os pares atributo-valor utilizado neste ambiente são atributos específicos. Os atributos pertencentes ao conjunto de treinamento são atributos booleanos e possuem valores no conjunto $\{0,1\}$. Os atributos booleanos são úteis em situações onde a única informação fornecida em relação a um dado atributo é que ele está presente (valor do atributo = 1) ou ausente (valor do atributo $=0$ ) no conjunto de treinamento.

A linguagem de descrição de conceitos usada neste ambiente são árvores de decisão construídas através dos exemplos, utilizando a metodologia da família TDIDT. Como os atributos são booleanos, a árvore de decisão induzida é, sempre, uma árvore binária.

Pode ser observado que, o Ambiente Experimental TDIDT adaptado para atributos booleanos está representado, graficamente, nas Figuras 4.1 e 4.2.

O Ambiente TDIDT para Atributos Booleanos é semelhante ao Ambiente Experimental TDIDT geral. A diferença consiste nos valores dos atributos e no modo como operam. Enquanto que o Ambiente Experimental TDIDT geral manipula atributos com valores indeterminados e no modo não incremental, o Ambiente Experimental TDIDT para Atributos Booleanos manipula atributos específicos no modo incremental e não incremental. Assim, o módulo Mecanismo de Janela é o mesmo do Ambiente Experimental TDIDT geral - Figura $3.4-$, e é utilizado apenas para o algoritmo não incremental.

Mais especificamente, os algoritmos implementados que constituem este ambiente são:

- algoritmo de construção da árvore de decisão binária no modo não incremental [Martins 94a] - pertencente ao módulo Ambiente Binário TDIDT

- algoritmo de construção da árvore de decisão binária no modo incremental [Martins 94b] — pertencente ao módulo Ambiente Binário TDIDT

- algoritmo de poda da árvore de decisão binária [Martins 94a] - pertencente ao módulo Mecanismo de Poda.

Os dois primeiros algoritmos constrõem a árvore de decisão a partir de um conjunto de treinamento. $O$ último algoritmo poda a árvore de decisão gerada pelo conjunto de treinamento, de acordo com um erro de classificação encontrado quando a árvore tenta classificar novos exemplos que não estão presentes no conjunto de treinamento. Estes novos exemplos pertencem a um conjunto denominado conjunto de teste. 


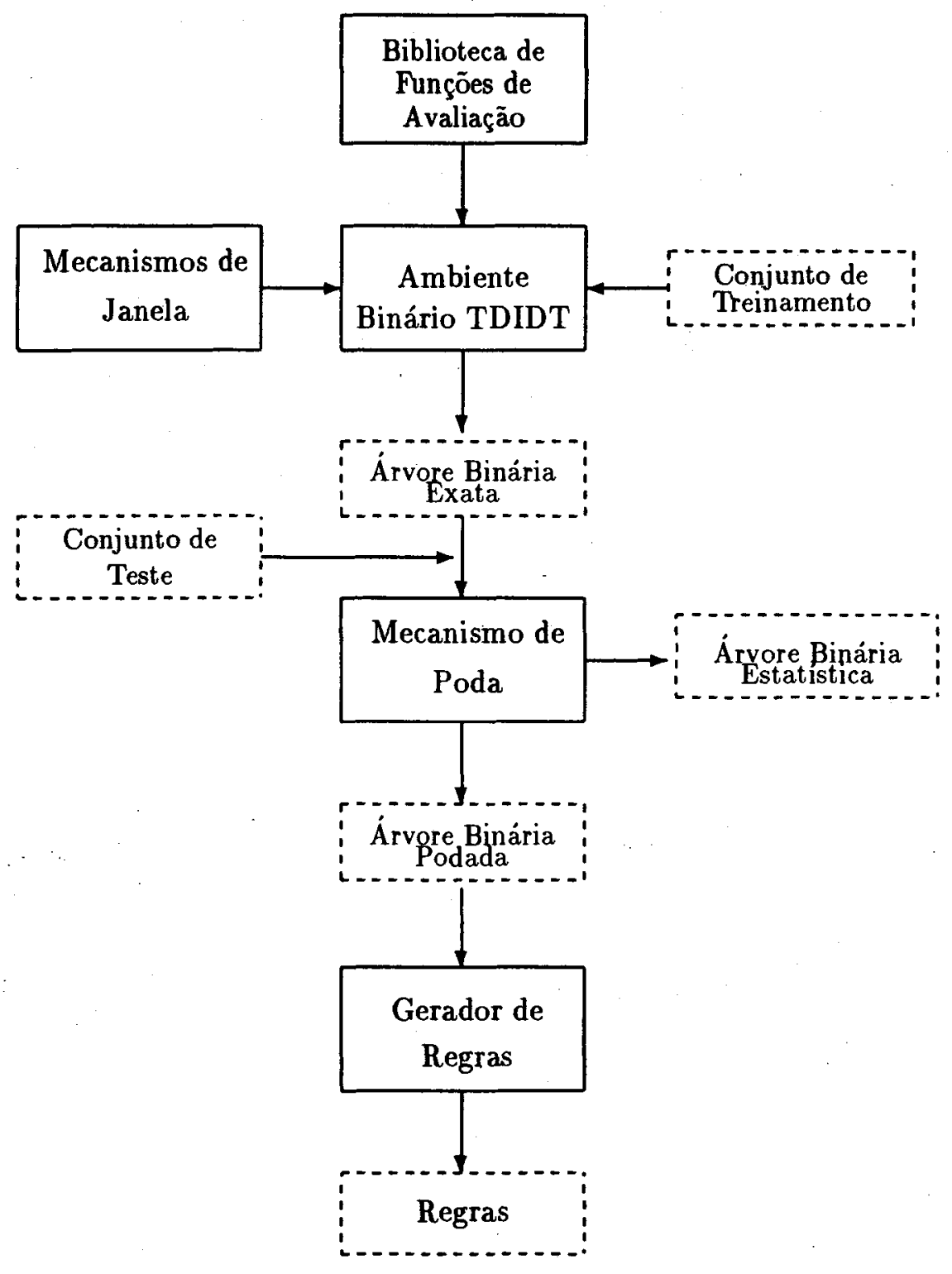

Figura 4.1: Ambiente Experimental TDIDT para Atributos Booleanos 


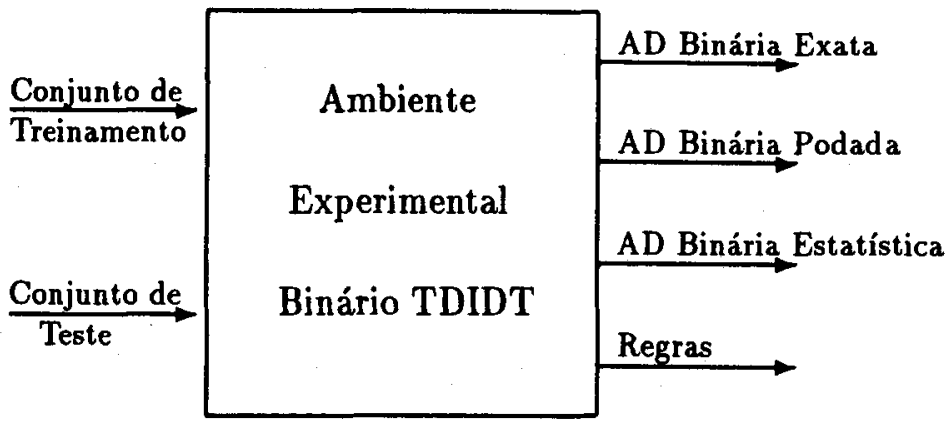

Figura 4.2: Visão Geral do Ambiente Experimental TDIDT para Atributos Booleanos

\subsection{Estrutura de Dados}

A estrutura de dados utilizada nas implementações para representar a árvore de decisão binária é

$$
\operatorname{arv}(S u b A r v E s q, \text { NoRaiz, SubArvDir) }
$$

onde NoRaiz é um nó de decisão rotulado com o atributo que possui o maior ganho de informação de acordo com uma função de avaliação. SubArvEsq e $S u b A r v D i r$ são subárvores de decisão binárias (esquerda e direita) para os quais o valor do atributo NoRaiz é 0 e 1 respectivamente. Cada subárvore pode ser um nó folha rotulado com o valor da classe ou outra árvore de decisão binária.

O conjunto de exemplos é representado por uma lista de lista, onde cada uma dessas listas corresponde a um exemplo. Os elementos dessas listas são estruturas da forma

$$
\begin{gathered}
<\text { nome do atributo }>:<\text { valor }> \\
\text { ou } \\
\text { classe: }<\text { valor }>
\end{gathered}
$$

Assim, o seguinte conjunto de treinamento da tabela

\begin{tabular}{|ccc|c|}
\hline \hline \multicolumn{3}{|c|}{ Atributos } & Classe \\
\hline x1 & x2 & x3 & \\
\hline sim & sim & sim & sim \\
não & não & não & sim \\
sim & não & não & não \\
sim & não & sim & sim \\
\hline \hline
\end{tabular}

deve ser transformado para uma estrutura de lista da seguinte forma 


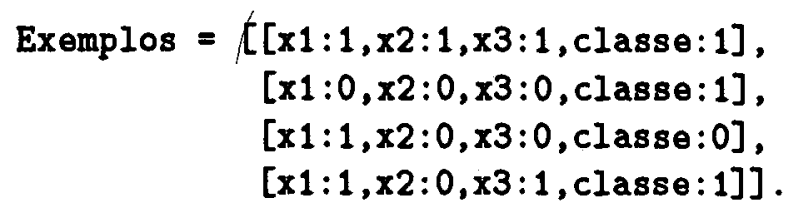

Nas implementações realizadas, a ordem dos elementos nas listas é irrelevante. 0 atributo $\times 1$, por exemplo, pode comparecer em diferentes posições em cada um dos exemplos considerados.

A seguir são descritos os algoritmos implementados que fazem parte do Ambiente Experimental TDIDT para Atributos Booleanos.

\subsection{Algoritmo Não Incrementạl para a Construção da Árvore de Decisão Binária}

Esta seção mostra a idéia geral de construção de árvores de decisão utilizada pelo algoritmo ID3, assim como a descrição do algoritmo implementado usando esta estratégia de aprendizado para atributos booleanos.

\subsubsection{O Algoritmo ID3}

O algoritmo ID3 é um algoritmo de aprendizado de conceitos que constrói uma árvore de decisão, de maneira eficiente, fazendo uma boa generalização dos exemplos fornecidos pelo ambiente [Utgoff 89].

Este algoritmo, bem como algumas variações do mesmo, foi proposto por Quinlan [Quinlan 83]. Seu objetivo consiste em discriminar exemplos positivos e negativos de um determinado conceito na construção da árvore de decisão. Os objetos utilizados na indução do conceito são descritos por um conjunto de atributos e seus respectivos valores. Uma medida de avaliação é aplicada a cada um dos atributos de maneira a determinar quão bem cada um deles discrimina entre exemplos (positivos) e não exemplos (negativos) do conceito. 0 atributo mais informativo é então usado como raiz, para formar a árvore de decisão, com ramificações para cada um dos valores do atributo da raiz. Os exemplos são divididos em grupos, construindo as subárvores. 0 processo continua até que os exemplos em uma subárvore sejam todos positivos ou negativos. Neste ponto a árvore discrimina completamente exemplos positivos e negativos do conceito a ser adquirido.

O ID3 é um algoritmo não incremental - o conjunto todo de treinamento deve estar completamente disponível no início do processamento. Em situações onde existe a 
disponibilidade do conjunto de treinamento, o algoritmo ID3 é uma boa escolha para construir regras de classificação. Algumas tentativas foram feitas para tornar o ID3 incremental. Uma dessas tentativas foi usar força bruta, uma abordagem sugerida por Schlimmer [Schlimmer 86] e conhecida como ID3'. A sugestão é a de executar o algoritmo cada vez que uma nova instância for observada. Esse procedimento, entretanto, é tremendamente ineficiente.

0 algoritmo ID3 - adaptado para atributos booleanos - é simplificado no que se refere à ramificação da árvore (apenas duas ramificações), e consiste do seguinte:

Dados um conjunto de exemplos de aprendizado $E$;

uma condição de parada $t(E)$;

uma função de avaliação aval $(E$, atributo $)$

If todas as instâncias em $E$ satisfazem a condição de término $t(E)$

Then retorne o valor da classe

Else

1. para cada atributo $a_{i}$ determine o valor da função aval $\left(E, a_{i}\right)$. Seja $a_{j}$ o atributo que possui o melhor valor de $\operatorname{aval}\left(E, a_{i}\right)$.

2. $a_{j}$ assume somente os valores 0 e 1 , crie o seguinte nó da árvore:

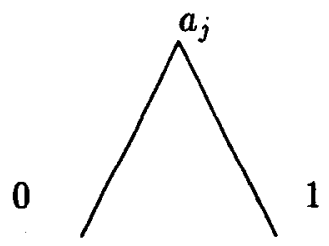

3. particione os exemplos do conjunto $E$ nos subconjuntos $E_{0}$ (correspondente aos valores de $a_{j}=0$ ) e $E_{1}$ (correspondente aos valores de $a_{j}=1$ ).

4. aplique o algoritmo recursivamente para os subconjuntos $E_{0}$ e $E_{1}$.

\section{Endif}

A função de avaliação - aval $\left(E, a_{i}\right)$ - que determina o atributo com maior ganho de informação - o atributo mais relevante na representação de um conceito - utilizada por ID3 é a Entropia, descrita a seguir

Entropia de classificação é usada em teoria da informação e interpretada como a quantidade de informação contida em uma mensagem. Quanto 
maior for o valor da entropia de classificação, maior a incerteza com relação ao conteúdo da mensagem. Neste contexto, uma árvore de decisão para a classificação de exemplos pode ser vista como uma fonte de informação que, dado um exemplo, gera uma mensagem indicando a classificação do exemplo. Quando o nó da árvore contém apenas exemplos da mesma classe, a entropia é igual a 0 - significando que a decisão de classificação é definitiva para exemplos pertencentes àquele nó [Shaw 90].

Para calcular a entropia de um determinado atributo binário, é necessário calcular a entropia de suas duas ramificações. Se um ramo contém observações de uma única classe, pode-se dizer que ele está ordenado e possui entropia zero; sua desorganização é nula. Caso contrário, uma observação pode ser classificada em 2 classes diferentes:

$$
c_{0}(\text { classe }=0) \text { e } c_{1}(\text { classe }=1) .
$$

Considerando que a probabilidade de um objeto pertencer à classe $c_{i}$ é $p(i)$, então a entropia de classificação do ramo é dada por

$$
E n\left(A=v_{j}\right)=-\sum_{i=0}^{1} p(i) \log _{2} p(i)
$$

onde $A=v_{j}$ significa que o atributo $A$ tem o valor $v_{j} \operatorname{com} v_{j} \in\{0,1\}$. Isto é, $\operatorname{En}(A=$ $v_{j}$ ) é a entropia do ramo correspondente ao valor $v_{j}$ do atributo $A$. Para calcular a entropia total de um atributo deve-se considerar a entropia de cada um dos ramos correspondentes a este atributo. Seja:

$M$ o número total de observações,

$E n_{0}$ e $E n_{1}$ as entropias dos dois ramos 0 e 1 respectivamente, associados ao atributo escolhido, e

$N_{0}$ e $N_{1}$ o número de observações de cada ramo.

Neste caso, a entropia de toda a ramificação, ou seja, a entropia do atributo A é dada por:

$$
E n(A)=\sum_{i=0}^{1} E_{i} \frac{N_{i}}{M}
$$

Assim, para gerar árvores de decisão mais simples, em cada nó da árvore deve-se escolher o atributo de menor entropia para continuar ramificando a árvore. 
Todas as implementações realizadas neste trabalho têm como função de avaliação a Entropia. Vale lembrar que as implementações estão estruturadas de tal forma que permitem trocar, facilmente, por qualquer outra função de avaliação.

\subsubsection{Descrição da Implementação do ID3 para Atributos Booleanos}

A implementação realizada tem como objetivo construir a árvore de decisão binária no modo incremental, baseada no algoritmo ID3. Como já mencionado, os atributos têm apenas dois valores possiveis, isto é, um atributo está presente (valor do atributo $=1$ ) ou ausente (valor do atributo $=0$ ) no conjunto de treinamento.

O procedimento principal - cuja implementação descrita em detalhes encontra-se em [Martins 94a] - responsável pela construção da árvore de decisão é mostrado, esquematicamente, na Figura 4.3.

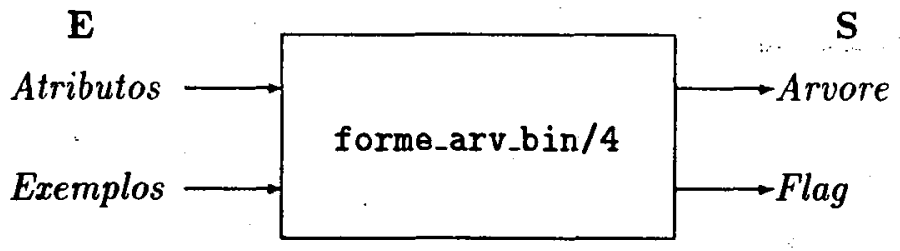

Figura 4.3: Procedimento Responsável pela Construção da Árvore de Decisão

Os dados de entrada para o procedimento consistem de um conjunto de exemplos e um conjunto de atributos que corresponde a uma lista que contém todos os atributos do conjunto de exemplos. Estes dados devem ser definidos pelo usuário e estão ligados à forma e ao meio onde serão armazenados. 0 procedimento terá como saída a árvore de decisão binária gerada pelo procedimento forme_arv_bin/4, e um flag indicando se a árvore é exata ou não ${ }^{1}$. Uma árvore de decisão não é exata quando existir no conjunto de treinamento dois ou mais exemplos com valores de atributos iguais e classes diferentes. Caso isso ocorra, o algoritmo rotula o nó com o valor da classe mais provável.

O algoritmo implementado considera várias situações que poderão acontecer durante o processo de construção da árvore:

1. todos os exemplos pertencem à mesma classe. Neste caso a subárvore correspondente consiste de um simples nó rotulado com o valor da classe.

2. durante o processo de construção da árvore, não é possível classificar exatamente exemplos que tenham atributos com o mesmo valor e que pertencem a classes diferentes. Neste caso, após a manipulação de todos os exemplos do conjunto de aprendizado, a estratégia adotada nesta implementação é a de rotular essa folha com o valor da classe mais provável.

\footnotetext{
${ }^{1} \mathrm{O}$ algoritmo implementado tem algumas extensões não presentes no algoritmo ID3 original.
} 
3. um nó folha é rotulado com o átomo null quando para um determinado valor de atributo não existirem exemplos no conjunto de treinamento que sejam classificados pelo ramo correspondente.

Os passos básicos do algoritmo, que começa com uma árvore de decisão vazia e o conjunto de exemplos positivos e negativos do conceito, são:

1. obter o melhor atributo segundo um determinado critério

2. particionar os exemplos de acordo com os valores do melhor atributo

3. retirar o melhor atributo da lista de possíveis atributos, $\mathrm{e}$

4. recursivamente continuar ramificando cada uma dessas partições de exemplos.

Durante o processo de construção da árvore, a árvore de decisão é representada pela seguinte estrutura geral:

$$
\operatorname{arv}([[\ldots],[\ldots], \ldots], \text { Melhor Atributo, }[[\ldots],[\ldots], \ldots])
$$

onde o primeiro e o terceiro argumentos são listas de listas de exemplos sem o atributo MelhorAtributo, particionados de acordo com o valor do atributo. Isto é, o primeiro argumento consiste dos exemplos onde o valor de Melhor Atributo é 0 e o terceiro argumento dos exemplos onde o valor de Melhor Atributo é 1 - Figura 4.4.

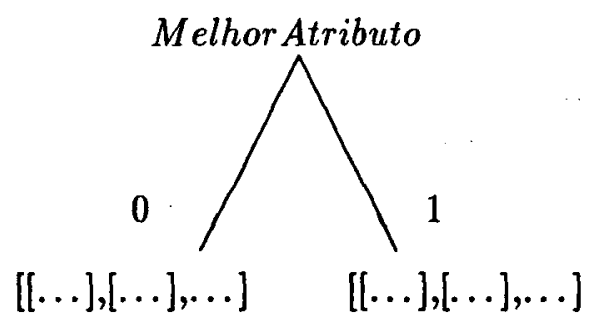

Figura 4.4: Estrutura da Árvore de Decisão Durante o Processo de Construção

Após encontrar o melhor atributo, o procedimento retira-o do conjunto de atributos e particiona os exemplos de acordo com valores 0 ou 1 , que o melhor atributo pode assumir.

Com a árvore expandida em um nível, é realizado, recursivamente, para cada subárvore, o mesmo processo. A estrutura final da árvore é representada por nós de decisão que são os atributos, particionados de acordo com seu valor, e nós folhas que representam a classe ou o rótulo null. 


\subsubsection{Exemplos de Execução}

Nesta seção, são apresetados alguns exemplos de execução, para um pequeno conjunto de exemplos, do algoritmo implementado. Em cada caso é mostrada a instanciação das variáveis de entrada e saída correspondentes à interrogação

$$
\text { ?- forme_arv_bin(Atributos, Exemplos, Arvore,Flag). }
$$

Exemplo 4.3.3.1

Entrada:

$$
\begin{aligned}
\text { Atributos }= & {[x 1, x 2, x 3] . } \\
\text { Exemplos }= & {[[x 1: 1, x 2: 1, \text { classe }: 1, x 3: 1],} \\
& {[x 1: 0, x 2: 0, \text { classe }: 1, x 3: 0], } \\
& {[x 1: 1, x 2: 0, \text { classe }: 0, x 3: 0], } \\
& {[x 1: 1, x 2: 0, \text { classe }: 1, x 3: 1]] . }
\end{aligned}
$$

Saída:

$$
\begin{aligned}
& \text { Arvore }=\operatorname{arv}(1, \times 1, \operatorname{arv}(0, \times 3,1)) \\
& \text { Flag }=\text { exata }
\end{aligned}
$$

Neste exemplo, a árvore de decisão gerada é pequena e exata. 0 ạtributo x2 é um atributo irrelevante, isto é, o atributo x2 não é um atributo significativo na representação do conceito.

\section{Exemplo 4.3.3.2}

\section{Entrada:}

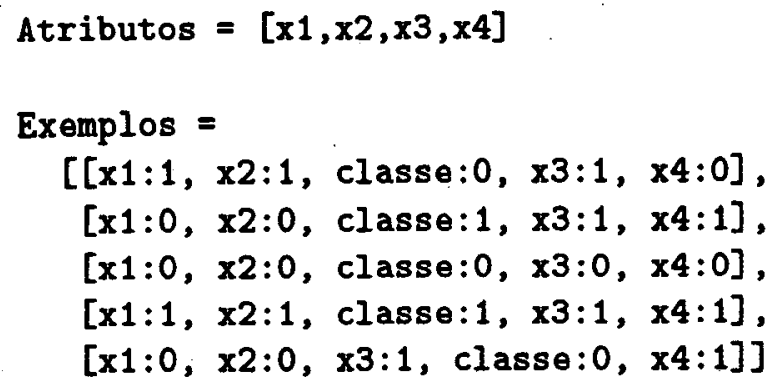


Saída:

$$
\begin{aligned}
& \text { Arvore }=\operatorname{arv}(0, x 4, \operatorname{arv}(\operatorname{null}, \times 3, \operatorname{arv}(\operatorname{arv}(1, x 2, \operatorname{null}), \times 1,1))) \\
& \text { Flag }=\text { nao_exata }
\end{aligned}
$$

A árvore gerada não é exata, o que indica que em pelo menos um ramo a classe foi aproximada pela classe majoritária, e não há atributos irrelevantes. Além disso, alguns nós folhas foram rotulados com o átomo null, mostrando que não há exemplos no conjunto de treinamento que sejam classificados pelo ramo correspondente.

\section{Exemplo 4.3.3.3}

\section{Entrada:}

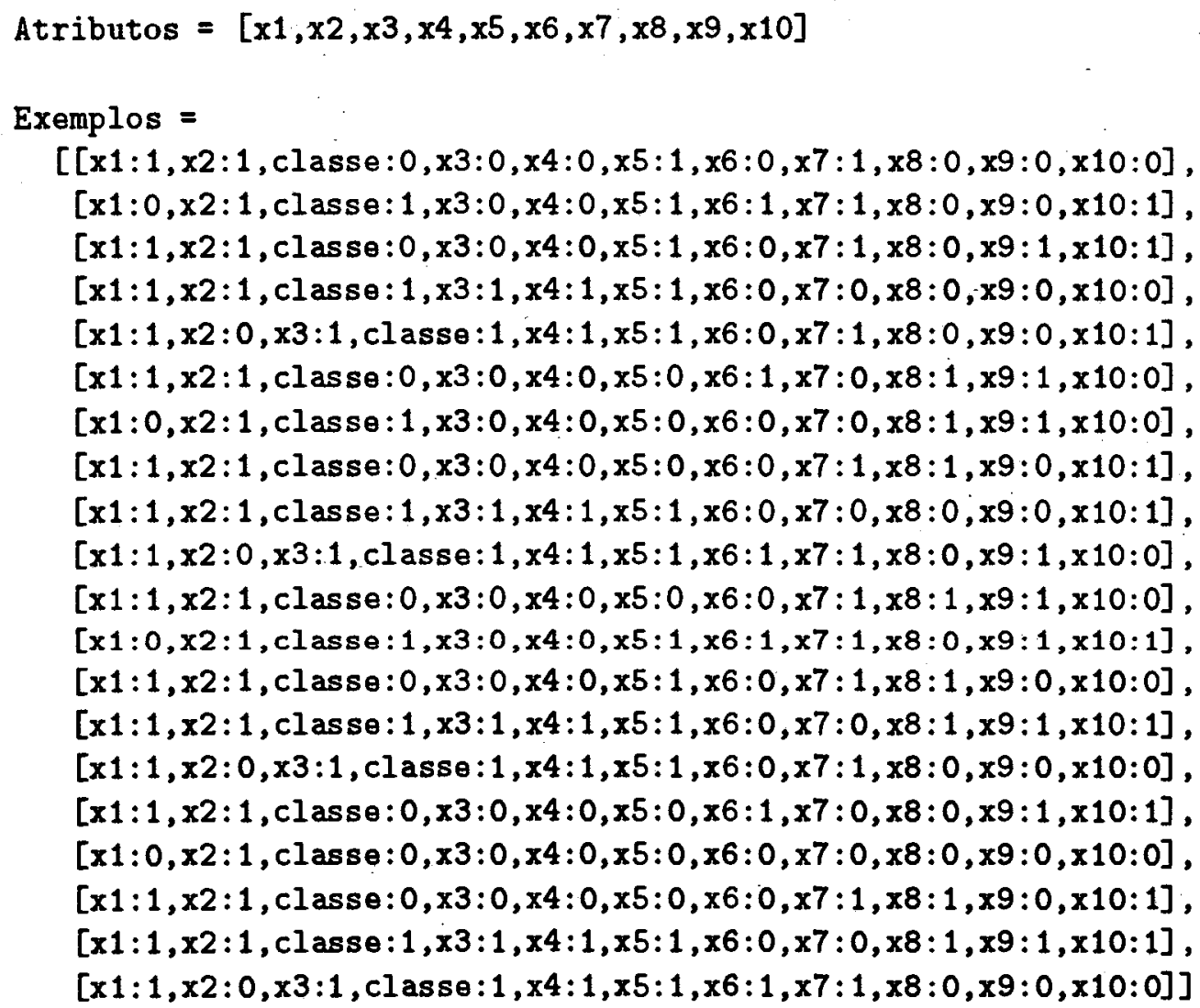

Saída:

$$
\begin{aligned}
& \text { Arvore }=\operatorname{arv}(1, \times 2, \operatorname{arv}(\operatorname{arv}(\operatorname{arv}(\operatorname{arv}(0, x 9, \operatorname{arv}(1, x 1,0)), \\
& x 6, \operatorname{arv}(1, x 1,0)), \times 4, \mathrm{nu} 11), \times 3,1)) \\
& \text { Flag = exata }
\end{aligned}
$$


A árvore construída é exata e relativamente grande. Alguns atributos são irrelevantes e possui nós folhas rotulados com null.

\subsection{Algoritmo Incremental para a Construção da Árvore de Decisão Binária}

Esta seção apresenta o algoritmo incremental que utiliza a estratégia de aprendizado do algoritmo ID5 para atributos booleanos. Este algoritmo difere do algoritmo não incremental no modo como opera os exemplos para classificá-los na árvore de decisão. No algoritmo descrito a seguir, os exemplos são tratados individualmente na construção da árvore, ocasionando uma acomodação na mesma, caso necessário, ao invés de induzir a árvore de decisão baseado no conjunto total de instâncias.

\subsubsection{Os Algoritmos ID5 e ID5R}

Os algoritmos ID5 e ID5R [Utgoff 88], assim como ID4 [Schlimmer 86] são sucessores de ID3 na tentativa de torná-lo incremental.

O algoritmo ID5R é um algoritmo incremental que constrói uma árvore de decisão similar àquela que ID3 construirá para um dado conjunto de instâncias de treinamento. Assim como o ID4 e ID5, o algoritmo ID5R mantém informações suficientes para calcular o E-score ${ }^{2}$ de um dado atributo em um nó, possibilitando a troca do atributo teste do nó caso necessário. Quando ID5R muda o atributo teste, ele não descarta toda subárvore abaixo do nó como faz o algoritmo ID4; ID5R reestrutura a árvore fazendo com que o atributo teste desejado seja a raiz da árvore. O processo de reestruturação, chamado pull-up, é um processo de rearranjo da árvore que preserva consistência com as instâncias de treinamento observadas, colocando o atributo desejado para ser a raiz da árvore ou subárvore. A vantagem do processo de reestruturação consiste em permitir a recontagem das classes positivas e negativas para cada valor do atributo, durante o rearranjo da árvore, sem o reprocessamento das instâncias de treinamento.

Formalmente, uma árvore de decisão ID5R é definida como sendo:

1. um nó folha (ou nó resposta) que contém

(a) o valor da classe, $\mathrm{e}$

(b) o conjunto de descrições de instâncias naquele nó, que pertencem à classe

\footnotetext{
${ }^{2} E$-score é o valor da função de avaliação utilizada na busca do atributo que tem o maior ganho de informação.
} 
2. um nó não folha (ou nó de decisão) que contém

(a) um atributo de teste que, para cada valor possível, tem ramificações para outra árvore de decisão, bem como contagem dos exemplos nas classes positiva e negativa, para cada um dos possiveis valores do atributo de teste

(b) o conjunto de atributos não-teste no nó, cada um com contagens positiva e negativa para cada possivel valor do atributo.

Esta forma de árvore de decisão difere das adotadas pelo ID3 e ID4, porque retém nela instâncias de treinamento, bem como as contagens de classes. Consequentemente, a árvore deverá ser interpretada diferentemente. Quando utilizada para classificar uma nova instância, a árvore é percorrida até encontrar um nó onde todas as instâncias de treinamento pertencem à mesma classe. Este nó pode ser um nó folha ou um nó não folha. Quando for um nó não folha, deverá apenas existir uma classe com um contador de instância não-zero.

O algoritmo básico ID5R, consiste dos seguintes passos:

If a árvore está vazia

Then define-a como uma forma não expandida ${ }^{3}$, setando o nome da classe para a classe da instância, e o conjunto de instâncias para um simples conjunto contendo a instância.

Else

If a árvore está na forma não expandida e a instância é da mesma classe

Then adicione a instância ao conjunto de instâncias mantidas no nó.

Else

If a árvore está na forma não expandida

Then expanda-a em um nível, escolhendo, arbitrariamente, um atributo teste para ser a raiz.

Para o atributo teste e todos os atributos não teste no nó corrente, atualize a contagem de instâncias positivas e negativas para o valor daquele atributo na instância de treinamento.

If o nó corrente contém um atributo teste que não tem a menor entropia

Then

(a) Reestruture a árvore (pull-up) para que o atributo com menor entropia fique na raiz.

\footnotetext{
${ }^{3}$ Chama-se um nó folha de árvore não expandida e um nó não folha de árvore expandida.
} 
(b) Recursivamente reestabeleça o melhor atributo teste em cada subárvore exceto naquela que será atualizada no próximo passo.

\section{Endif}

Recursivamente atualize a árvore de decisão abaixo do nó de decisão corrente pertencente ao ramo para o valor do atributo teste que ocorre na descrição da instância. Aumente o ramo se necessário.

\section{Endif}

O algoritmo pull-up de ID5R consiste dos seguintes passos:

If o atributo $a_{\text {new }}$ a ser "empurrado" já é a raiz da árvore

Then pare.

Else

1. Recursivamente empurre o atributo $a_{\text {new }}$ para a raiz de cada subárvore imediata. Converta qualquer árvore não expandida para a forma expandida caso necessário, escolhendo o atributo $a_{\text {new }}$ como $o$ atributo teste.

2. Transforme a árvore, resultando em uma nova árvore com $a_{n e w}$ na raiz, e o antigo atributo raiz $a_{\text {old }}$ na raiz de cada subárvore imediata.

\section{Endif}

Para efeito de ilustração do algoritmo considere o seguinte conjunto de exemplos:

\begin{tabular}{|cc|c|}
\hline \hline \multicolumn{2}{|c|}{ Atributos } & Classe \\
\hline $\mathbf{x 1}$ & $\mathbf{x 2}$ & \\
\hline 0 & 1 & 0 \\
1 & 0 & 1 \\
0 & 0 & 1 \\
1 & 1 & 0 \\
\hline
\end{tabular}

0 algoritmo de construção da árvore irá processar cada instância individualmente. Para a primeira instância ( $x 1: 0, x 2: 1$, classe:0), a árvore resultante consiste de um simples nó folha

$$
0 /[[x 1: 0, x 2: 1]]
$$

Na segunda instância (x1:1,x2:0,classe:1), a classe é positiva, então a árvore é expandida escolhendo $\mathrm{x} 1$, arbitrariamente, para ser a raiz da árvore. 


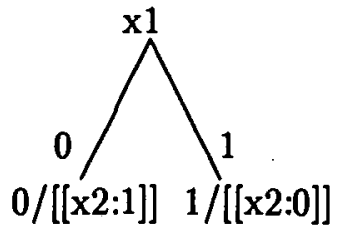

A representação gráfica da árvore de decisão apresentada não mostra a lista de contadores associada a cada nó de decisão. Estes são criados no momento da expansão da árvore e atualizados a cada nova instância classificada pelo nó.

Quando se realiza o processamento da terceira instância (x1:0,x2:0,classe:1), verifica-se que $o$ atributo $x 2$ contém o menor valor de entropia, assim a árvore deve ser reestruturada. 0 objetivo, então, é fazer com que o atributo $x 2$, seja a raiz da árvore. Após este processo, a árvore resultante será:

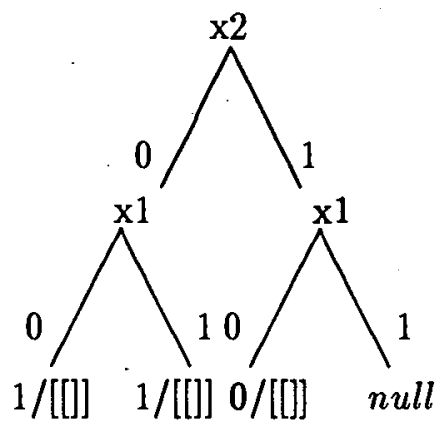

Por fim, o último exemplo (x1:1,x2:1,classe:0), é classificado pela árvore sem causar uma reestruturação na mesma. A árvore final é representada por:

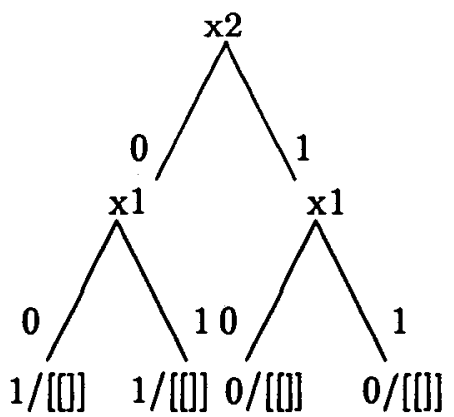

$\mathrm{O}$ algoritmo ID5R é sucessor do algoritmo ID5. A diferença entre os dois algoritmos reside no passo (b) do algoritmo ID5R, pg. 65, que é omitido no algoritmo ID5. Isto significa que, após reestruturar a árvore para trazer o atributo desejado para a raiz, a subárvore que não classifica o exemplo não será reestruturada recursivamente, ou seja, nada garante que a raiz desta subárvore terá o melhor atributo. Eliminando-se este passo, o custo para manipulação da árvore é reduzido. Entretanto, a consequên cia dessa 
omissão é que a árvore resultante pode não ser equivalente àquela que ID3 construirá para o mesmo conjunto de treinamento. Outra imposição para que as duas árvores, àquelas construídas por ID3 e ID5R, sejam iguais, é que ambos devem dar o mesmo tratamento para escolher entre dois atributos com o mesmo valor da entropia.

\subsubsection{Descrição da Implementação do ID5 para Atributos Booleanos}

A implementação realizada tem como objetivo construir uma árvore de decisão binária no modo incremental baseada no algoritmo ID5. Como visto anteriormente, este algoritmo considera que os exemplos do conjunto de treinamento são fornecidos um a um. $\mathrm{Na}$ classificação de um novo exemplo na árvore de decisão, para cada nó da árvore, busca-se o atributo que tem o maior ganho de informação e reestrutura-se a árvore caso o atributo seja diferente do atributo do nó corrente.

A implementação realizada utiliza listas e árvores binárias como estrutura de dados. Durante o processo de construção e atualização da árvore de decisão incremental, a seguinte estrutura é utilizada

$$
\operatorname{arv(SubArvEsq,Raiz/ListaContadores,SubArvDir)}
$$

onde a árvore de decisão é representada pelo nó raiz, uma lista de contadores é associada à raiz - Raiz/ListaContadores -, a subárvore esquerda - SubArvEsq - e a subárvore direita - SubArvDir - para as ramificações cujo valor da raiz é 0 e 1 respectivamente. Cada subárvore pode ser outra árvore de decisão ou um nó folha rotulado com o valor da classe e o conjunto de exemplos associado. É válido lembrar que a árvore poderá ser representada com o átomo null, quando estiver vazia, ou representada através de um nó folha rotulado com o valor da classe, no caso de todos os exemplos pertencerem à mesma classe.

A árvore de decisão retém informações suficientes para calcular a entropia de cada atributo em um determinado nó. Estas informações são armazenadas em uma lista - ListaContadores - do tipo

$$
\left[\left[A t_{1}, A_{1}: B_{1}, C_{1}: D_{1}\right],\left[A t_{2}, A_{2}: B_{2}, C_{2}: D_{2}\right], \ldots,\left[A t_{n}, A_{n}: B_{n}, C_{n}: D_{n}\right]\right]
$$

onde $A_{i}, B_{i}, C_{i}, D_{i}$ para $i=1,2, \ldots n$ representam o número de exemplos positivos e negativos, respectivamente, para cada valor possível do atributo $A t_{i}$ que pertence àquele nó. A árvore retém, também, informação referente às instâncias de treinamento nos nós folhas. Essas instâncias de treinamento são utilizadas para expandir a árvore ou para auxiliar na contagem dos atributos na lista de contadores.

0 procedimento responsável pela construção incremental da árvore de decisão, ilustrado na Figura 4.5, tem como entrada o exemplo a ser inserido na árvore e a árvore anteriormente construída pelo algoritmo na forma acima descrita. 


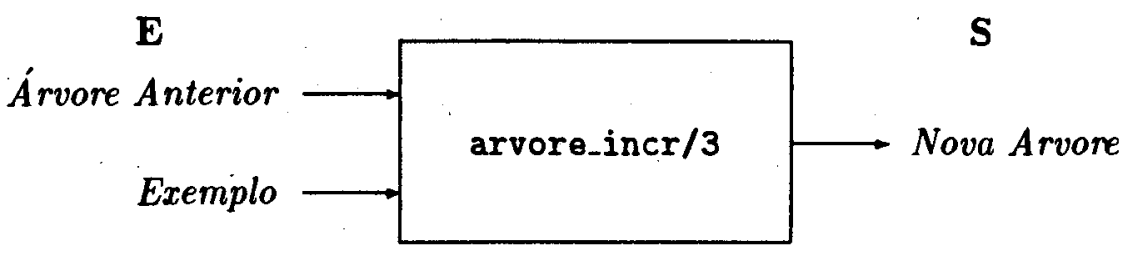

Figura 4.5: Procedimento Responsável pela Construção da Árvore de Decisão Incremental

No caso de não existir a árvore de entrada, ou seja, a primeira vez que o procedimento vai ser ativado, a árvore anterior pode ser representada por uma variável livre ou o átomo null. A ordem dos elementos na lista que representa o exemplo é irrelevante.

A implementação realizada tenta classificar o exemplo independente se ele tem o mesmo número de atributos que àqueles que compareceram na árvore an teriormente construída. Se o número de atributos do exemplo for maior, existe a possibilidade de não poder ser inserido nessa árvore e, nesse caso, o exemplo é ignorado. Caso o exemplo possa ser inserido na árvore, os novos atributos são adicionados nos nós folhas. Portanto, é recomendável que os atributos compareçam em todos os exemplos.

A estrutura da árvore de decisão incremental no argumento de entrada poderá ser representada por:

- uma árvore vazia, neste caso ela pode estar rotulada com o átomo null ou ser uma variável livre

- um simples nó rotulado com o valor do atributo classe

- uma estrutura de árvore de decisão incremental - $\operatorname{arv}(S e, R a i z / L, S d)$.

Quando o procedimento encontra o átomo null representando a árvore de decisão, seu objetivo é retornar um nó rotulado com o valor da classe juntamente com o exemplo sem o atributo classe. A árvore de decisão é representada, simplesmente, por esse nó folha.

Para o seguinte exemplo,

Exemp10 $=[x 1: 0, \times 2: 1, \times 3: 0$, classe: 1$]$

e a variável livre $X$, representando uma árvore vazia, a interrogação

?- arvore_incr(Exemplo, X,Arvore).

é bem sucedida com 
Arvore $=1 /[[\times 1: 0, x 2: 1, x 3: 0]]$

Quando a árvore é representada por um simples nó rotulado com o valor do atributo classe e os vários exemplos pertencentes àquele nó, duas situações diferentes poderão ocorrer. Na primeira situação, o valor do atributo classe do exemplo a ser classificado é igual ao valor da classe rotulado no nó que representa a árvore de decisão. Neste caso, o exemplo é, simplesmente, adicionado à lista de exemplos, sem o atributo classe que o nó possui. Caso os valores das classes sejam diferentes - a classe do exemplo diferente do valor contido no nó - , um atributo é escolhido, aleatoriamente, no conjunto de exemplos armazenado naquele nó e são criadas subárvores para este atributo. A árvore que antes consistia de apenas um nó é expandida em uma árvore com a seguinte estrutura

$$
\operatorname{arv}(\text { SubArvEsq, Raiz/Lista,SubArvDir) }
$$

onde

- Raiz é o atributo escolhido aleatoriamente para ser a raiz da árvore

- Lista é a lista de atributos com contadores para exemplos positivos e negativos para cada valor do atributo, positivo e negativo, e

- SubArvEsq e SubArvDir são as subárvores esquerda e direita de Raiz onde os exemplos são particionados, respectivamente, de acordo com os valores 0 e 1 do atributo Raiz.

Por exemplo, na expansão de uma árvore representada pór

Arvore $=0 /[[x 1: 1, x 2: 0],[x 1: 0, x 2: 0]]$

onde o atributo $x 1$ é escolhido aleatoriamente para ser a raiz da árvore, tem-se a seguinte árvore expandida

$$
\operatorname{ArvExp}=\operatorname{arv}(0 /[[x 2: 0]], x 1 /[[x 1,1: 0,1: 0],[x 2: 2: 0,0: 0]], 0 /[[x 2: 0]])
$$

Árvore Gráfica ${ }^{4}$

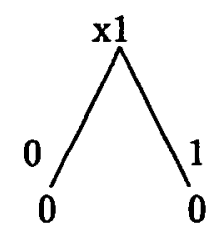

\footnotetext{
${ }^{4} \mathrm{~A}$ árvore representada graficamente não contém as informações adicionais (lista de contadores e exemplos armazenados nos nós folhas), para maior facilidade de visualização.
} 
Com a árvore expandida em um nível, o processo de classificar o exemplo é repetido, agora com a nova árvore. ${ }^{5}$

Quando o exemplo a ser classificado encontra a árvore de decisão representada pela estrutura geral arv $(S e, R a i z / L, S d)$, o primeiro passo a ser realizado é atualizar a lista que faz a contagem dos elementos positivos e negativos, de acordo com o novo exemplo. É através desta lista que será calculada a entropia de cada atributo. Após calcular a entropia dos possíveis atributos em um nó, o atributo com menor valor de entropia será a raiz da nova árvore. 0 processo pull_up é o responsável por "empurrar" este atributo para a raiz.

A fim de ilustrar o processo pull_up considere a seguinte árvore de decisão

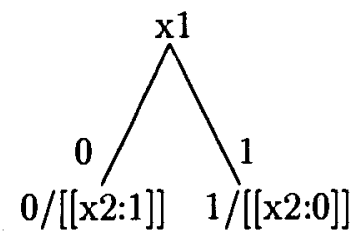

Através do cálculo da entropia, verifica-se que o melhor atributo é x2. 0 primeiro passo é fazer com que $\mathrm{x} 2$ seja a raiz de cada subárvore de $\mathrm{x} 1$. Assim a árvore é expandida nos nós folhas, como ilustrado a seguir:

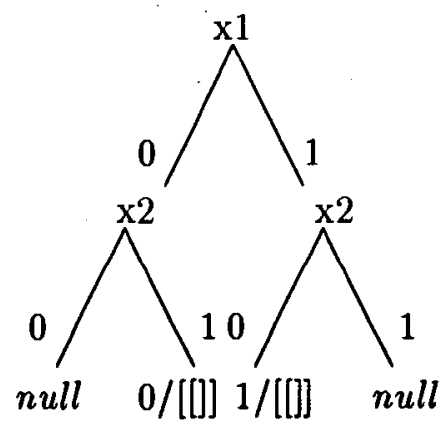

logo após, a árvore é dividida em duas:

\footnotetext{
${ }^{5}$ Note que os dois nós folhas da árvore expandida têm o mesmo valor de classe. Isto é devido ao fato de considerar apenas o conjunto de exemplos pertencentes àquele nó. $O$ novo exemplo não é considerado na expansão da árvore.
} 

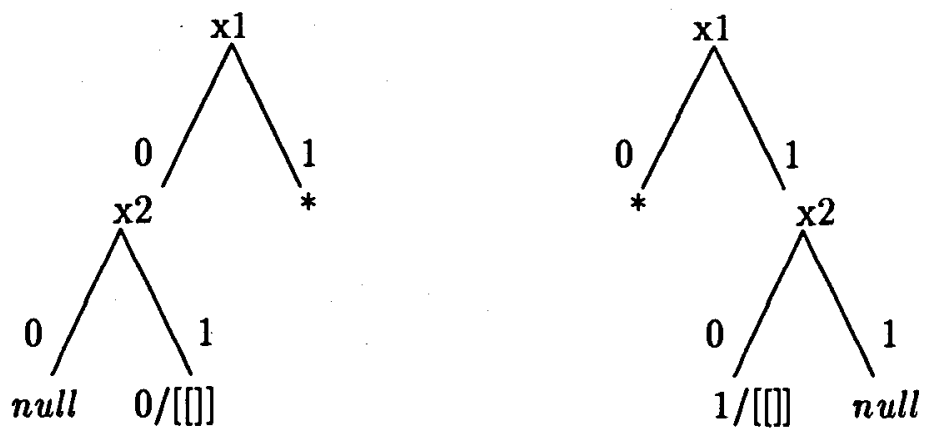

e os atributos do nível 0 e 1 são trocados:

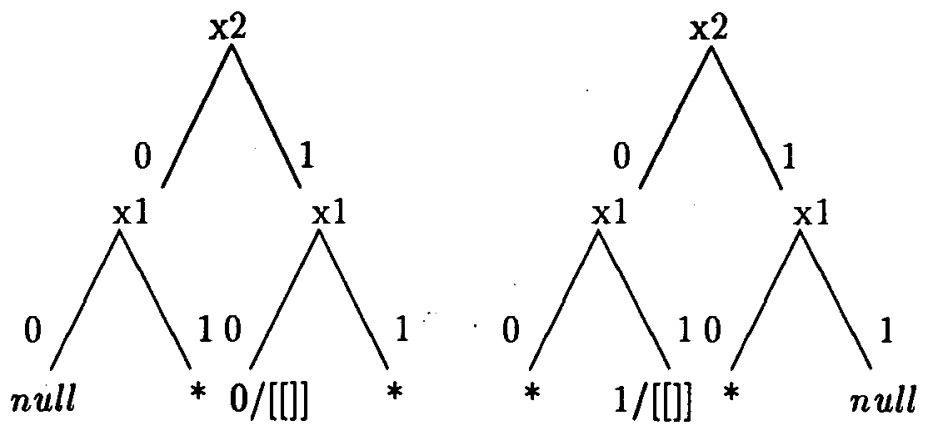

finalmente, as duas árvores são agrupadas:

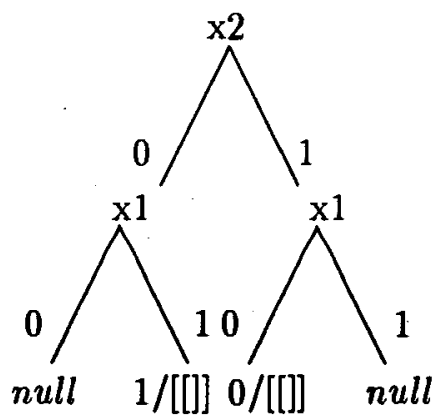

O processo pull_up trata as diferentes situações apresentadas na árvore de decisão incremental no processo de reestruturação, acarretando a cada uma um tratamento diferente. Estas situações são descritas a seguir.

- o nó a ser reestruturado é um nó folha rotulado com o átomo null. Quando isso ocorre, o nó passa a ser representado na forma de uma árvore de decisão onde a raiz da árvore contém o melhor atributo e suas subárvores são rotuladas com null. São criados os contadores com valor 0 para o atributo no nó, isto porque apesar da árvore ser expandida em um nível, nenhum exemplo é classificado naquele nó. 
- o nó é representado como um nó folha contendo o valor da classe. Neste caso, o nó é expandido, também, em um nível. Na árvore expandida, a raiz contém o melhor atributo e os exemplos armazenados no nó são divididos de acordo com os valores que a raiz pode assumir. É criado o contador de exemplos positivos e negativos para cada atributo possível para aquele nó de acordo com os exemplos armazenados, e as subárvores são rotuladas com o valor da classe.

- a raiz da subárvore já é o atributo mais informativo. Neste caso, não haverá nenhuma transformação e a árvore original não é alterada.

- a raiz da árvore é um atributo diferente do atributo mais informativo e suas subárvores estão rotuladas com null. 0 ob jetivo, então, é trocar o atributo da raiz conservando a lista de contadores e suas subárvores. Não é necessário expandir a árvore porque não existe nenhum exemplo classificado pelo nó, dessa forma o atributo que representa a raiz é irrelevante. Com isto economiza-se tempo e espaço, pois em cada nó de decisão, todos os contadores para os atributos devem ser mantidos.

- a árvore é representada na forma genérica - $\operatorname{arv}(S e, R / L, S d)$. Como o procedimento é recursivo, é realizado pára cada subárvore, esquerda e direita, o processo de pull_up para "empurrar" o atributo mais relevante para a raiz de cada subárvore imediatamente inferior à raiz do nó que será reestruturado. Com o atributo mais relevante sendo a raiz de cada subárvore no nível 1, a árvore é, teoricamente, dividida para realizar a troca entre os atributos das raízes do nível 0 e 1. Depois de realizada a troca, unem-se as duas árvores e com isso todas as informações necessárias são mantidas e a consistência da árvore é preservada.

Após o processo de reestruturação do nó, é verificado o valor do melhor atributo, que agora é a raiz da árvore, no exemplo que está sendo classificado para que o processo seja repetido na subárvore esquerda ou direita, respectivamente, dependendo se o valor do melhor atributo for 0 ou 1.

\subsubsection{Exemplos de Execução}

Nesta seção são apresentados alguns exemplos de execução do algoritmo implementado, para um pequeno conjunto de exemplos. Em cada caso é mostrada a instanciação das variáveis de entrada e saída correspondentes à interrogação

?- arvore_incr(Exemplos, Arvore, ArvoreIncr), enxugue_arv(ArvoreIncr, ArvorePadrao).

onde o procedimento enxugue_arv/2 é responsável por transformar a árvore incremental para o formato padrão - veja seção 4.2 pag. 56 . 


\section{Exemplo 4.4.3.1}

Entrada:

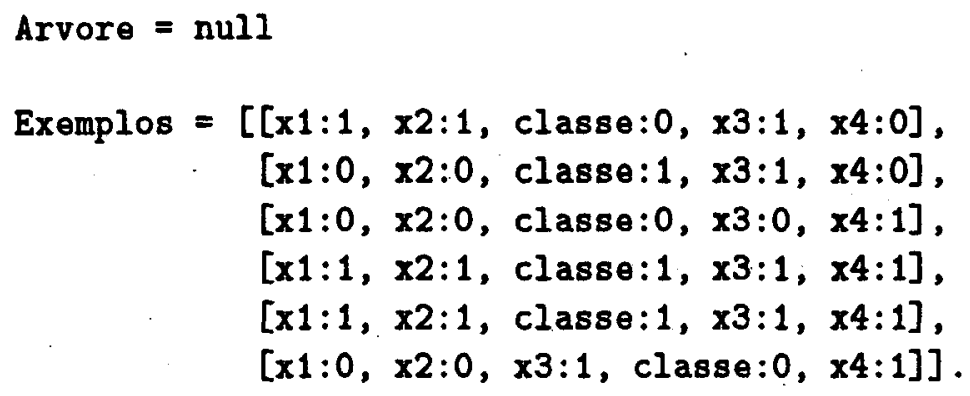

Saída:

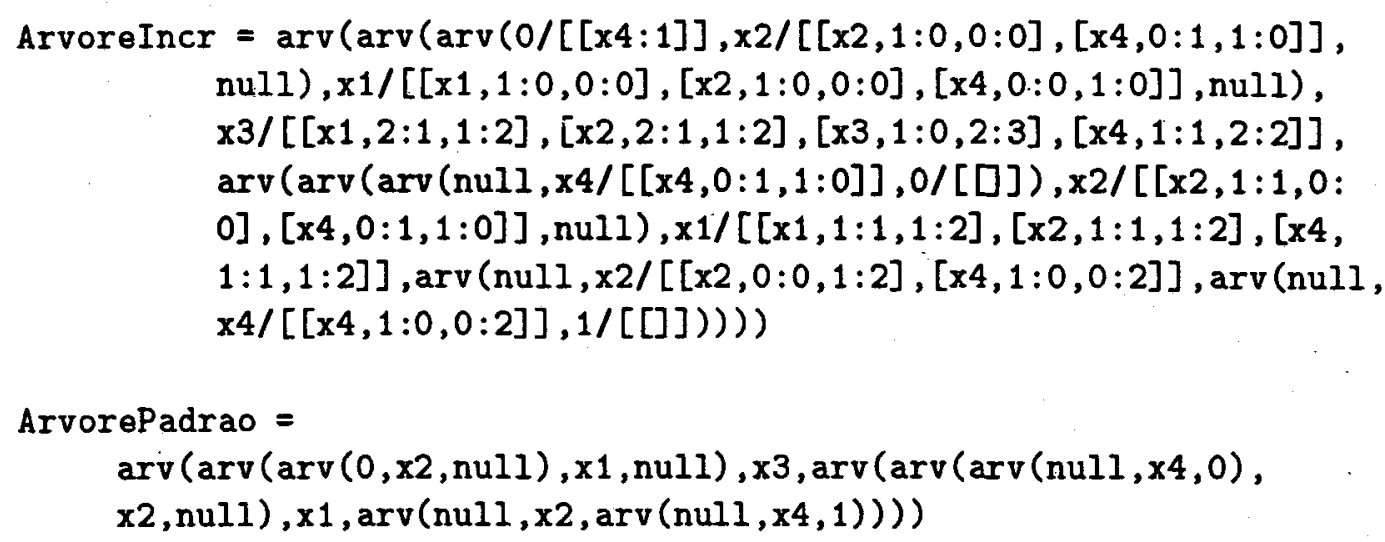

Neste exemplo, a árvore de decisão inicial está vazia - null. Após a construção e classificação de todos exemplos, individualmente, a árvore de decisão gerada ArvoreIncr - está em sua forma geral, isto é, contém tanto as informações necessárias ao cálculo da entropia armazenadas nos nós de decisão, quanto as instâncias de treinamento armazenados nos nós folhas. Esta mesma árvore de decisão em sua forma padrão é dada por ArvorePadrao.

Nos exemplos a seguir, apenas a árvore de decisão no formato padrão é mostrada.

\section{Exemplo 4.4.3.2}

Entrada:

Arvore $=\operatorname{arv}(\operatorname{arv}(\operatorname{arv}(0 /[[x 4: 1]], x 2 /[[x 2,1: 0,0: 0],[x 4,0: 1,1: 0]]$, null $)$, 
$x 1 /[[x 1,1: 0,0: 0],[x 2,1: 0,0: 0],[x 4,0: 0,1: 0]]$, nul 1$), x 3 /[[x 1,2:$ $1,1: 2],[\times 2,2: 1,1: 2],[\times 3,1: 0,2: 3],[\times 4,1: 1,2: 2]], \operatorname{arv}(\operatorname{arv}(\operatorname{arv}($ null $, x 4 /[[x 4,0: 1,1: 0]], 0 /[[]]), x 2 /[[x 2,1: 1,0: 0],[x 4,0: 1,1: 0]$ ]$, null $), x 1 /[[x 1,1: 1,1: 2],[\times 2,1: 1,1: 2],[\times 4,1: 1,1: 2]]$, arv(null, $x 2 /[[x 2,0: 0,1: 2],[x 4,1: 0,0: 2]]$, arv(null, $x 4 /[[x 4,1: 0,0: 2]], 1 /$ $[[]])))$

Exemplos $=[[x 1: 1, x 2: 1$, classe: $0, x 3: 0, x 4: 0]$, $[x 1: 0, x 2: 1$, classe: $1, x 3: 0, x 4: 0]$, $[x 1: 1, x 2: 1$, classe: $0, x 3: 0, x 4: 0]$, $[x 1: 1, x 2: 1$, classe: $1, x 3: 1, x 4: 1]$, $[x 1: 1, x 2: 0, x 3: 1$, classe: $1, x 4: 1]]$.

Saída:

ArvorePadrao $=\operatorname{arv}(\operatorname{arv}(\operatorname{arv}(\operatorname{arv}($ null $, x 1, n u l l), x 4, \operatorname{arv}($ null $, x 1, n u l l)), x 2$, $\operatorname{arv}(\operatorname{arv}($ null,$x 4$, null $), x 1, \operatorname{arv}(0, x 4$, null $))), x 3, \operatorname{arv}(\operatorname{arv}($ $\operatorname{arv}(n u l l, x 4,0), \times 2, n u l 1), \times 1, \operatorname{arv}(\operatorname{arv}($ null $, \times 2, n u l 1), \times 4$, $\operatorname{arv}(1, x 2,1)))$ )

Exemplo 4.4.3.3

Entrada:

Arvore $=$ null

Exemplos $=[[$ verde $: 1$, amarelo 0,0, lasse: 0, azul $: 1$, vermelho: 0, preto $: 0]$, [verde: 1 , amarelo: 1 , classe: 0 , azul $: 1$, vermelho: 1 , preto: 1 ], [verde: 0 , amarelo: 0 , azul: 1 , classe: 1 , vermelho: 1 , preto: 1 ], [verde: 0 , amarelo: 1 , azul: 0 , classe: 0 , vermelho: 0 , preto:1], [verde: 1 , amarelo: 1 , azul: 1 , vermelho:0,preto: 1, class $\theta: 0$ ], [verde: 1 , amarelo: 1 , azul: 1 , vermelho:0,preto: 0, classe:1], [verde: 0 , amarelo: 0 , azul: 0 , vermelho: 0 ,preto: 0, classe:0], [verde: 1 , amarelo: 1 , azul: 1 , vermelho: 1 ,preto: 1 , classe:0], [verde: 1 , amarelo: 0 , azul: 1 , vermelho: 0 ,preto: 1, classe:0], [verde:0, amarelo: 1 , azul: 0 , vermelho: 1 , preto: 0, classe:1]] .

Saída:

ArvorePadrao $=\operatorname{arv}(\operatorname{arv}(\operatorname{arv}(\operatorname{arv}(0, v e r d e, \operatorname{arv}(n u l l, \operatorname{azul}$, null $))$, preto, $\operatorname{arv}($ null, verde, $\operatorname{arv}($ null, azul, 0$))), \operatorname{amarelo}, \operatorname{arv}(0$, 
verde, arv (null, azul, arv $(1$, preto, null)))), vermelho, $\operatorname{arv}(1$, verde, 0$))$

\subsection{Algoritmo de Poda da Árvore de Decisão Binária}

Existem duas maneiras de realizar a poda em uma árvore de decisão, a pré-poda e a pós-poda - seção $3.5, \mathrm{pg}$. 45. A pré-poda, realizada durante a construção da árvore, utiliza o mesmo conjunto de treinamento para realizar a poda. A pós-poda é realizada após a construção da árvore e utiliza dois conjuntos distintos de exemplos

1. conjunto de treinamento para construir a árvore $\mathrm{e}$

2. conjunto de teste utilizado para podar a árvore.

$\mathrm{Na}$ prática, do conjunto total de exemplos disponíveis, esta divisão deve ser feita de forma aleatória na proporção 70/30 [Mingers 89] a fim de obter resultados confiáveis.

\section{Exemplos}

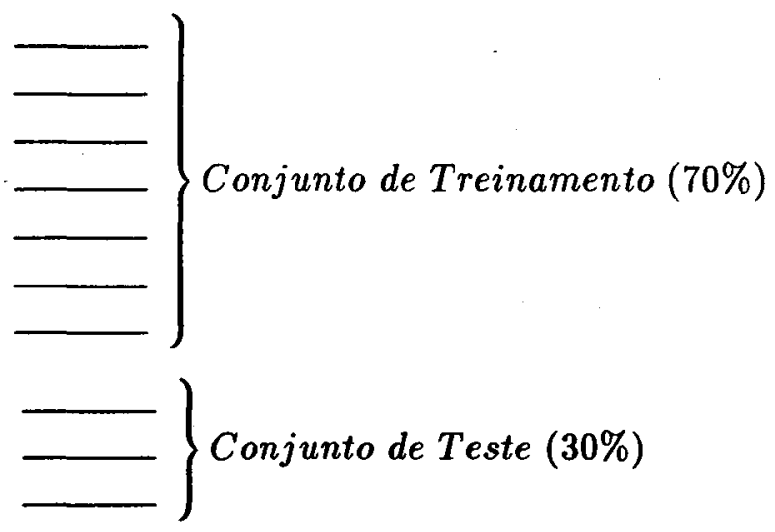

Diversos métodos de pós-poda, bem como resultados empíricos da aplicação desses métodos, são encontrados na literatura, onde é mostrado que não há uma diferença marcante nos resultados obtidos pelos diversos métodos de pós-poda propostos. Entretanto, os resultados obtidos pelos métodos de pós-poda são, em geral, superiores aos métodos de pré-poda.

A seguir é descrito o método de pós-poda implementado, que faz parte do Ambiente Experimental TDIDT para Atributos Booleanos - Figura 4.1 pg. 55 - denominado Método de Poda de Redução do Erro [Quinlan 87b]. Segue a descrição desse método, bem como a sua implementação para árvores de decisão com atributos booleanos. 


\subsubsection{Método de Poda de Redução do Erro}

O Método de Poda de Redução do Erro - MPRE - produz uma série de árvores podadas, usando o conjunto de teste diretamente, ao invés de usá-lo apenas na seleção da melhor árvore. A árvore de decisão obtida é áquela que possui o menor número de exemplos não classificados para o conjunto de teste. O MPRE necessita da árvore de decisão construída utilizando o conjunto de treinamento, bem como do conjunto de testes, para produzir a árvore podada.

Após construir a árvore de decisão utilizando o conjunto de treinamento, o conjunto de testes é introduzido na árvore de decisão original contando, em cada nó da árvore, o número de exemplos em cada classe. Esta árvore é denominada árvore estatística - Figura 4.6, pg. 78. A seguir, para toda subárvore não folha $S$ de $T$, são contados

1. o número de exemplos dos nós folhas não classificados $\left(d_{s}\right)$

2. o número de exemplos que não seriam classificados, se a subárvore $S$ em questão fosse substituída por sua melhor folha $\left(d_{p s}\right)$.

Se com a nova árvore o número de erros de classificação obtido $\left(g_{s}\right)$ é igual ou menor ao obtido com a árvore anterior, ou seja, $g_{s}=d_{s}-d_{p s} \geq 0$, e se $S$ não contiver qualquer subárvore com a mesma propriedade, $S$ é definitivamente substituída pela sua melhor folha e o processo prossegue com essa nova árvore. $O$ processo finaliza quando não for mais possível diminuir o valor do erro, ou seja, qualquer substituição de uma subárvore por uma folha aumenta o erro de classificação.

0 fato $g_{s}>0$ significa que um número maior de exemplos será classificado pela árvore de decisão se a subárvore $S$ for podada, ou seja, substituída por sua melhor folha. A poda, quando $g_{s}=0$ (ganho nulo) não incrementa a precisão da árvore, mas favorece a diminuição do tamanho da árvore.

Assim, o MPRE gera um conjunto de árvores e termina com a obtenção da árvore podada que melhor classifica, segundo este critério, o conjunto de testes. Pode ser que aconteça a situação de existirem várias subárvores com o mesmo valor de $g$. Quinlan não especifica qual subárvore escolher nesta situação. Entretanto, resultados experimentais [Mingers 89] mostram que a escolha entre essas subárvores interfere muito pouco na precisão de classificação; escolhe-se, portanto, a maior, na certeza que essa escolha irá reduzir o número de iterações necessárias para podar completamente a árvore.

Este método possui duas desvantagens: a necessidade de um conjunto de teste separado do conjunto de treinamento, e a poda indesejável de partes da árvore original que poderiam corresponder a casos especiais mais raros, eventualmente não presentes no conjunto de teste.

Como ilustração do MPRE, considere uma subárvore de uma árvore estatística binária 
de classificação - Figura 4.6. Considerando o nó I, já que o algoritmo trata a poda a partir dos nós folhas até chegar à raiz, a Figura 4.6 mostra que este nó classifica um total de 19 exemplos, sendo 15 da classe 0 e 4 da classe 1 . Se a subárvore for podada, o nó I se torna uma folha rotulada com o valor da classe com o maior número de exemplos classificados - neste caso $0-\mathrm{e}$, consequentemente, 4 dos 19 exemplos estarão sendo classificados erradamente $\left(d_{p s}\right)$.

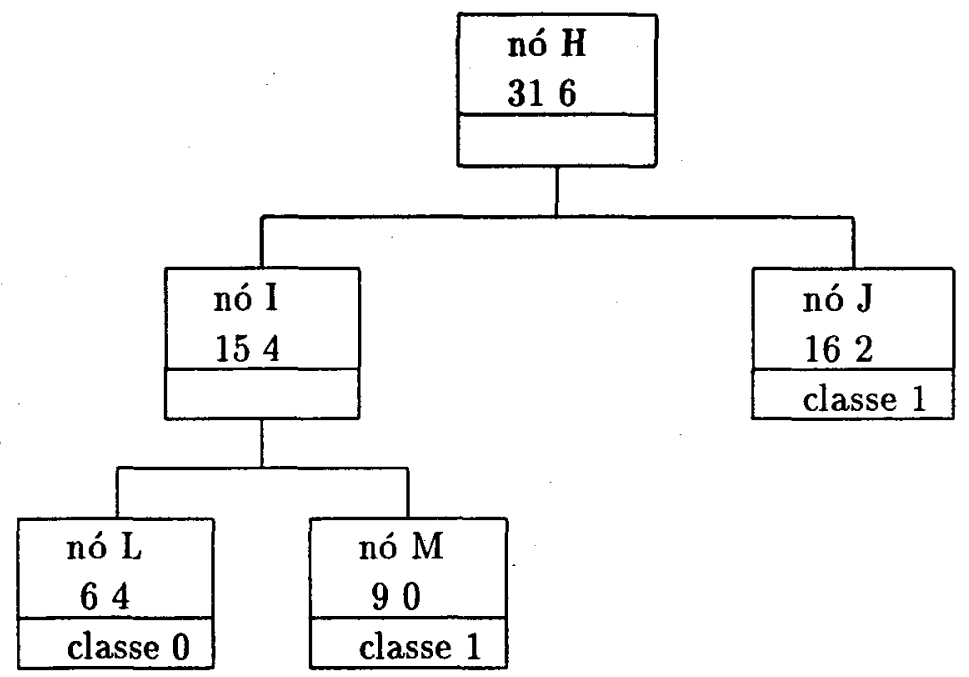

Figura 4.6: Subárvore de uma Árvore Estatística de Classificação

Somando os erros atuais de classificação dos nós folhas da subárvore, tem-se:

- para o nó L o erro de classificação é 4

- para o nó M o erro de classificação é 9

- o total de erros de classificação dos nós folhas é $d s=13$.

Assim, o erro de classificação dos nós folhas é maior que o erro de classificação do nó I se ele for podado

$$
g_{s}=d_{s}-d_{p s}=13-4=9 \geq 0
$$

Com isso, decide-se podar o nó I. Isto é feito recursivamente com todos os nós da árvore de decisão até não ser possível continuar a poda, isto é, incrementa o erro de classificação.

$\mathrm{O}$ algoritmo MPRE que realiza a poda da árvore de decisão para atributos booleanos consiste dos seguintes passos

Dados uma árvore de decisão $A$;

um conjunto de teste $E$; 
uma condição de parada $t(A)$

gerar uma árvore estatística $A E$ de acordo com $E$

If as subárvores do nó de decisão $n_{i}$ de $A E$ são nós folhas e são rotuladas com o mesmo valor da classe

Then pode as subárvores rotulando $n_{i}$ com o valor da classe

Else

para cada nó de decisão $n_{i}$ calcule o erro de classificação $S$ dos nós filhos de $n_{i}$ e o erro de classificação $S 1$ caso $n_{i}$ fosse podado e substituído por sua melhor folha

If $S 1<S$ Then pode $n_{i}$

If $A$ não foi podada Then pare.

Endif

\subsubsection{Descrição da Implementação do MPRE para Árvores de Decisão Binárias}

O algoritmo implementado que realiza a poda de uma árvore de decisão binária, utilizando o Método de Poda de Redução do Erro, faz uso da árvore de decisão criada, a partir do conjunto de treinamento, pelos algoritmos descritos nas seções 4.3 e 4.4 , pgs. 57 e 64, respectivamente, bem como do conjunto de teste.

O procedimento responsável por realizar a poda da árvore de decisão binária está ilustrado na Figura 4.7.

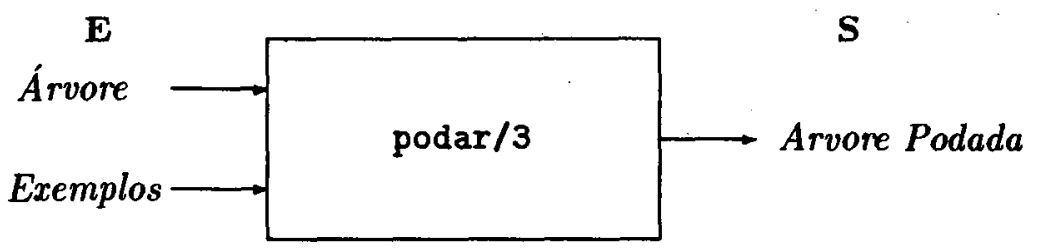

Figura 4.7: Procedimento Responșável pela Poda da Árvore de Decisão

Como já mencionado, a estrutura padrão dessa árvore de decisão é:

$$
\text { arv(SubarvEsq, MelhorAtributo,SubarvDir) }
$$

com base nessa árvore e utilizando os exemplos do conjunto de teste, a árvore estatística é criada. A estrutura que representa a árvore estatística tem a seguinte forma:

$\operatorname{arv}($ SubarvEsq/L1,MelhorAtributo/L,SubarvDir/L2) 
onde $L, L 1$ e $L 2$ são listas de dois 2 elementos (números inteiros maiores ou iguais a zero), cuja soma representa o número total de exemplos nesse nó da árvore. 0 primeiro e o segundo elemento da lista representam, respectivamente, o número de exemplos com valor da classe $=0$ e classe $=1$. A poda é realizada sobre esta árvore estatística e, quando o processo de poda termina, a árvore podada é novamente expressa com a mesma estrutura da árvore inicial.

Como ilustração da construção da árvore estatística, considere a árvore e os exemplos de teste instanciados da seguinte forma:

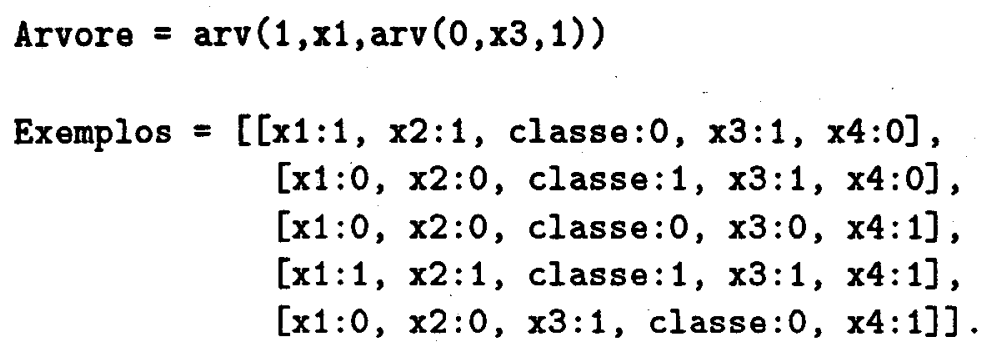

a árvore estatística gerada é representada por

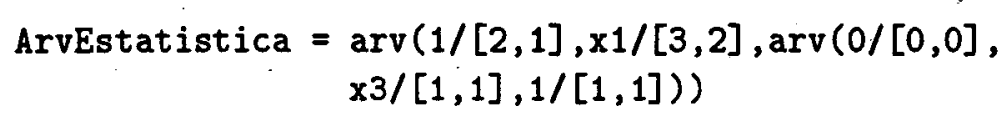

Após gerada a árvore estatística, o procedimento que realmente realiza a poda da árvore, quando ativado, pode encontrar as seguintes situações nos nós a serem podados:

1. o nó considerado é um nó folha rotulado com o valor da classe. Neste caso, não há poda e o nó permanece inalterado.

2. a subárvore esquerda e a subárvore direita de um nó são folhas e contém o mesmo valor da classe. É importante notar que isto somente acontece se a árvore já foi podada, pelo menos uma vez (no caso do algoritmo não incremental), e a classe majoritária de um nó for igual ao valor da classe do outro nó. Neste caso, a subárvore é podada e o nó é rotulado com o valor da classe em questão.

3. se as subárvores do nó são nós folhas, com valores de classe diferentes, é ativado, para o nó em questão, um procedimento que busca uma possível folha candidata. Uma folha candidata é um nó folha que contém o valor da classe que classifica os exemplos em major número no nó e o número de exemplos que não seriam classificados pelo nó, caso fosse podada a subárvore rotulando o nó folha com o valor da classe, é armazenado em uma variável $S 1$. Por exemplo, se a folha candidata fosse rotulada com classe $=0$, (suponha que a folha classifique dois exemplos da classe 0 e um da classe 1 ), estaria classificando 1 exemplo erradamente $(\mathrm{S} 1=1)$. 
Para o mesmo nó, é verificado quantos exemplos suas subárvores, que são nós folhas, estarão classificando erradamente (suponha que a subárvore esquerda esteja classificando 1 exemplo errado e a subárvore esquerda, 2 exemplos. $O$ erro de classificação total das subárvore, então, é $S=3$ ). Como o erro de classificação da folha candidata é menor do que o erro de classificação de suas subárvores, então a subárvore é podada. Caso contrário a subárvore permanece inalterada.

Como o algoritmo é recursivo, o critério de parada consiste em fazer uma comparação entre as árvores de decisão anterior e posterior à chamada do procedimento. Se as duas árvores são árvores diferentes, significa que houve poda, então é necessário ativar o procedimento recursivamente a fim de verificar se uma nova poda é necessária. Se este não for o caso - as duas subárvores são iguais -, a árvore permanece a mesma e o procedimento finaliza.

\subsubsection{Exemplos de Execução}

Nesta seção, são apresentados alguns exemplos de execução, para diversas árvores de decisão, do algoritmo implementado. Em cada caso é mostrada a instanciação das variáveis de entrada e saída correspondentes à interrogação

?- podar(Arvore, ExemplosTeste, ArvorePodada).

\section{Exemplo 4.5.3.1}

Entrada:

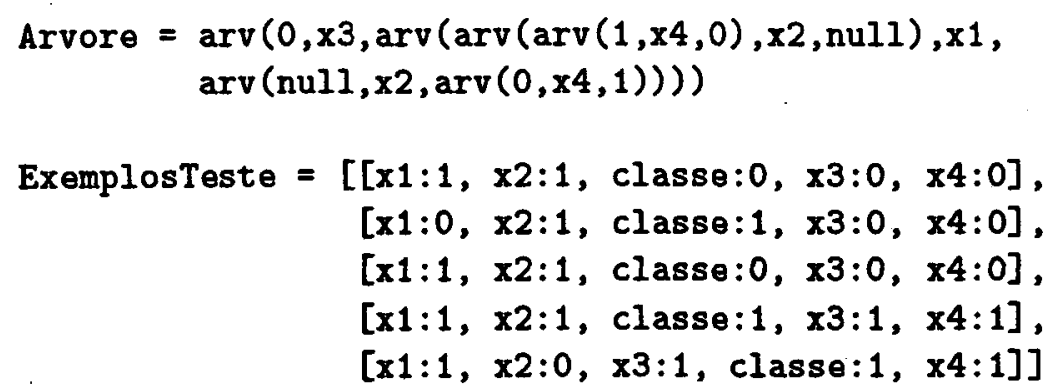

Saída:

ArvorePodada $=\operatorname{arv}(0, \times 3,1)$ 
neste caso a árvore foi podada e é representada por um simples nó de decisão - atributo x3 - que divide os exemplos em classes iguais.

\section{Exemplo 4.5.3.2}

Entrada:

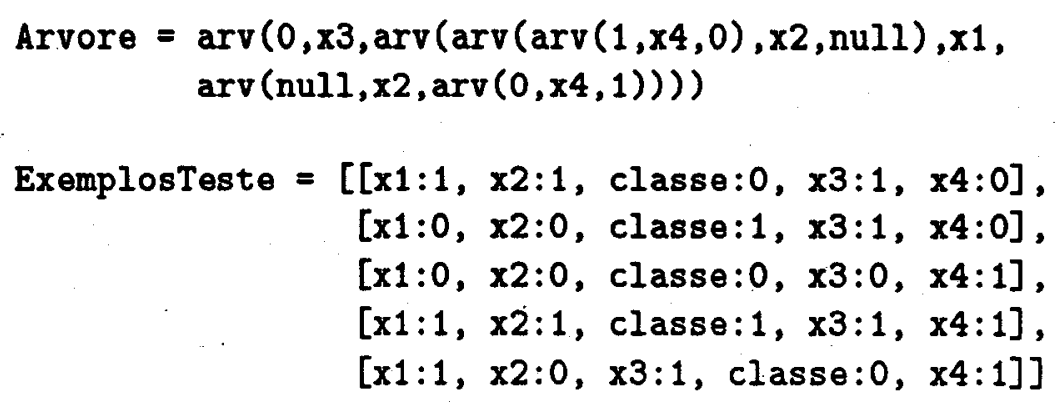

Saída:

ArvorePodada $=\operatorname{arv}(0, x 3, \operatorname{arv}(1, x 1, \operatorname{arv}(\operatorname{null}, \times 2, \operatorname{arv}(0, x 4,1))))$

A árvore é podada mas mantém algumas folhas rotuladas null.

\subsection{Considerações Finais}

Neste Capítulo foram apresentados os algoritmos principais pertencentes ao Ambiente Experimental TDIDT para Atributos Booleanos. 0 ambiente implementado é composto, basicamente, por dois algoritmos que constrõem a árvore de decisão binária, no modo incremental e não incremental, e um algoritmo que realiza a poda das árvores de decisão construídas.

O fato dos algoritmos somente manipularem atributos booleanos, é justificado pelo fato de que a única informação que se tem em relação aos atributos é que eles estão presentes ou ausentes no conjunto de treinamento. Outro motivo é que estes algoritmos serão utilizados no aprendizado construtivo de máquina. Aprendizado construtivo de máquina amplia o espaço de descrições de instâncias através de combinações entre os atributos na tentativa de torná-los mais relevantes na indução de um conceito. Está sendo desenvolvido no ICMSC-USP um ambiente experimental de construção automática de features utilizando o domínio de funções booleanas. Este ambiente experimental de construção automática de features é o assunto do próximo Capítulo. 


\section{Capítulo 5}

\section{Ambiente Experimental Construtivo para Atributos Booleanos}

Em uma linguagem de descrição de atributos é importante determinar quais atributos são significativos à tarefa do aprendizado. Muitas vezes, os atributos iniciais usados para descrever os exemplos não são diretamente relevantes para descrever um conceito mas, quando combinados, convenientemente, geram novos atributos, chamados features $^{1}$, podendo tornar-se altamente representativos para expressar um conceito. Para tentar superar a limitação de uma linguagem baseada em atributos, uma alternativa que está sendo bastante utilizada é a Indução Construtiva de Features que muda o espaço de descrições de instâncias. 0 processo de construção de features quando inserido no contexto de um sistema de aprendizado indutivo é conhecido como aprendizado construtivo ou indução construtiva e pode ser direcionado e controlado pelo usuário ou conduzido automaticamente pelo sistema.

Neste Capítulo, é descrito o Ambiente Experimental Construtivo para Atributos Booleanos que consiste de diversos algoritmos implementados para a construção automática de features. A descrição desses algoritmos, bem como os exemplos da sequência de construção de árvores usando diversos bias foram retirados de [Nicoletti 94].

\subsection{Indução Construtiva de Features}

A indução construtiva de features pode ser definida como [Matheus 90]

\footnotetext{
${ }^{1} \mathrm{Os}_{\mathrm{s}}$ atributos iniciais são denominados de features primitivas.
} 
a aplicação de operadores construtivos ${ }^{2}$ à features já existentes, resultando na definição de uma ou mais features.

Um operador construtivo é uma função que associa uma n-upla de features a uma nova feature. As features às quais o operador construtivo é aplicado são chamadas de operandos construtivos. Este é um processo iterativo, uma vez que as novas features podem, também, ser operandos construtivos. Devido a esta combinação de features primitivas e novas features, o espaço de busca pode ser infinito, sendo necessário a escolha de heurísticas poderosas que viabilizam a determinação de um conjunto de features apropriado. Mas, é importante lembrar que as features obtidas contém informações relacionadas às features primitivas que a compõem.

O seguinte exemplo, citado frequentemente na literatura de $\mathrm{AM}$, ilustra bem o processo de construção de features.

Suponha que seja necessário encontrar as descrições que identificam um robô amigo e inimigo, respectivamente, em função de um conjunto de características, dado um conjunto de exemplos expressos em função dessas características e de seus valores, como mostrado na Tabela 5.1.

\begin{tabular}{|c|c|c|c|c|c|}
\hline \multicolumn{7}{|c|}{ Atributo-valor } & classe \\
\hline sorri & segura & tem_gravata & cabeça & corpo & \\
\hline sim & balão & sim & quadrada & quadrada & amigo \\
sim & bandeira & sim & triangular & triangular & amigo \\
$\operatorname{sim}$ & espada & sim & redonda & triangular & inimigo \\
sim & espada & não & quadrada & triangular & inimigo \\
não & espada & não & triangular & redonda & inimigo \\
não & bandeira & não & redonda & triangular & inimigo \\
\hline
\end{tabular}

Tabela 5.1: Exemplos de Robôs Amigos e Robôs Inimigos

O algoritmo da família TDIDT, utilizando a entropia como função de avaliação, induz a árvore de decisão mostrada na Figura 5.1.

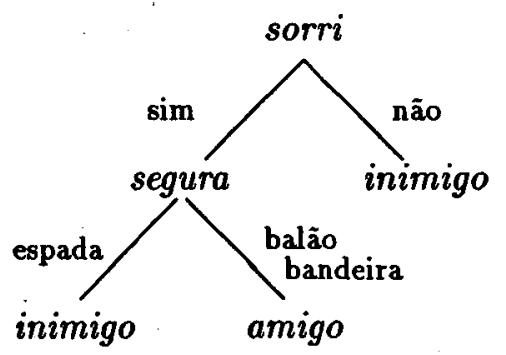

Figura 5.1: Árvore de Decisão que Classifica um Robô em amigo ou inimigo

No caso do exemplo considerado, os atributos tem_gravata, cabeça e corpo são irrelevantes na indução daquela árvore de decisão. Entretanto, se a linguagem de descrição

\footnotetext{
${ }^{2}$ Operadores usados para compor features.
} 
for estendida, combinando os atributos primitivos cabeça e corpo através do operador = em um novo atributo, mesma_forma, o conjunto de exemplos considerando esse novo atributo passa a ser aquele mostrado na Tabela 5.2.

\begin{tabular}{|c|c|c|c|c|c|c|}
\hline \multicolumn{6}{|c|}{ Atributo-valor } & \multirow[t]{2}{*}{ classe } \\
\hline sorri & segura & tem_gravata & cabeça & corpo & mesma_forma & \\
\hline $\operatorname{sim}$ & balão & sim & quadrada & quadrada & $\mathbf{v}$ & amigo \\
\hline $\operatorname{sim}$ & bandeira & $\operatorname{sim}$ & triangular & triangular & $\mathbf{v}$ & amigo \\
\hline $\operatorname{sim}$ & espada & $\operatorname{sim}$ & redonda & triangular & f & inimigo \\
\hline $\operatorname{sim}$ & espada & não & quadrada & triangular & $\mathbf{f}$ & inimigo \\
\hline não & espada & não & triangular & redonda & f & inimigo \\
\hline não & bandeira & não & redonda & triangular & f & inimigo \\
\hline
\end{tabular}

Tabela 5.2: Exemplos de Robôs Amigos e Robôs Inimigos Estendidos cóm o Novo Atributo mesma_forma

Para este último conjunto de exemplos, a árvore de decisão correspondente está representada na Figura 5.2. $\mathrm{Na}$ árvore de decisão, pode ser visto que o novo atributo criado - mesma forma - é mais informativo que os primitivos.

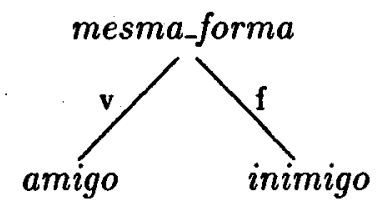

Figura 5.2: Árvore de Decisão que Classifica um Robô em amigo ou inimigo Usando a Feature mesma_forma

Uma questão fundamental no processo de construção de features está relacionado à escolha de qual operador construtivo utilizar, quando existir mais de um, e determinar a quais operandos este operador será aplicado. Este processo é computacionalmente caro, mesmo utilizando heurísticas poderosas, pois o conjunto de features é proporcional ao número de possíveis operadores construtivos potenciais. Neste trabalho é usado o operador construtivo and.

\subsection{Construção Automática de Features para Atributos Booleanos}

Como visto anteriormente, quando os atributos dos exemplos de treinamento são do tipo booleano, a árvore de decisão obtida é uma árvore de decisão booleana, que representa uma função booleana. Cada ramo do nó raiz à uma folha rotulada com valor 1 , define um termo da função. A função representada por tal árvore é a disjunção de todos os 
termos assim obtidos, estando consequentemente, na Forma Normal Disjuntiva - FND. Cada variável da função booleana pode ser tratada como um atributo booleano.

Seja, por exemplo, a função booleana $f\left(x_{1}, x_{2}, x_{3}, x_{4}\right)=\sum \min (1,3,5,7)^{3}$ representada pela árvore de decisão da Figura 5.3.

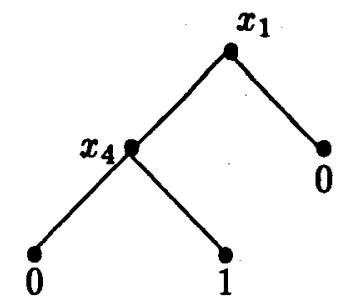

Figura 5.3: Árvore de Decisão da Função $f\left(x_{1}, x_{2}, x_{3}, x_{4}\right)=\sum \min (1,3,5,7)$

Convenciona-se que o ramo de um nó que sai à sua esquerda está associado ao valor 0 do atributo que aquele nó representa, e o que sai à sua direita, ao valor 1. Estabelecida a convenção, a árvore da Figura 5.3 é lida como

- quando $x_{1}=0$ e $x_{4}=0$ o valor da função é 0

- quando $x_{1}=0$ e $x_{4}=1$ o valor da função é 1

- quando $x_{1}=1$ o valor da função é 0

O aprendizado de uma função booleana a partir de sua tabela-verdade parcial consiste em gerar uma árvore de decisão que a represente.

A expressão da função pode ser reduzida através da construção da feature que compõe os atributos $x_{1}$ e $x_{4}$ (estão num ramo de comprimento $\geq 2$ cuja folha é 1), e a árvore passa, então, a ser aquela mostrada na Figura 5.4.

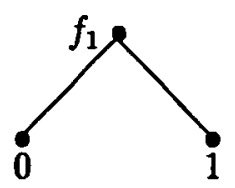

Figura 5.4: Árvore de Decisão da Função $f\left(x_{1}, x_{2}, x_{3}, x_{4}\right)=\sum \min (1,3,5,7)$ com a Feature $f_{1}=\operatorname{and}\left(x_{1}=0, x_{4}=1\right)$

No caso geral, a eleição dos operandos do operador construtivo vai depender do bias de seleção de operandos escolhidos. A abordagem de construção de features tratada neste

\footnotetext{
${ }^{3}$ Esta notação é usada para representar uma função na Forma Normal Disjuntiva. No exemplo, a função $f\left(x_{1}, x_{2}, x_{3}, x_{4}\right):\{0,1\}^{4} \rightarrow\{0,1\}$ assume valor 1 para os seguintes elementos do domínio: $\langle 0,0,0,1\rangle,\langle 0,0,1,1\rangle,\langle 0,1,0,1>\mathrm{e}<0,1,1,1\rangle$, ou seja $f\left(x_{1}, x_{2}, x_{3}, x_{4}\right)=\overline{x_{1} x_{2} x_{3}} x_{4} \vee \overline{x_{1} x_{2}} x_{3} x_{4} \vee$ $\overline{x_{1}} x_{2} \overline{x_{3}} x_{4} \vee \overline{x_{1}} x_{2} x_{3} x_{4}$.
} 
trabalho utilizando três bias diferentes, deixa o algoritmo de aprendizado adaptativamente definir e ampliar suas próprias features - bias dinâmico - durante o processo de aprendizado.

\subsection{Descrição do Ambiente}

Uma visão geral do Ambiente Experimental Construtivo para funções booleanas implementado, é ilustrado na Figura 5.5, onde ADF refere-se a Árvore de Decisão com Features.

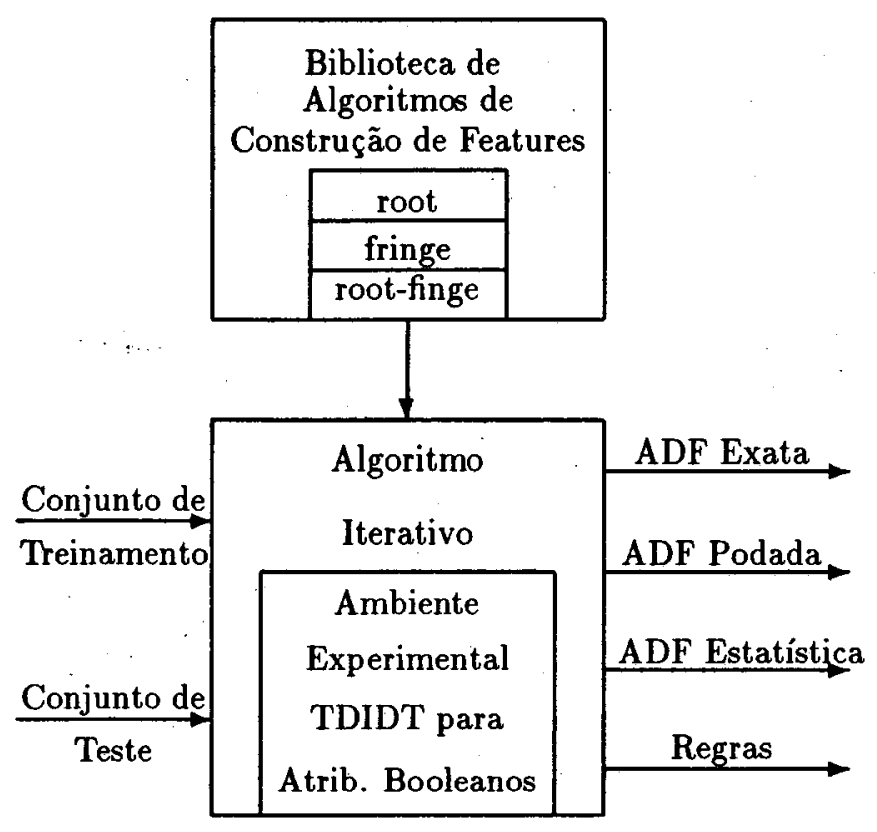

Figura 5.5: Visão Geral do Ambiente Experimental Construtivo

Neste ambiente, o Ambiente Experimental TDIDT para Atributos Booleanos é o descrito no Capítulo anterior. Ele é o responsável pela criação (no modo incremental e não incremental) e poda de árvores de decisão construídas a partir de um conjunto de treinamento com atributos booleanos.

Os algoritmos responsáveis pela construção de features constituem o módulo Biblioteca de Algoritmos de Construção de Features. Neste módulo, estão implementados as seguintes estratégias de construção de features: o bias root [Matheus 90], o bias fringe [Pagallo 90] e o bias root_fringe [Nicoletti 92]. Como já mencionado, estas estratégias são, na realidade, biases disponíveis para a seleção dos operandos do operador construtivo and, que irão compor as features.

Deve ser observado que as estratégias desenvolvidas para aprendizado de funções bo- 
oleanas podem, eventualmente, ser aplicadas a outros domínios. Especificamente, elas podem ser aplicadas em situações nas quais a expressão do exemplo tem a informação da ausência ou presença de determinado atributo. $\mathbf{O}$ conjunto de tais atributos pode ser isolado, métodos construtivos de construção de features booleanas podem ser aplicados e as features assim construídas, incorporadas às expressões dos exemplos e ao conjunto de atributos. Neste caso, o algoritmo de construção da árvore de decisão, para qualquer tipo de valores de atributos, que faz parte do Ambiente Experimental TDIDT, pode ser utilizado para induzir a árvore de decisão. Se alguma feature construída isoladamente para os atributos booleanos comparecer nesta árvore, pode-se concluir que a linguagem de descrição dos exemplos foi estendida.

No processo de construção de features, os três biases implementados consideram apenas os ramos positivos - classe 1 - da árvore de decisão. Em cada passo da iteração, após a construção da árvore, a escolha das features é realizada da seguinte forma

- bias root seleciona as duas primeiras features de cada ramo a partir da raiz. Compõe a cada passo features que têm os menores valores de entropia, são features que mais contribuem para a classificação.

- o bias fringe seleciona as duas últimas features de cada ramo, a partir das folhas. Compõe a cada passo features com os maiores valores de entropia, são features que menos contribuem para a classificação.

- o bias root_fringe seleciona a primeira e a última feature de cada ramo. Compõe a cada passo uma feature com um baixo valor de entropia, com uma outra com alto valor de entropia.

Para uma mesma árvore de decisão, a atuação de cada um destes biases é ilustrado na Figura 5.6.

\subsection{Descrição dos Algoritmos}

0 processo de construção de features envolve a construção da árvore de decisão. Primeiramente, é apresentado o algoritmo que constrói iterativamente a árvore de decisão usando features [Pagallo 90] e logo após os algoritmos que implementam os três biases de construção de features.

Dados um conjunto de features primitivas $V$ e um conjunto de exemplos $E$, expressos em termos de $V$, o algoritmo começa construindo uma árvore de decisão $T$, cujos nós são elementos de $V$. Uma vez construída a árvore, um procedimento iterativo que implementa um dos três biases de construção de features é invocado. Este procedimento pode ser visualizado na Figura 5.7. 


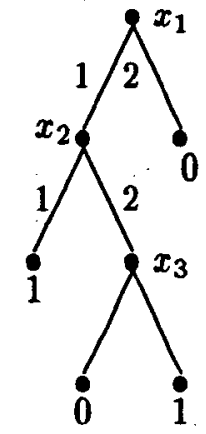

root

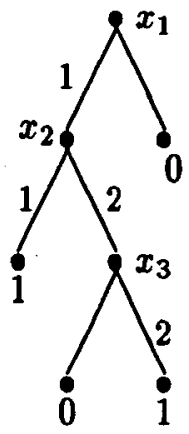

fringe

1) and $\left(x_{1}=0, x_{2}=1\right)$

1) $\operatorname{and}\left(x_{1}=0, x_{2}=0\right)$

2) and $\left(x_{1}=0, x_{2}=0\right)$

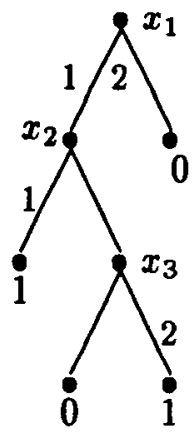

root-fringe

2) and $\left(x_{1}=0, x_{3}=1\right)$

Figura 5.6: Biases para a Construção de Features para Atributos Booleanos

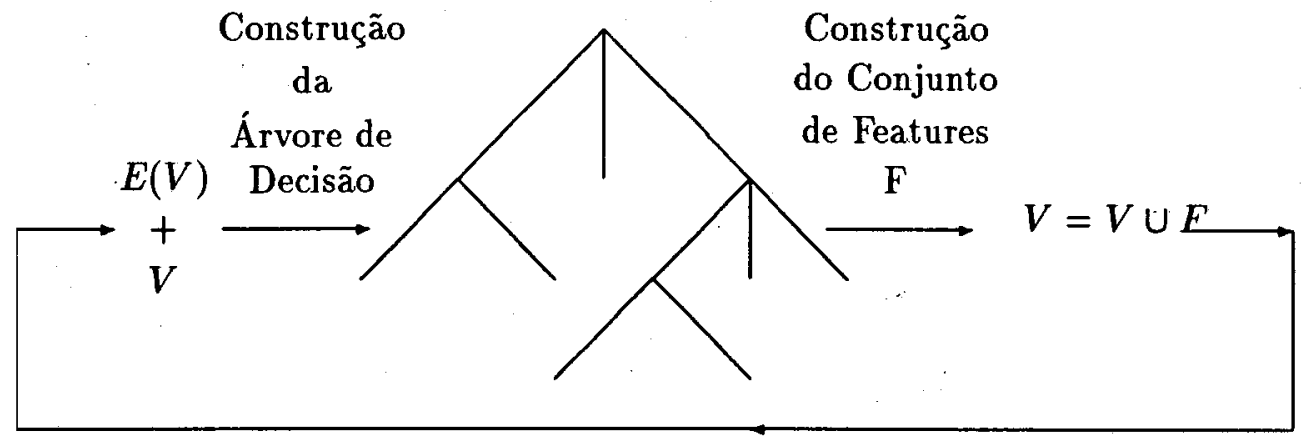

Figura 5.7: Construção de Árvore de Decisão com Construção Automática de Features

\subsubsection{Algoritmo Iterativo de Construção de Árvore de Decisão com Construção Automática de Features}

$\{V$ : conjunto de features primitivas

$E$ : conjunto de exemplos expressos em função de $V$

begin

input : $V, E$

$k \leftarrow 0$ contador do passo de iteração\}

$V_{1} \leftarrow V$

repeat

$k \leftarrow k+1$

construir a árvore de decisão $T_{k}$, usando $E$ expresso em função de $V_{k}$ conjunto_features $\leftarrow$ encontra_feature_n $\{n=1,2,3\}$ 


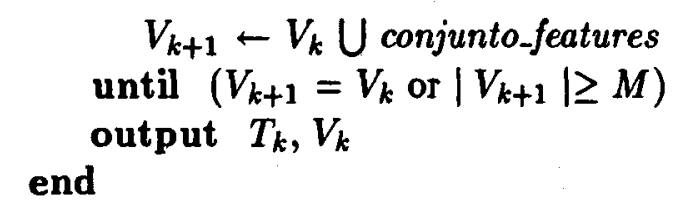

O processo de construção das features irá - a cada passo da iteração - compor, através de conjunção, dois nós da árvore. A escolha de quais dos nós é definida pelo bias utilizado. Os procedimentos que correspondem à construção das features são

- encontra_feature_1, que implementa o bias root

- encontra_feature_2, que implementa o bias fringe

- encontra_feature_3, que implementa o bias root-fringe

O procedimento encontra_feature_1 constrói, no máximo, 4 features em cada passo da iteração, uma vez que este bias sempre elege como operandos do operador and a raiz da árvore e um filho seu, desde que estejam num ramo com uma folha rotulada 1.

Cada um dos dois procedimentos: encontra_feature_2 e encontra_feature_3 constrói uma feature para cada folha com rótulo 1 da árvore, desde que tal folha se encontre a uma profundidade, na árvore, maior ou igual a 2. Assim, serão construídas tantas features quantas forem tais folhas.

Obtidas as novas features, o conjunto de exemplos é reescrito, ampliando cada exemplo com a introdução das novas features e de seus respectivos valores. $O$ conjunto de features é também atualizado, de maneira a incorporar as features geradas. Com esses novos conjuntos - de exemplos e atributos - é gerada uma nova árvore de decisão e o processo se repete. $O$ processo termina quando não são geradas novas features ou, então, quando o número de features geradas atinge um limite pré-estabelecido $-M$.

A seguir são apresentados os três procedimentos de construção de features implementados, todos eles acompanhados de um exemplo - extraídos de [Nicoletti 94] - que ilustram o aprendizado de uma mesma função booleana. Para os três procedimentos

- $T$ representa a árvore de decisão construída a partir do conjunto de exemplos, expressos em função das features primitivas e das features obtidas até então, por chamadas anteriores à encontrafeature $i(i=1,2,3)$

- nós de $T$ são representados pelas variáveis: $x_{1}, \ldots, x_{n}$

- a função a ser aprendida é dada por

$$
f\left(x_{1}, x_{2}, x_{3}\right)=\sum \min (0,1,2,5)
$$

ou seja,

$$
f\left(x_{1}, x_{2}, x_{3}\right)=\overline{x_{1} x_{2} x_{3}} \vee \overline{x_{1} x_{2}} x_{3} \vee \overline{x_{1}} x_{2} \overline{x_{3}} \vee x_{1} \overline{x_{2}} x_{3}
$$




\subsubsection{Algoritmo Root}

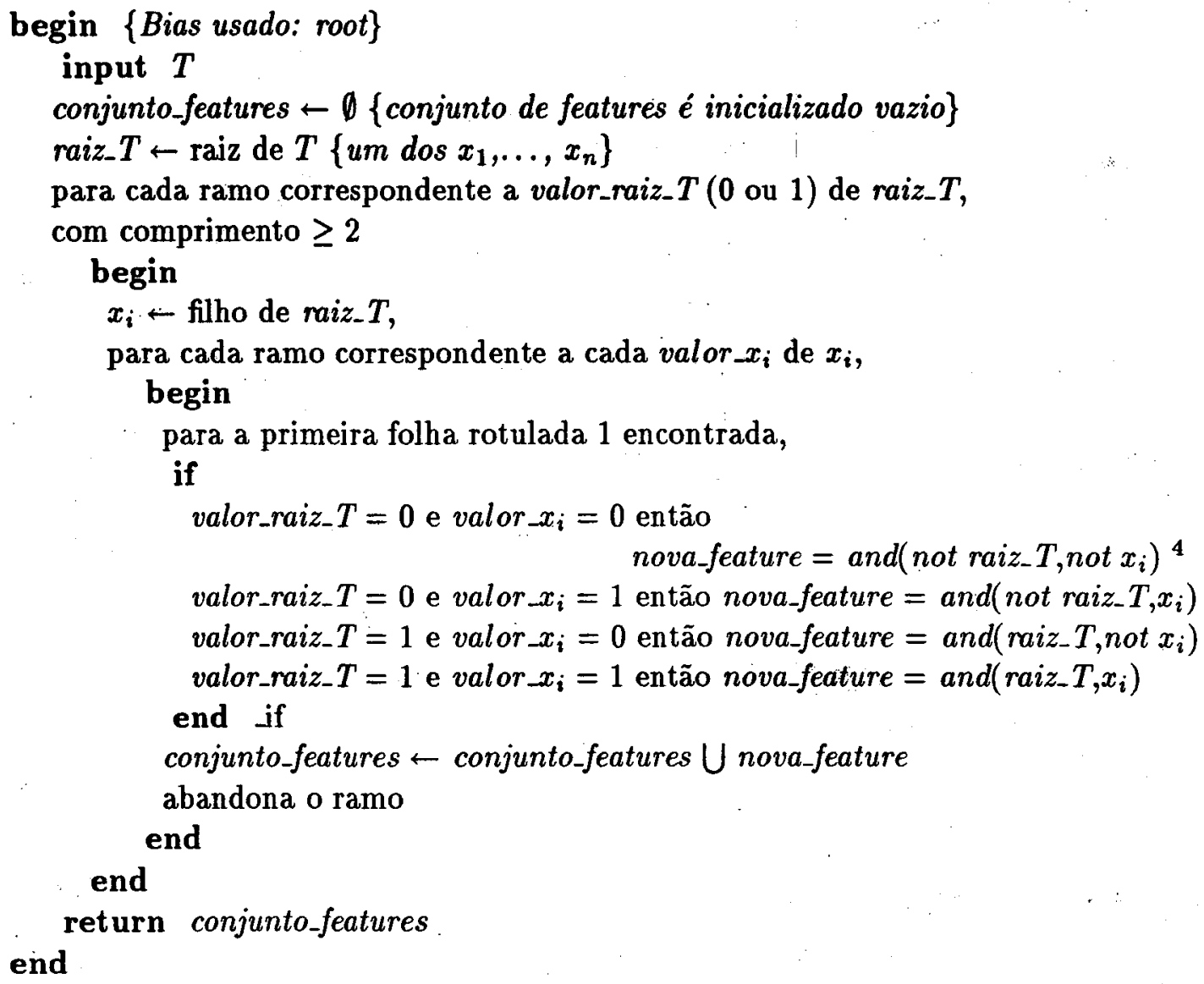

Seqüência de Construção de Árvores usando o Bias Root

\footnotetext{
${ }^{4}$ Notação equivalente a and $\left(\operatorname{raiz} T=0, x_{i}=0\right)$.
} 


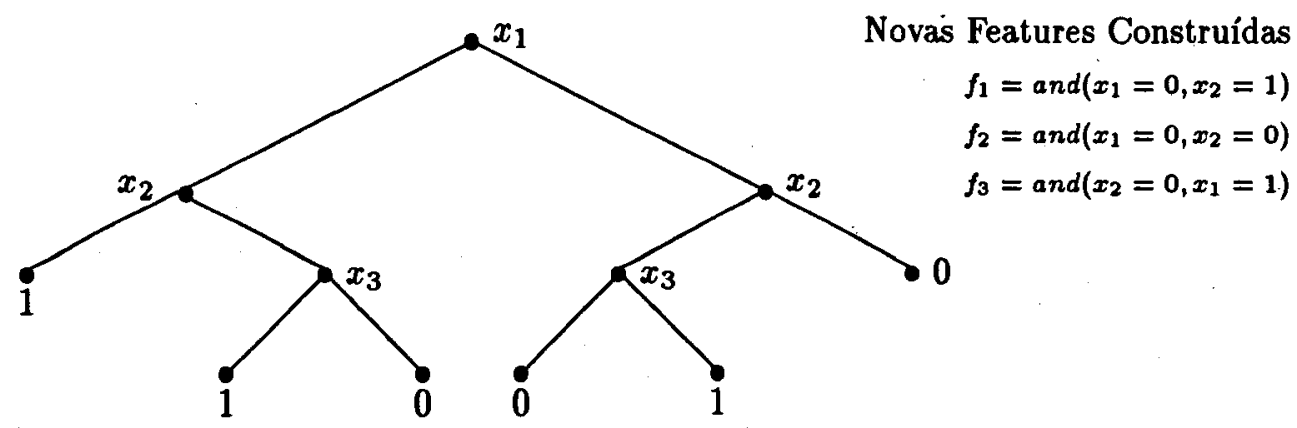

Figura 5.8: Root - Primeira Iteração

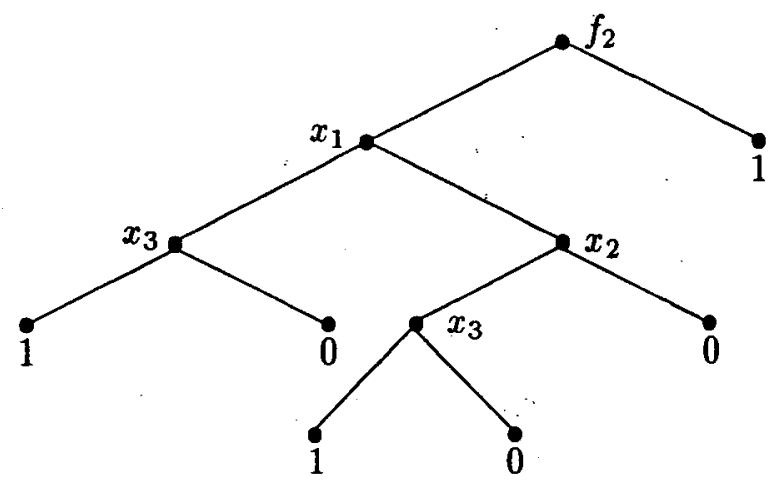

Novas Features Construídas

$f_{5}=\operatorname{and}\left(f_{2}=0, x_{1}=0\right)$

$f_{4}=\operatorname{and}\left(f_{2}=0, x_{1}=1\right)$

Figura 5.9: Root - Segunda Iteração

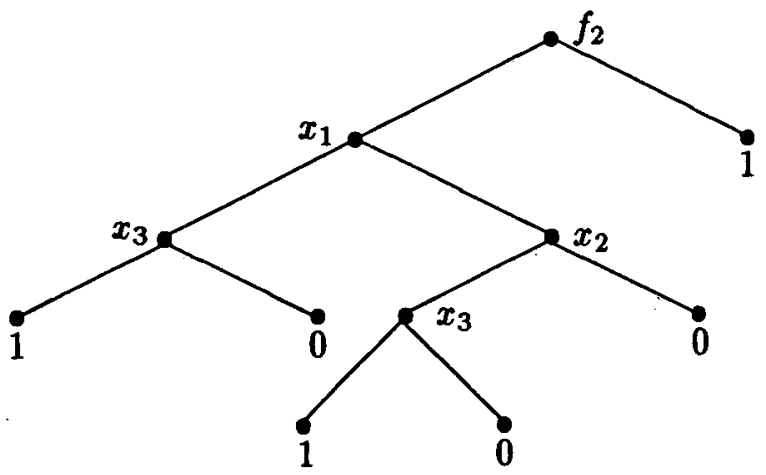

Novas Features Construídas: nenhuma (Constrói as mesmas da iteraçāo anterior)

Figura 5.10: Root - Terceira e Última Iteração 


\subsubsection{Algoritmo Fringe}

begin \{Bias usado: fringe\}

input $T$

conjunto-features $\leftarrow$ \{conjunto de features é inicializado vazio\}

raiz_$T \leftarrow$ raiz de $T\left\{u m\right.$ dos $\left.x_{1}, \ldots, x_{n}\right\}$

para cada folha rotulada 1 , com profundidade maior ou igual a 2 ,

begin

$x_{i} \leftarrow$ pai de folha; $x_{j} \leftarrow$ avộ de folha;

sejam valor $x_{i}$ e valor $\_x_{j}$ os valores dos ramos que conduzem à folha

if

valor $x_{i}=0$ e valor $x_{j}=0$ então nova-feature $=\operatorname{and}\left(\right.$ not $x_{i}$, not $\left.x_{j}\right)$

valor $x_{i}=0$ e valor $x_{j}=1$ então nova_feature $=$ and $\left(\right.$ not $\left.x_{i}, x_{j}\right)$

valor $x_{i}=1$ e valor $x_{j}=0$ então nova_feature $=$ and $\left(x_{i}\right.$, not $\left.x_{j}\right)$

valor $\_x_{i}=1$ e valor_- $x_{j}=1$ então nova_feature $=\operatorname{and}\left(x_{i}, x_{j}\right)$

endif

conjunto_features $\leftarrow$ conjunto_features $\bigcup$ nova_feature

return conjunto_features

end

Sequência de Construção de Árvores usando o Bias Fringe

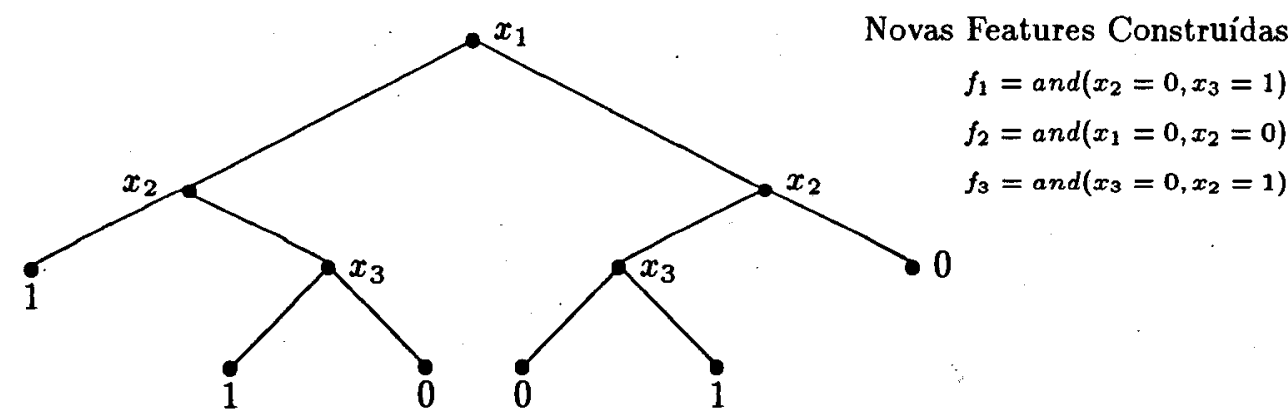

Figura 5.11: Fringe - Primeira Iteração 


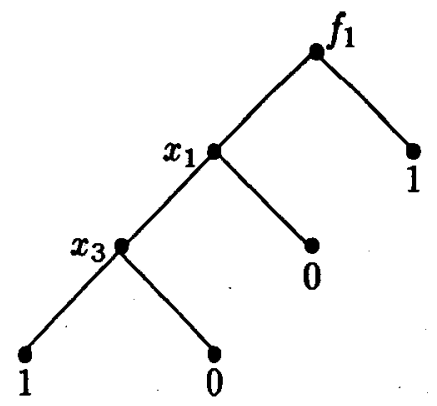

Novas Features Construídas

$f_{4}=\operatorname{and}\left(x_{1}=0, x_{3}=0\right)$

Figura 5.12: Fringe - Segunda Iteração

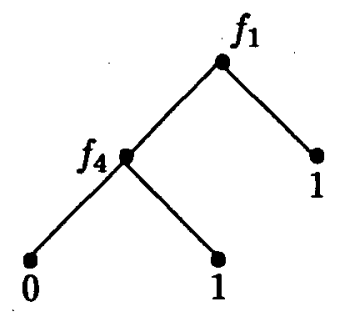

Novas Features Construídas

$f_{5}=\operatorname{and}\left(f_{1}=0, f_{4}=1\right)$

Figura 5.13: Fringe - Terceira Iteração 


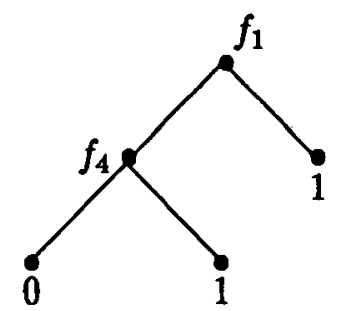

Novas Features Construídas: nenhuma

(Constrói as mesmas da iteração anterior)

Figura 5.14: Fringe - Quarta e Última Iteração

\subsubsection{Algoritmo Root-Fringe}

begin $\{$ Bias usado: root-fringe $\}$

input $T$

conjunto_features $\leftarrow \emptyset$ \{conjunto de features é inicializado vazio $\}$

raiz_ $T \leftarrow$ raiz de $T\left\{\right.$ um dos $\left.x_{1}, \ldots, x_{n}\right\}$

para cada ramo correspondente a cada valor_raiz_ $T$ ( 0 ou 1$)$ de raiz_ $T$, para cada folha rotulada 1 , com profundidade major ou igual a 2 ,

begin

seja $x_{i}$ o nó pai dessa folha, e valor $\_x_{i}$ o ramo que chega em folha,

if

valor_raiz_ $T=0$ e valor_- $x_{i}=0$ então

nova_feature $=$ and $\left(\right.$ not raiz $_{-} T$, not $\left.x_{i}\right)$

valor_raiz_ $T=0$ e valor_ $x_{i}=1$ então nova_feature $=\operatorname{and}\left(\right.$ not raiz_ $\left.T, x_{i}\right)$

valor_raiz_ $T=1$ e valor_$x_{i}=0$ então nova_feature $=$ änd(raiz_T,not $\left.x_{i}\right)$

valor_raiz_ $T=1$ e valor_ $x_{i}=1$ então nova_feature $=\operatorname{and}\left(\operatorname{raiz} T, x_{i}\right)$ endif

conjunto_features $\leftarrow$ conjunto_features $\bigcup$ nova_feature

end

end

return conjunto_features

Sequência de Construção de Árvores usando o Bias Root_Fringe 


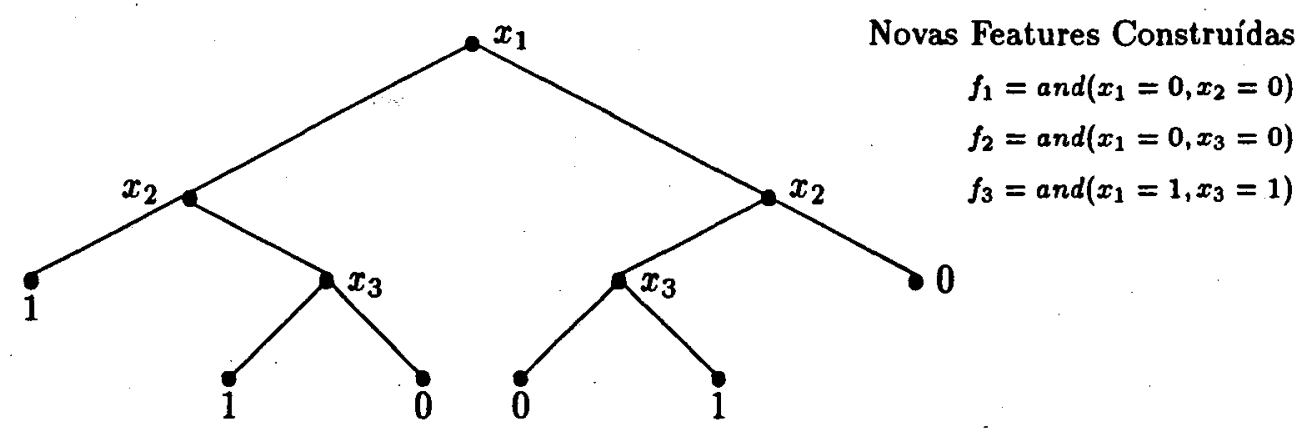

Figura 5.15: Root-Fringe - Primeira Iteração

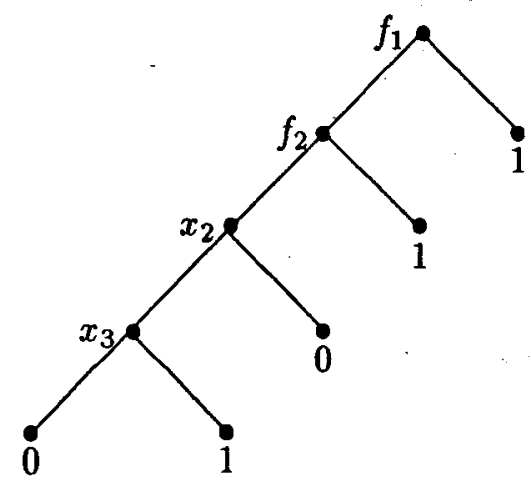

Novas Features Construidas

$f_{4}=\operatorname{and}\left(f_{1}=0, f_{2}=1\right)$

$f_{5}=\operatorname{and}\left(f_{1}=0, x_{3}=1\right)$

Figura 5.16: Root-Fringe - Śegunda Iteração

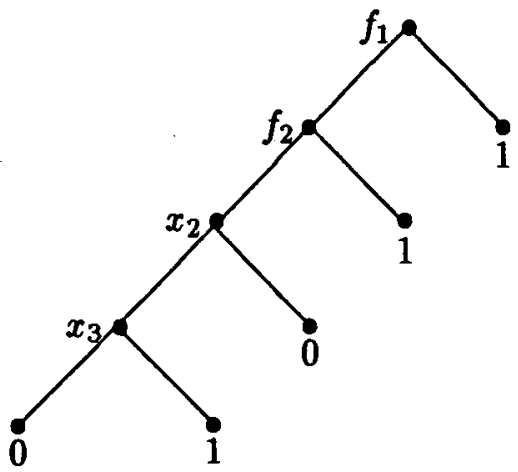

Novas Features Construidas: nenhuma

(Constrói as mesmas da iteração anterior)

Figura 5.17: Root-Fringe - Terceira e Última Iteração 


\subsubsection{Exemplos de Execução}

0 procedimento correspondente à encontre_feature_n $(\mathbf{n}=1,2,3)$, do algoritmo iterativo - seção 5.4.1, pg. 89 - onde 1 corresponde ao bias root, 2 ao fringe e 3 ao root_fringe, foi implementado através do procedimento

$$
\text { crie_features(Algoritmo, Arvore, ListaFeatures) }
$$

onde

- Algoritmo deve estar instanciado com os átomos root, fringe e rootfringe, respectivamente

- Arvore é a árvore de decisão construída com o conjunto corrente de exemplos e atributos

- ListaFeatures é a lista de novas features encontrada nessa iteração

Os exemplos a seguir mostram a atuação do algoritmo iterativo para cada um dos três biases implementado usando o mesmo conjunto de exemplos. 0 critério de parada do algoritmo iterativo é a condição $V_{k+1}=V_{k}$ - seção 5.4.1.

Em cada caso é mostrado

- Número de iterações realizadas

- Árvore final construída

- Conjunto final de exemplos

- Conjunto final de atributos

- Features construídas

O conjunto de exemplos e conjunto de atributos iniciais considerados são

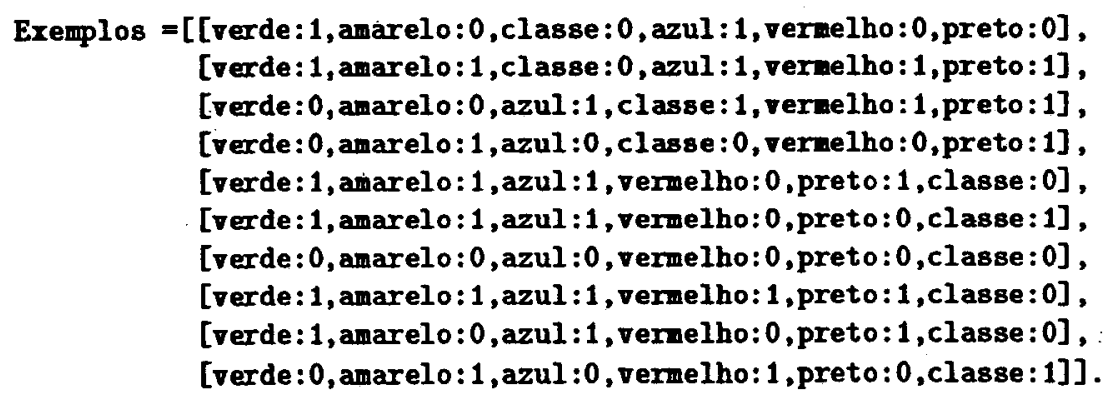




$$
\text { Atributos }=[\text { verde, amarelo, azul, vermelho, preto }]
$$

a árvore de decisão criada para os três biases, na primeira iteração do algoritmo iterativo, pelo procedimento arvore_bin/4 é

$$
\begin{aligned}
& \text { Arvore }=\operatorname{arv}(\operatorname{arv}(0, \operatorname{amarelo}, \operatorname{arv}(1, \operatorname{preto}, 0)), \text { vermelho, } \operatorname{arv}(1, \text { verde }, 0)) \\
& \text { Flag }=\operatorname{exata}
\end{aligned}
$$

que representa a árvore de decisão mostrada na Figura 5.18.

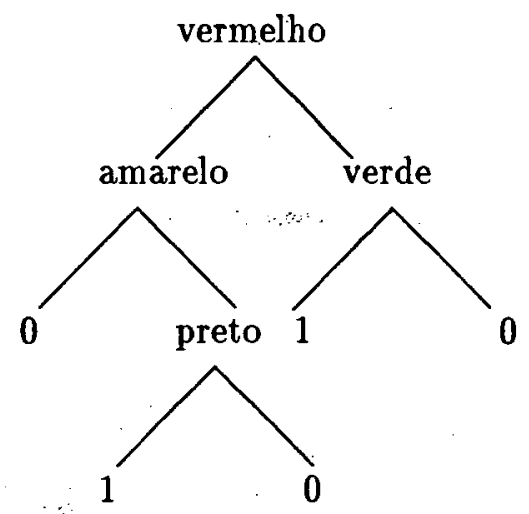

Figura 5.18: Árvore de Decisão Inicial

Seguem os resultados obtidos para cada um dos algoritmos - root, fringe e rootfringe.

\section{Exemplo 5.4.5.1 Root}

No de Iterações: 3

Árvore Final com Features:

$\operatorname{arv}(\operatorname{arv}(\operatorname{arv}(0, \operatorname{amarelo}, \operatorname{arv}(1$, preto, 0$))$, vermelho, 0$), f 2,1)$

que representa a árvore de decisão mostrada na Figura 5.19.

Exemplos Finais:

$[[f 3: 1, f 1: 0, f 2: 0$, verde $: 1$, amarelo: 0, classe $: 0$, azul $: 1$, vermelho: 0 , preto $: 0]$, $[f 3: 0, f 1: 0, f 2: 0$, verde: 1 , amarelo: 1, classe $: 0$, azul $: 1$, vermelho: 1 , preto: 1$]$,

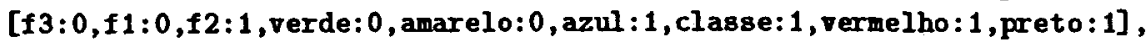
$[f 3: 1, f 1: 1, f 2: 0$, verde $: 0$, amarelo: 1 , azul $: 0$, classe $: 0$, vermelho: 0, preto: 1$]$, $[f 3: 1, f 1: 1, f 2: 0$, verde: 1 , amarelo: 1 , azul $: 1$, vermelho: 0 ,pret $0: 1$, classe $: 0]$, $[f 3: 1, f 1: 1, f 2: 0$, verde: 1 , amarelo: 1 , azul $: 1$, vermelho: 0, preto $0: 0$, classe $: 1]$, 


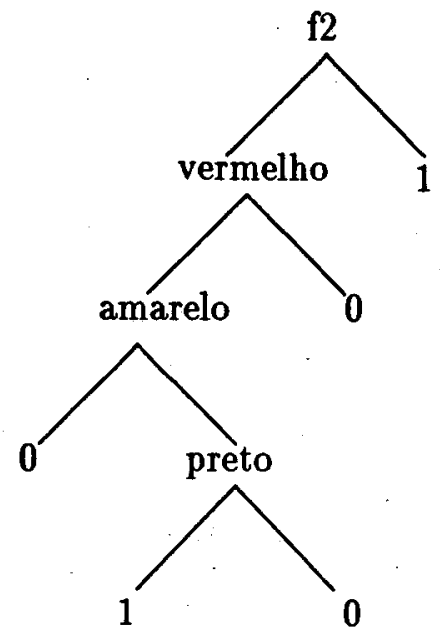

Figura 5.19: Árvore de Decisão após o Processamento do Algoritmo Root

$[f 3: 1, f 1: 0, f 2: 0$, verde: 0 , amarelo: 0, azul $: 0$, vermelho: 0 ,preto: 0, classe $: 0]$, [f3:0,f1:0,f2:0, verde: 1 , amarelo: 1 , azul : 1 , vermelho: 1 , preto: 1 , classe $: 0]$, $[f 3: 1, f 1: 0, f 2: 0$, verde $: 1$, amarelo: 0 , azul $: 1$, vermelho: 0 ,preto: 1, classe $: 0]$, $[f 3: 0, f 1: 0, f 2: 1$, verde $: 0$, amarelo: 1 , azul $: 0$, vermelho: 1 , preto: 0, classe $: 1]]$.

Atributos Finais:

$[f 3, f 1, f 2$, verde, amarelo, azul, vermelho, preto]

Features Construídas:

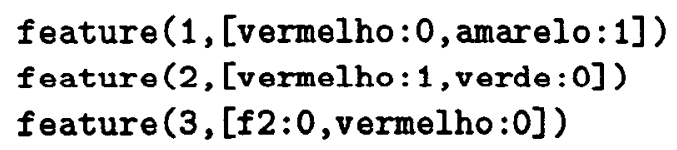

Na notação utilizada na seção $5.2, \mathrm{pg}$. 85 , os fatos feature/2 acima, representam o seguinte

$$
\begin{aligned}
& \text { f1 }=\text { and }(\text { vermelho }=0, \text { amarelo } 0=1) \\
& \text { f2 }=\text { and }(\text { vermelho }=1, \text { verde }=0) \\
& \text { f3 }=\text { and }(f 2=0, \text { vermelho }=0)
\end{aligned}
$$

Neste caso, na árvore final somente a feature $\$ 2$ comparece.

\section{Exemplo 5.4.5.2 Fringe}

No de Iterações: 4

Árvore Final com Features: 
$\operatorname{arv}(\operatorname{arv}(0, f 1,1), f 3,1)$

que representa a árvore de decisão mostrada na Figura 5.20.

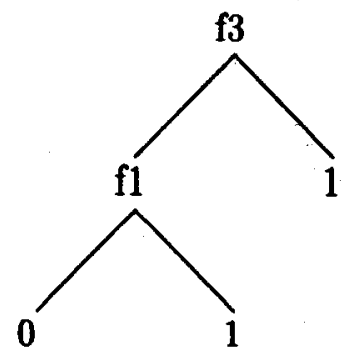

Figura 5.20: Árvore de Decisão após o Processamento do Algoritmo Fringe

Exemplos Finais:

$[[f 4: 0, f 3: 0, f 1: 0, f 2: 0$, verde: 1 , amarelo: 0, classe $: 0$, azul $: 1$, vermelho: 0 , preto: 0$]$, $[f 4: 0, f 3: 0, f 1: 0, f 2: 0$, verde: 1 , amarelo: $0:$ classe $: 0$, azul: 1 , vermelho: 1 , preto: 1$]$, [f $4: 0, f 3: 1, f 1: 0, f 2: 1$, verde: 0 , amarelo: 0 , azul $: 1$, classe: 1 , vermelho: 1 , preto: 1$]$, $[f 4: 0, f 3: 0, f 1: 0, f 2: 0$, verde: 0 , amarel $0: 1$, azul $: 0$, classe $: 0$, vermelho: 0 , preto: 1$]$, $[f 4: 0, f 3: 0, f 1: 0, f 2: 0$, verde: 1 , amarelo: 1 , azul $: 1$, vernelho: 0 ,preto: 1, classe: 0 , [f $4: 1, f 3: 0, f 1: 1, f 2: 0$, verde: 1 , amarelo: 1 , azul : 1 , vernelho: 0 ,preto: 0, classe: 1$]$, [f $4: 0, f 3: 0, f 1: 0, f 2: 0$, verde: 0 , amarelo: 0 , azul $: 0$, vermelho: 0 , preto: 0, classe: 0 , $[f 4: 0, f 3: 0, f 1: 0, f 2: 0$, verde 1 , amarelo: 1 , azul $: 1$, vernelho: 1 , preto: 1 , classe $: 0]$, $[f 4: 0, f 3: 0, f 1: 0, f 2: 0$, verde: 1 , amarelo: 0 , azul $: 1$, verme lho $: 0$,preto: 1 , classe $: 0]$, $[f 4: 1, f 3: 0, f 1: 1, f 2: 1$, verde: 0 , amarelo: 1 , azul $: 0$, vermelho: 1 ,preto: 0, classe:1]]

Atributos Finais:

$[f 4, f 3, f 1, f 2$, verde, amarelo, azul, vermelho, preto]

Features Construídas:

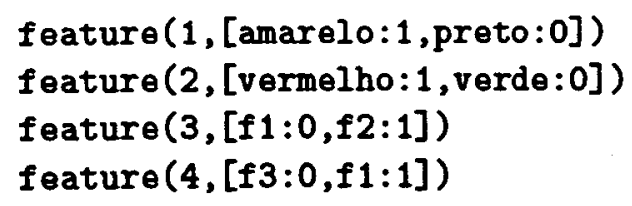

Exemplo 5.4.5.3 Root-Fringe

No de Iterações: 3

Árvore Final com Features:

$\operatorname{arv}(\operatorname{arv}(\operatorname{arv}(0, \operatorname{amarelo}, \operatorname{arv}(0, f 1,1)), \operatorname{vermelho}, 0), f 2,1)$ 


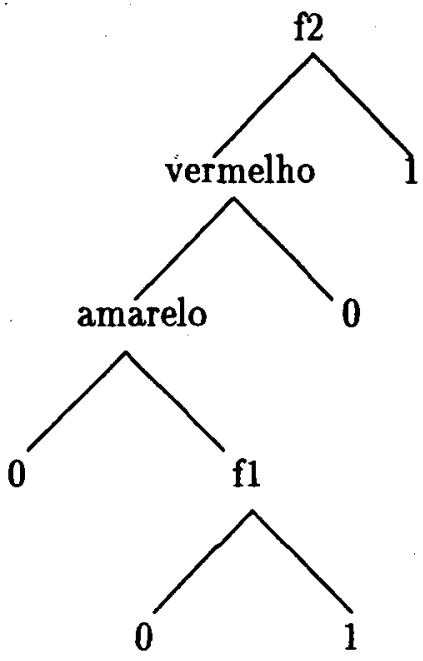

Figura 5.21: Árvore de Decisão após o Processamento do Algoritmo Root_Fringe que representa a árvore de decisão mostrada na Figura 5.21.

Exemplos Finais:

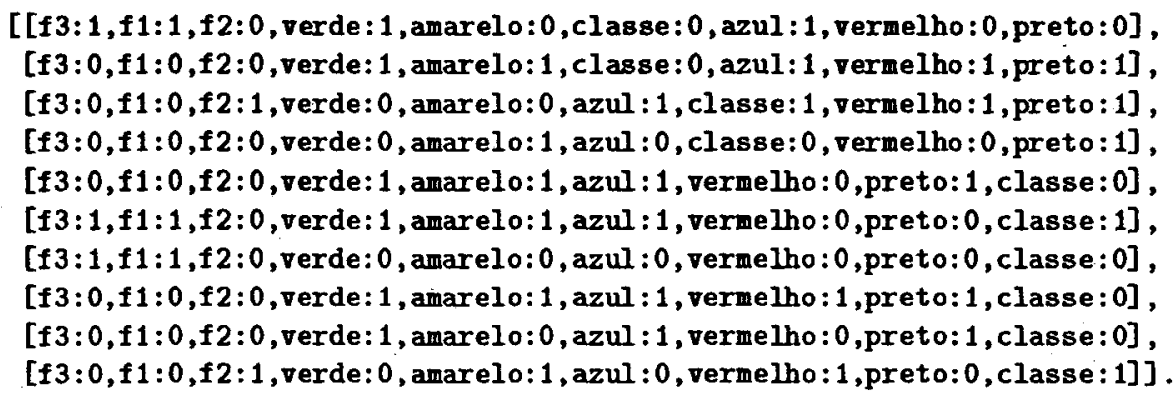

Atributos Finais:

$[f 3, f 1, f 2, v e r d e$, amarelo, azul, vermelho, preto $]$

Features Construidas:

feature $(1,[$ vermelho: 0 ,preto:0])

feature $(2,[$ vermelho: 1 , verde:0])

feature $(3,[f 2: 0, f 1: 1])$

\subsection{Módulo Gerador de Exemplos de Funções Booleanas}

A fim de verificar o comportamento dos algoritmos, foi também implementado um 
sistema auxiliar denominado Módulo Gerador de Exemplos de Funções Booleanas Figura 5.22.

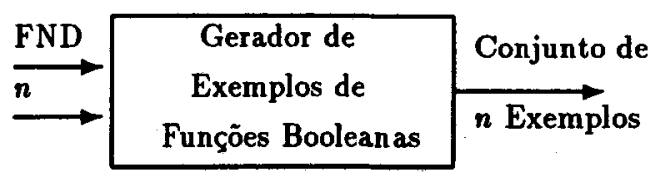

Figura 5.22: Módulo Gerador de Exemplos

A função do Módulo Gerador de Exemplos é a de, dados

- uma fórmula booleana $F$ na forma FND

- um número inteiro $n$

- gerar $n$ instâncias de $F$

A implementação tem como objetivo criar um conjunto randômico de $n$ instâncias de treinamento de acordo com uma dada fórmula booleana. A fórmula booleana em sua representação FND deve ser fornecida pelo usuário, como uma lista de listas, onde cada uma das listas representa um termo da função. Por exemplo, a função booleana na FND

$$
f\left(x_{1}, x_{2}, x_{3}, x_{4}\right)=x_{1} \overline{x_{2}} x_{3} \vee x_{5} x_{7}
$$

deve ser fornecida ao sistema como uma lista de lista da seguinte forma

$$
[[x 1, n x 2, x 3],[x 5, x 7]]
$$

onde $x 1, x 2, x 3, x 5$ e $x 7$ são os nomes das variáveis booleanas (atributos) e $n x 2$ corresponde à negação do atributo $x 2$. A negação $n$ é definida como um operador prefixo Prolog da seguinte forma

$$
:-o p(200, f y, n)
$$

A Tabela 5.3 mostra como devem ser representadas, respectivamente, as seguintes funções booleanas na FND, utilizando a sintaxe adotada pela implementação.

$$
\begin{gathered}
f\left(x_{1}, x_{2}, x_{3}, x_{4}, x_{8}\right)=x_{1} x_{4} \vee \overline{x_{2}} x_{8} x_{3} \\
f\left(x_{1}, x_{2}, x_{3}, x_{4}, x_{5}, x_{6}\right)=x_{5}, x_{3} \overline{x_{4}} \vee x_{2} \overline{x_{1}} x_{6} \\
f\left(x_{2}, x_{3}, x_{4}\right)=x_{4} \vee x_{3} x_{2} \\
f\left(x_{1}, x_{4}, x_{6}, x_{10}, x_{11}\right)=x_{10} \overline{x_{1} x_{6}} \vee x_{4} x_{11}
\end{gathered}
$$




\begin{tabular}{|c|}
\hline \hline FND's \\
\hline$[[x 1, x 4],[n x 2, x 8, x 3]]$ \\
{$[[x 5, x 3, n x 4],[x 2, n x 1, x 6]]$} \\
{$[[x 4],[x 3, x 2]]$} \\
{$[[x 10, n x 1, n x 6],[x 4, x 11]]$} \\
\hline \hline
\end{tabular}

Tabela 5.3: Formas Normais Disjuntivas

O algoritmo básico do Módulo Gerador de Exemplos de Funções Booleanas consiste do seguinte:

Dados uma fórmula booleana $F$ na forma FND

o número de exemplos a ser gerados $N$

\section{Begin}

1. crie um dicionário binário incompleto contendo os átomos (atributos) da fórmula booleana

While número de exemplos gerados $<>N$

Do

(a) instancie os valores dos atributos com 0's e 1's, aleatoriamente, nesse dicionário binário

(b) insere o atributo classe no conjunto de atributos, avaliando o valor correspondente do atributo classe

(c) output exemplo

EndDo

2. output conjunto de atributos

End

\subsubsection{Descrição da Implementação}

Este módulo está implementado pelo procedimento conjunto_exemplos/4, ilustrado na Figura 5.23.

Os dados de entrada consistem de um número que representa a fórmula ${ }^{5}$ a fórmula booleana na FND, a quantidade de exemplos a ser gerada e a especificação do arquivo

\footnotetext{
${ }^{5}$ Ainda que este identificador não é absolutamente necessário, ele permite realizar com maior facilidade a análise empírica - realizada por M.C. Nicoletti [Nicoletti 94] -, dos biases implementados.
} 


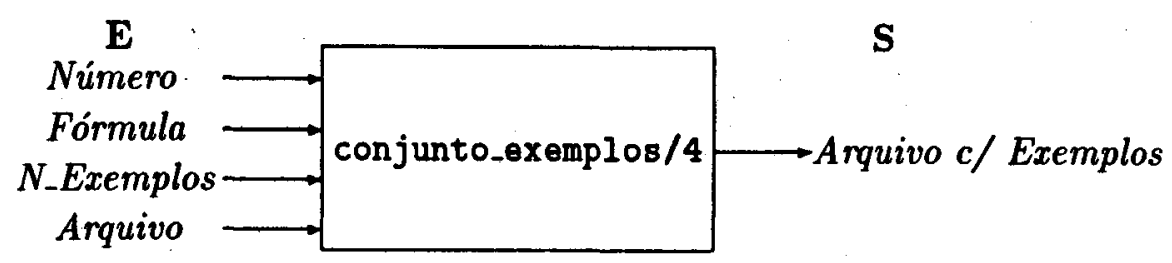

Figura 5.23: Procedimento Principal do Módulo Gerador de Exemplos

onde os exemplos serão gravados. A saída do processamento são os exemplos gerados e gravados no arquivo especificado.

A implementação, primeiramente, constrói um dicionário binário incompleto [Monard 93], que contém os símbolos atômicos (identificados com as variáveis) que comparecem na fórmula booleana. Os nós do dicionário têm a forma $A t t: V a l$, onde $A t t$ é o nome de uma variável da fórmula booleana e $V a l$ o valor que $A t t$ assumirá, que será instanciado ${ }^{6}$ com 0 ou 1. A estrutura que representa o dicionário binário é a seguinte:

$$
\operatorname{dic}(\text { SubArvEsq, NoRaiz, SubArvDir) }
$$

O dicionário binário está ordenado da esquerda para a direita, i.e.

1. todos os nós da subárvore esquerda - SubArvEsq - são menores que o NoRaiz

2. todos os nós da subárvore direita - SubArvDir - são maiores que o NoRaiz

3. a subárvore esquerda e direita também estão ordenadas

Após a criação do dicionário binário a partir dos atributos que comparecem na fórmula booleana, os valores associados aos atributos são gerados aleatoriamente. 0 primeiro passo é criar uma lista com apenas elementos 0's e 1's. O número de elementos desta lista é igual ao número de nós do dicionário binário que será instanciado de acordo com esta lista da seguinte forma:

1. o primeiro elemento da lista é colocado no dicionário binário como sendo o valor associado ao atributo que está na raiz

2. o restante da lista é processado, instanciando as variáveis das subárvores esquerda e direita de acordo com o item anterior.

O valor da classe é avaliado (neste caso, a classe corresponde à avaliação da fórmula, isto é, à atribuição de valor-verdade 0 ou 1). Cada exemplo da função booleana $F$ que têm como atributos Atr $1, A t r 2, \ldots$ Atrn é gerado como uma lista que segue o padrão

$$
\text { [Atr1 : Val1, Atr2 : Val2,.,, Atrn: Valn,Classe : Valor] }
$$

\footnotetext{
${ }^{6}$ Quando se cria o dicionário binário incompleto, a variável Val não está instanciada.
} 
onde o Valor associado à Classe corresponde à avaliação da função $F$, quando os valores $V$ al1, Val2, .., Valn são associados aos atributos Atr 1, Atri2, $\ldots$, Atrn respectivamente.

A descrição detalhada desta implementação encontra-se em [Monard 94a].

\subsubsection{Exemplos de Execução}

A seguir são apresentados alguns exemplos da execução do módulo gerador de exemplos de funções booleanas implementado. Em cada caso é mostrada a instanciação das variáveis de entrada e saída gravada no arquivo, correspondentes à interrogação

$$
\text { ?- conjunto_exemplos (N,DNF,N_Exs, a_teste). }
$$

No caso do arquivo a_teste existir, o usuário é informado deste fato. $\mathrm{O}$ procedimento continua sempre que o usuário concordar pois, neste caso, o conteúdo do arquivo original será perdido.

\section{Exemplo 5.5.2.1}

Entrada:

$$
\begin{aligned}
& N=1 \\
& \text { DNF }=[[x 1, x 2],[n \times 1, x 2, x 3],[x 4, n \times 3]] . \\
& N_{-} \text {Exs }=4
\end{aligned}
$$

Saída:

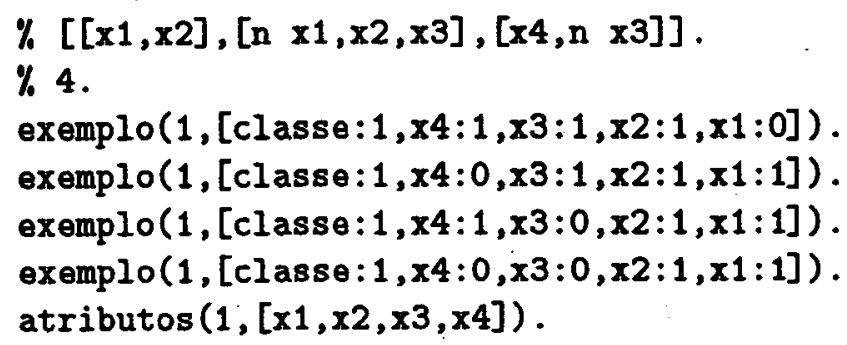

\section{Exemplo 5.5.2.2}

Entrada: 


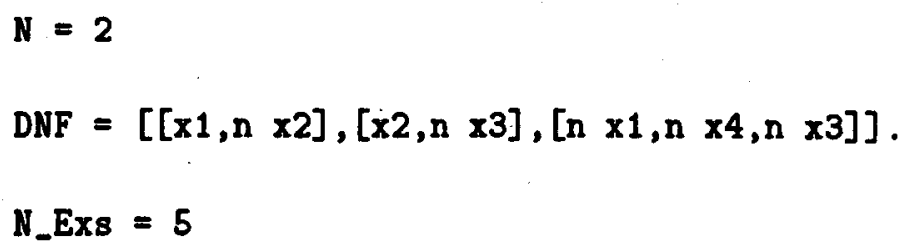

Saída:

$\left.\%\left[\begin{array}{lll}x 1, n & \times 2\end{array}\right],[\times 2, n \times 3],[n \times 1, n \times 4, n \times 3]\right]$.

$\% 5$.

exemplo(2,[classe: $1, x 4: 1, \times 3: 0, \times 2: 1, \times 1: 0])$.

exemplo( $2,[$ classe: $1, x 4: 0, x 3: 0, x 2: 1, x 1: 0])$.

exemplo(2,[classe:0,x4:0,x3:1,x2:1,x1:1]).

exemplo(2,[classe: $1, x 4: 0, x 3: 0, x 2: 1, x 1: 0])$.

exemplo(2,[classe:0,x4:1,x3:1,x2:0,x1:0]).

atributos $(2,[x 1, x 2, x 3, x 4])$.

\subsection{Avaliação Empírica dos Algoritmos para Construção de Features}

A avaliação empírica dos três biases implementados não foi objeto deste trabalho. Essa avaliação foi realizada por M.C. Nicoletti e os resultados obtidos podem ser encontrados no Capítulo 7 de [Nicoletti 94], onde são descritos os experimentos realizados relacionados ao aprendizado construtivo de funções booleanas utilizando os biases root, fringe e root_fringe.

Os três biases foram experimentalmente verificados no aprendizado de funções booleanas do tipo l-termo $k F N D$. Uma função booleana l-termo kFND é expressa pela disjunção de $l$ termos, onde cada um deles tem, no máximo, $k$ features. Por exemplo

$$
\left(\begin{array}{lll}
\bar{x}_{1} & x_{5} & x_{4}
\end{array}\right) \vee\left(x_{7} \bar{x}_{3}\right) \text { é uma função 2-termo 3FND }
$$

Com a variação dos valores de $l$ e $k$ foram automaticamente geradas funções a serem aprendidas com diferentes graus de complexidade.

Várias características das árvores induzidas e das features criadas pelos três biases, para diversos conjuntos de funções booleanas l-termo $k F N D$, foram medidas. Entre elas

Os resultados obtidos mostram que o algoritmo fringe tem um comportamento muito superior aos outros dois biases, enquanto que os comportamentos de root e root_fringe são semelhantes. 


\begin{tabular}{|ll|}
\hline NF & Número de Folhas \\
NN & Número de Nós \\
H & Altura \\
CC & Comprimento de Caminho \\
P $(\%)$ & Precisäo da Árvore \\
NI & Número de Iteraçōes \\
FC & Número de Features Distintas Construídas \\
FA & Número de Features Distintas na Árvore \\
FFA & Número de Features na Árvore \\
PF & Número de Primitivas Distintas nas Features da Árvore \\
FPF & Número de Primitivas nas Features \\
Pr & Número de Primitivas Distintas na Árvore \\
FPr & Número de Primitivas na Árvore \\
\hline
\end{tabular}

Tabela 5.4: Características Medidas

\subsection{Considerações Finais}

Este Capítulo apresentou o Ambiente Experimental Construtivo para Atributos Booleanos implementado que utiliza a indução construtiva como um processo que amplia, dinamicamente, o conjunto inicial de descritores presentes na linguagem utilizada para a descrição do conjunto de treinamento. Foi, também, mostrada a importância desse processo no aprendizado de conceitos.

As implementações desenvolvidas para este ambiente, na construção de novas features, consiste de 3 biases: root, fringe e root-fringe; no domínio de funções booleanas representadas na FND. Um módulo que cria um conjunto de treinamento com $n$ exemplos através de uma fórmula na FND, denominado Módulo Gerador de Exemplos de Funções Booleanas, também é apresentado.

O próximo Capítulo consiste das conclusões dos trabalhos desenvolvidos e sugestões para trabalhos futuros. 


\section{Capítulo 6}

\section{Conclusões e Trabalhos Futuros}

Aprendizado de Máquina é uma área que adquirir conhecimento utilizando alguns mecanismos especiais. Um destes mecanismos é o Aprendizado Indutivo por Exemplos, que infere a descrição de conceitos através de processos de generalização e especialização utilizando um conjunto de treinamento.

Como mencionado, está sendo desenvolvido no ICMSC-USP um projeto geral de AM que utiliza o mecanismo de Aprendizado Indutivo por Exemplos e cujo objetivơ é a geração de regras de conhecimento através de árvores de decisão da família TDIDT.

Neste projeto já foram desenvolvidos alguns ambientes experimentais distintos, porém interligados, que compõem o projeto geral. Um dos ambientes desenvolvidos, denominado Ambiente Experimental TDIDT, consiste de um procedimento geral que constrói árvores de decisão no modo não incremental. A partir da árvore de decisão construída por este procedimento, diversas implementaçóes foram desenvolvidas tais como: o mecanismo de janela e um método de pós-poda da árvore de decisão. Para este ambiente experimental foi utilizada uma estrutura geral e bastante complexa que pode representar qualquer árvore de decisão com uma quantidade indeterminada de valores de atributos.

Utiliżando este ambiente foi abordado aprendizado construtivo como forma de ampliar os limites da linguagem de descrição de exemplos através da construção de features. Especificamente, utilizando a estrutura geral e complexa da árvore construída pelo Ambiente Experimental TDIDT, foram implementados algoritmos para a construção automática de features, no domínio de funções booleanas.

Entretanto, a árvore de decisão resultante no caso de atributos booleanos é uma árvore binária. Assim, a estrutura de dados que representa a árvore de decisão pode ser simplificada. Devido a esta vantagem, decidiu-se implementar algoritmos semelhantes utilizando a estrutura de árvores binárias.

Neste trabalho foram desenvolvidos dois ambientes: 
1. A Ambiente Experimental Construtivo para Atributos Booleanos e,

2. o Ambiente Experimental TDIDT para Atributos Booleanos.

Para o primeiro ambiente foram implementados três algoritmos que utilizam indução construtiva que tenta ampliar o espaço de descrições de conceitos, a saber: root, fringe e root_fringe. Entre as vantagens do uso de indução construtiva, mesmo com elevado custo computacional, destaca-se:

- a construção de novas features pode permitir uma maior tolerância a ruídos [Pagallo 89],

- a viabilização da construção de hipóteses mais concisas, e

- quando a construção de features é acompanhada de avaliação e poda, o tempo necessário ao aprendizado do conceito pode ser reduzido [Drastal 89].

O segundo ambiente - Ambiente Experimental TDIDT para Atributos Booleanos -, tem como objetivo, entre outros, construir árvores de decisão binárias que serão utilizadas no Ambiente Experimental Construtivo para Atributos Booleanos. As implementações realizadas foram:

- algoritmo de construção não incremental de árvores de decisão binárias

- algoritmo de construção incremental de árvores de decisão binárias

- algoritmo de pós-poda da árvore de decisão binária

O algoritmo não incremental implementado consiste de uma versão simplificada do algoritmo de construção da árvore de decisão do Ambiente Experimental TDIDT, assim como o método de pós-poda. Foi utilizada a estratégia de aprendizado do algoritmo ID3 adaptado para atributos booleanos. Os algoritmos não incrementais criam um problema de eficiência computacional quando o número de exemplos de aprendizado é muito grande.

Para tentar superar este problema, foram pesquisados vários algoritmos da família TDIDT que constrõem a árvore de decisão considerando os exemplos individualmente. A estratégia de aprendizado escolhida para implementação foi o algoritmo ID5 que constrói a árvore de decisão similar àquela construída pelo ID3, para um dado conjunto de treinamento. Este algoritmo tem a vantagem, além de ser um algoritmo incremental - sem o custo de construir toda a árvore de decisão a cada nova instância de treinamento - , de não perder informações de treinamento quando tenta classificar um novo exemplo na árvore de decisão como faz, por exemplo, o algoritmo ID4. Na classificação de um novo exemplo, o algoritmo utiliza um processo de reestruturação da árvore de decisão para manter sempre como raiz da árvore, o atributo com o menor valor de 
entropia. Este processo manipula a árvore de forma a preservar a sua consistência com as instâncias de treinamento observadas.

Porém, como consequência desta reestruturação, houve uma grande demanda de utilização dos recursos da máquina. 0 algoritmo realiza muita recursão no processo de reestruturação, tornando muitas vezes a memória principal da máquina "pequena" e insuficiente para manipular as informações. Na tentativa de contornar parcialmente este problema, foi utilizada memória secundária para armazenar as informações.

Este "estouro". de memória é influenciado, também, pelo fato de que é necessário armazenar muitas informações na árvore de decisão, tais como a lista de exemplos associada a cada nó folha e a lista de contadores dos atributos utilizada no cálculo da entropia. Todas estas informações são necessárias para expandir e reestruturar a árvore de decisão quando tenta classificar um novo exemplo.

Os algoritmos foram implementados utilizando a linguagem de programação lógica Prolog, especificamente, Arity Prolog para microcomputadores PC compativeis. Apesar de que, vários dos problemas referentes ao uso de memória, durante a execução do procedimento, estão diretamente relacionados à deficiência do software utilizado, a conclusão que se pode chegar é que o algoritmo ID5 não é uma boa escolha na indução de um conceito, quando se utiliza o modo incremental. As informações armazenadas e a recursividade necessária à atualização da árvore, faz com que o algoritmo tenha um baixo desempenho mesmo utilizando outra linguagem de programação, como por exemplo, a linguagem $\mathrm{C}$.

Como sugestões para trabalhos futuros, cita-se:

- pesquisar outros métodos de aprendizado no modo incremental

- pesquisar outros algoritmos para construção automática de features. 


\section{Bibliografia}

[Anderson 79] Anderson, J.R.; Kline, P.J. A Learning System and its Psychological Implications. Proceedings of the Sixth International Joint Conference on Artificial Intelligence, Tokio, Japão, p. 16-21, 1979.

[Anderson 83] Anderson, J.R. Acquisition of Proof Skills in Geometry. Machine Learning: An Artificial Intelligence Approach, R.S. Michalski \& J.G. Carbonell \& T.M. Mitchell (Ed.), Tioga Publishing Company, CA, p. 191-220, 1983.

[Arity 92] Arity Corporation. The Arity/Prolog Programming Language. 1992.

[Barletta 91] Barletta, R. An Introduction to Case-based Reasoning. AI Expert, August, p. 43-59, 1991.

[Bratko 89] Bratko, I. Machine Learning. In Human and Machine Problem Solving, K. Gilhosly, Academic Press, p. 265-87, 1989.

[Breiman 84] Breiman, L.; Fredman, J.H.; Olshen, R.A; Stone, C.J. Classification and Regression Trees. Belmont: Wadsworth, 1984.

[Buchanan 78] Buchanan, B.G.; Mitchell, T.M. Model-directed Learning of Production Rules. Pattern-directed Learning of Production Rules, Academic Press, NY, 1978.

[Carbonell 87] Carbonell, J.G.; Langley P. Machine Learning. Encyclopedia of Artificial Intelligence, S.C. Shapiro (Ed.), John Wiley \& Sons, U.S.A., p. 464-88, 1987.

[Castineira 90] Castineira, M.I. Aprendizado de Máquina por Exemplos Usando Árvores de Decisão. Dissertação de Mestrado, ICMSC-USP, 1990.

[Castineira 90a] Castineira, M.I.; Monard, M.C. Análise de Um Método de Poda para Árvores Indutivas de Decisão. SUCESU, Anais Tecninfo 90, p. 49-51, Setembro, 1990.

[Castineira 91] Castineira, M.I.; Monard, M.C.; Nicoletti, M.C. Aprendizado de Máquina: Descrição e Implementação de um Algoritmo Geral para a 
Construção de Árvores de Decisão. Notas do ICMSC-USP, n. 98, p.42, Outubro, 1991.

[Cestnik 87] Cestnik, B.; Kononenko, I.; Bratko, I. Assistant 86: A KnowledgeElicitation Tool for Sophisticated Users. Progress in Machine Learning, I. Bratko \& N. Lavrac (Ed.), Sigma Press, p. 11-30, 1987.

[Charniak 86] Charniak, E.; McDermott, D. Introduction to Artificial Intelligence. Addison Wesley, USA, 1986.

[Clark 87] Clark, P.; Nibblet, T. Induction in Noisy Domains. Progress in Machine Learning, I. Bratko \& N. Lavrac (Ed.), Sigma Press, p. 11-30, 1987.

[De Jong 88] De Jong, K. Learning with Genetic Algorithms: An Overview. Machine Learning, n. 3, p. 121-38, 1988.

[Drastal 89] Drastral, G.; Raatz, S.; Czako, G. Induction in an Abstract Space. In: Proceedings of the Eleventh International Joint Conference on Artificial Intelligence, Detroit, Mi, August, Morgan Kaufmann, 1989.

[Durkin 91] Durkin, J. Desingning an Induction Expert System. AI Expert, p. 29-35, December, 1991.

[Fikes 72] Fikes, R.E.; Hart, P.E.; Nilsson, N.J. Learning and Executing Generalized Robot Plans. Artificial Intelligence, n. 3, p. 251-88, 1972.

[Fisher 87] Fisher, D. Knowledge Acquisition via Incremental Conceptual Clustering. Machine Learning, n. 2, p. 139-72, 1987.

[Ford 87] Ford; Nige]. How Machines Think. John Willey \& Sons, Great Britain, 1987.

[Francelin 92] Francelin, R.A. Uma Introdução a Redes Neurais. Anais do I Workshop sobre Redes Neurais, UFSCar, São Carlos, p. 20-33, Setembro, 1992.

[Freitas 92] Freitas, A.A.; Kirner, C. Introduçäo a Algoritmos Genéticos. Anais do I Workshop sobre Redes Neurais, UFSCar, São Carlos, p. 71-88, Setembro, 1992 .

[Gams 87] Gams, M.; Lavrac, N. Review of Five Empirical Learning Systems within e Proposed Schemata. Progress in Machine Learning, I. Bratko \& N. Lavrac (Ed.), Sigma Press, p. 46-66, 1987.

[Gold 67] Gold, E. Language Identification in the Limit. Information and Control, n. 16 , p. 447-74, 1967.

[Hart 85] Hart, A. Machine Induction: Practical Issues and Advice. Proceedings of the First International ES Conference, London, p. 71-8, 1985. 
[Haussler 88] Haussler, D. Quantifying Inductive Bias: AI Learning Algorithms and Valiant's Learning Framework. Artificial Intelligence, n. 36, p. 177-222, 1988.

[Hunt 66] Hunt, E.B.; Marin, J.; Stone, P.J. Experiments in Induction. Academic Press, NY, 1966.

[Kocabas 91] Kocabas, S. A Review of Learning. The Knowledge Engineering Review, v. 6, n. 3, p. 195-222, 1991.

[Kononenko 84] Kononenko, I.; Bratko, I.; Roskar, E. Experiments in Automatic Learning of Medical Diagnostic Rules. Technical Report, Josef Stefan Institute, Ljubljana Yugoslavia, 1984.

[Lenat 77] Lenat, D.B. The Ubiquity of Discovery. Artificial Intelligence, n. 9, p. 257-85, 1977.

[Martins 94a] Martins, C.A.; Monard, M.C. Árvores de Decisão Binárias: Descrição e Implementação de Algoritmos para a Construção e Poda no Aprendizado Indutivo de Máquina. Relatórios Técnicos do ICMSC, n. 17, 35 pg., fevereiro, 1994.

[Martins 94b] Martins, C.A.; Monard, M.C. Descrição e Implementação de um Algoritmo Indutivo Incremental para Aprendizado de Árvores de Decisão Binárias. (em preparação).

[Matheus 90] Matheus, C.J. Feature Construction: An Analytic Framework and an Application to Decision Trees. Ph.D. thesis, University of Illinois at Urbana Champaign, Urbana, Illinois, USA, 1990.

[McDonald 89] McDonald, C. Machine Learning: A Survey of Current Techniques. Artificial Intelligence Review, n. 3, p. 243-80, 1989.

[Michalski 80] Michalski, R.S.; Chilausky, R.L. Learning by Being Told and Learning from Examples: An Experimental Comparison of the Two Methods of Knowledge Acquisition in the Context of Developing an Expert System for Soybean Disease Diagnosis. Policy Analysis and Information Systems, n. 4, p. 125-60, 1980.

[Michalski 83a] Michalski, R.S.; Stepp, R.E. A Theory and Methodology of Inductive Learning. Artificial Intelligence, n. 20, p. 111-6, 1983.

[Michalski 83b] Michalski, R.S.; Stepp, R.E. Learning from Observation: Conceptual Clustering. Machine Learning: An Artificial Intelligence Approach, R.S. Michalski \& J.G. Carbonell \& T.M. Mitchell (Ed.), Tioga Publishing Company, CA, p. 331-64, 1983.

[Michalski 87] Michalski, R.S. Concept Learning. Encyclopedia of Artificial Intelligence, S.C. Shapiro (Ed.), John Willey \& Sons, U.S.A., p. 185-94, 1987. 
[Michie 90] Michie, D. Human and Machine Learning of Descriptive Concepts. ICOT Journal, Institute for New Generation Computer Technology, n. 27, p. 2-20, March, 1990.

[Mingers 87] Mingers, J., Expert Systems: Rule Induction with Statistical Data. J. Operational Research Soc., v. 38, n. 1, p. 39-47, 1987.

[Mingers 89] Mingers, J. An Empirical Comparison of Selection Measures for Decision Tree Induction. Machine Learning, n. 3, p. 226-43, 1989.

[Minsky 69] Minsky, M.S.; Papert, S. Perceptrons: An Introduction to Computational Geometry. MIT Press, Cambridge, Mass., 1969.

[Minton 87] Minton, S.N.; Carbonell, J.G.; Etzioni, O.; Knoblock, C.A.; Kuokka, D.R. Acquiring Effective Search Control Rules: Explanation-based Learning in the PRODIGY System. Proceedings of the Fourth International Workshop on Machine Learning, Irvine, CA: Morgan Kaufmann, p. 12233, 1987.

[Mitchell 80] Mitchell, T.M. The Need for Biases in Learning Genenalizations. Technical Report n. 117, New Brunswick, NJ: Rutgers University, Department of Computer Science, 1980.

[Mitchell 82] Mitchell, T.M. Generalization as Search. Artificial Intelligence, n. 18, p. 203-26, 1982.

[Mitchell 86]. Mitchell, T.M.; Keller, R.M.; Kedar-Cabelli, S.T. Explanation-basead Generalization: A Unifying View. Machine Learning, n. 1, p. 47-80, 1986.

[Monard 93] Monard, M.C.; Nicoletti, M.C. Técnicas Avançadas de Programação Prolog para Tratamento de Árvores. Notas Didáticas do ICMSC, n. 8, 51 pg., Fevereiro, 1993.

[Monard 94a] Monard, M.C.; Martins, C.M.; Nicoletti, M.C. Descrição do Módulo Gerador de Exemplos de Funções Booleanas do Ambiente Experimental Construtivo de Aprendizado de Máquina. (em preparação).

[Mowforth 86] Mowforth, P. Some Applications with Inductive Expert Systems Shells. Technical Report, Turing Institute TIOP-86-002, Glasgow, July, 1986.

[Newell 76] Newell, A.; Simon, H.A. Computer Science as Empirical Inquiry: Simbols and Search. Communications of the ACM, v. 19, n. 3, March, 1976.

[Nicoletti 92] Nicoletti, M.C.; Bezerra, P.C.; Monard, M.C.; Learning Boolean Functions Using Prime-implicants as Features. In: Proceedings International AMSE Conference on "Signals, Data, Systems", Chicago, USA, September 2-4, AMSE Press, v. 1, p. 177-83, 1992. 
[Nicoletti 92a] Nicoletti, M.C.; Monard, M.C.; Construção Automática de Features no Aprendizado de Funções Booleanas. Série C\&T do ILTC, v. 1, n. 8, p. 1-20, Junho, 1992.

[Nicoletti 92b] Nicoletti, M.C.; Castineira, M.I.; Monard, M.C.; Mecanismos de Janela e Poda em Árvores de Decisão no Aprendizado Indutivo de Máquina. Notas do ICMSC-USP, n. 98, p.42, Outubro, 1991.

[Nicoletti 93a] Nicoletti, M.C. Compilação de Conhecimento em Aprendizado Baseado em Explicação. Monografia do Exame de Qualificação de Doutorado, IFQSC-USP, Abril, 1993.

[Nicoletti 93b] Nicoletti, M.C.; Monard, M.C.; The Role of Description Languages in Inductive Concept Learning. Anais I SBAI, Rio Claro, SP, p. 403-12, Setembro, 1993.

[Nicoletti 93b] Nicoletti, M.C.; Monard, M.C. Empirical Evaluation of Two Pruning Methods Applied to Constructive Learning of Boolean Functions. Proceedings I International Congress and Exposition in Informatics, Mendoza, Argentina, p. 265-77, Junho, 1993.

[Nicoletti 94] Nicoletti, M.C. Ampliando os Limites do Aprendizado Indutivo de Máquina através das Abordagens Construtiva Relacional. Tese de doutorado, IFQSC-USP, Maio, 1994.

[Nilsson 80] Nilsson, N.J. Principles of Artificial Intelligence. Tioga Publishing Company, Palo Alto, CA, 1980.

[Pagallo 89] Pagallo, G.; Haussler, W. Learning DNF by Decision Trees. In: Proceedings of the Eleventh Internation Joint Conference on Artificial Intelligence, Detroit, MI, Augut, Morgan Kaufmann Publishers , p. 639 44, 1989.

[Pagallo 90] Pagallo, G.; Haussler, W. Boolean Feature Discovery in Empirical Learning. Machine Learning n. 5, p. 71-99, 1990.

[Partridge 91] Partridge, D. Learning to do it Right. A New Guide to Artificial Intelligence, p. 351-457, 1991.

[Patterson 83] Patterson, A.; Nibblett, T. ACLS User Manual. Glasgow, Intelligent Terminals Ltd, 1983.

[Quinlan 79] Quinlan, J.R. Discovering Rules by Induction from Large Collections of Examples. Expert Systems in the Micro Electronic Age, D. Michie (Ed.), Edinburgh University Press, Edinburgh, p. 168-201, 1979. 
Bibliografia

x [Quinlan 83] Quinlan, J.R. Learning Efficient Classification Procedures and their Application to Chess Endgames. Machine Learning: An Artificial Intelligence Approach, R.S. Michalski \& J.G. Carbonell \& T.M. Mitchell (Ed.), San Mateo, CA: Morgan Kaufmann, v. 1, 1983.

[Quinlan 86a] Quinlan, J.R. Induction of Decision Trees. Machine Learning, n. 1, p. 81-106, 1986.

[Quinlan 86b] Quinlan, J.R. The Effect of Noise on Concept Learning. R.S. Michalski \& J.G. Carbonell \& T.M. Mitchell (Ed.), Machine Learning: An Artificial Intelligence Approach, San Mateo, CA: Morgan Kaufmann, v. 2, 1986.

[Quinlan 86c] Quinlan, J.R. Inductive Knowledge Acquisition: A Case Study. Proceedings of the Second Australian Conference on Applications of E.S., Sydney, p. 183-203, 1986.

[Quinlan 87a] Quinlan, J.R. Generating Production Rules from Decision Trees. Proceedings of the Tenth International Joint Conference on Artificial Intelligence, Milan, Italy: Morgan Kaufmann, p. 304-7, 1987.

[Quinlan 87b] Quinlan, J.R. Simplifying Decision Trees. International Journal of ManMachine Studies, n. 27, p. 221-34, 1987.

[Raggett 92] Raggett, J.; Bains, W. Artificial Intelligence from $A$ to $Z$. Chapman \& Hall, 1992.

$\times$ [Rosenblatt 58] Rosenblatt, F. The Penceptron: A Probabilistic Model for Information Storage and Organization in the Brain. Psychological Review, n. 65, p. 386-408, 1958.

[Salmon 81] Salmon, W.S. Lógica. Zahar (Ed.), Rio de Janeiro, 1981.

× [Samuel 59] Samuel, A.L. Some Studies in Machine Learning Using the Game of Checkers. IBM Journal of Research and Development, n. 3, p. 211-29, 1959.

- [Samuel 63] Samuel, A.L. Some Studies in Machine Learning Using the Game of Checkers. Computers and Thougth, E.A. Feigenbaum \& J. Feldman (Ed.), Mc Graw-Hill, New York, p. 71-105, 1963.

[Schlimmer 86] Schlimmer, J.C.; Fisher, D. A Case Study of Incremental Concept Induction. Proceedings of the Fifth National Conference on Artificial Intelligence, Philadelphia, PA: Morgan Kaufman, p. 496-501, 1986.

* [Shavlik 90] Shavlik, J.; Dietterich, T.G. Readings in Machine Learning. San Mateo, CA: Morgan Kaufmann, 1990.

X [Shaw 90] Shaw, M.J.; Gentry, J.A. Inductive Learning for Risk Classification. University of Illinois at Urbana-Champaign, IEEE, p. 47-53, February, 1990. 
[Simon 83] Simon, H.A. Search and Reasoning in Problem Solving. Artificial Intelligence, n. 21, p. 7-30, 1983.

[Sterling 86] Sterling, L.; Shapiro, E. The Art of Prolog. MIT Press Series in Logic Programming, E. Shapiro (Ed.), 1986.

[Utgoff 88] Utgoff, P.E. ID5: An Incremental ID3. Proceedings of the Fifth International Conference on Machine Learning, University of Michigan, Ann Arbor, MI: Morgan Kaufmann, p. 107-20, June, 1988.

[Utgoff 89] Utgoff, P.F. Incremental Induction of Decision Trees. Machine Learning, n. 4, p. 161-86, 1989.

[Valiant 84] Valiant, L.G. A Theory of the Learning. Communications of the ACM, n. 27, p. $1134-42,1984$.

[Van Harmelen 88] Van Harmelen, F.; Bundy, A. Explanation-basead Generalization = Partial Evaluation. Artificial Intelligence, n. 36, p. 401-12, 1988.

[VanLehn 87] VanLehn, K. Learning one Subprocedure per Lesson. Artificial Intelligence, n. 31, p. 1-40, 1987.

[Van de Velde 89] Van de Velde, W. IDL, or Taming the Multiplexer. EWSL-89, Proceedings of the Fourth European Working Session on Learning, K. Morik (Ed.), Montpellier, Pitmam Publishing, p. 211-25, December, 1989.

[Winston 70] Winston, P.H. Learning Structure Descriptions from Examples. Massachusetts Institute of Technology, AI Laboratory, Cambridge, MA, Technical Report n. 231, 1970.

[Winston 75] Winston, P.H. Learning Structural Descriptions from Examples. The Psychology of Computer Vision, P.H. Winston (Ed.), McGraw-Hill; New York, p. 157-209, 1975.

[Winston 80] Winston, P.H. Learning and Reasoning by Analogy. Comunications of ACM, n. 23, p. 689-703, 1980. 